\author{
UNIVERSIDADE DE SÃO PAULO - USP \\ FACULDADE DE ECONOMIA, ADMINISTRAÇÃO E CONTABILIDADE \\ DEPARTAMENTO DE ECONOMIA \\ PROGRAMA DE PÓS-GRADUAÇÃO EM ECONOMIA
}

\title{
Cigarette Consumers Behavior: Effects of Smoking Bans in Brazil
}

O Comportamento dos Consumidores de Cigarro: Efeitos das Áreas Livres de Fumo no Brasil

Camila Steffens

Orientadora: Profa. Dra. Paula Carvalho Pereda

São Paulo 
Prof. Dr. Vahan Agopyan

Reitor da Universidade de São Paulo

Prof. Dr. Adalberto Américo Fischmann

Diretor da Faculdade de Economia, Administração e Contabilidade

Prof. Dr. Eduardo Amaral Haddad

Chefe do Departamento de Economia

Prof. Dr. Ariaster Baumgratz Chimeli

Coordenador do Programa de Pós-Graduação em Economia 
CAMILA STEFFENS

\section{Cigarette Consumers Behavior: \\ Effects of Smoking Bans in Brazil}

O Comportamento dos Consumidores de Cigarro: Efeitos das Áreas Livres de Fumo no Brasil

Dissertação apresentada ao Departamento de Economia da Faculdade de Economia, Administração e Contabilidade da Universidade de São Paulo como requisito parcial para a obtenção do título de Mestre em Ciências.

Orientadora: Profa. Dra. Paula Carvalho Pereda

Versão Original

São Paulo

2018 
FICHA CATALOGRÁFICA

Elaborada por Rafael Mielli Rodrigues - CRB-8/7286

Seção de Processamento Técnico do SBD/FEA/USP

\section{Steffens, Camila}

Cigarette consumers behavior: effects of smoking bans in Brazil /

Camila Steffens. - São Paulo, 2018.

$101 \mathrm{p}$.

Dissertação (Mestrado) - Universidade de São Paulo, 2018.

Orientador: Paula Carvalho Pereda.

1. Economia da saúde 2. Fumo 3. Avaliação de impacto 4. Áreas livres de tabaco 5. Economia do cigarro I. Universidade de São Paulo. Faculdade de Economia, Administração e Contabilidade. II. Título. 
Dedico este trabalho aos professores e às professoras que foram imprescindíveis na minha formação acadêmica e no meu desenvolvimento como pessoa. Vocês são minha inspiração; seus ensinamentos e suas orientações foram meu alicerce. 



\section{Acknowledgements}

I thank Sao Paulo Research Foundation (FAPESP) for the financial support that made this dissertation possible, under the grants \#2016/18683-5 and \#2017/11879-4.

I thank the professors of the Department of Economy at the University of São Paulo (USP) for the classes and the teaching during the Masters in Theoretical Economics. I am also thankful for the professors of Economics at the University of Rio Grande do Sul (UFRGS), that were essential to my literacy. In special, I thank Professors Sérgio Monteiro, Flavio Tosi Feijó and Marcelo Milan for their inspiration and for believing that I was capable of achieving my goals, even when it seemed impossible to myself.

I am very grateful to Professor Paula Pereda, my supervisor during my Masters, by her teaching, support, inspiration and advices that were indispensable to my graduation and to the development of this dissertation.

I thank Professor Carlos Azzoni, from USP, for his participation in my Qualification and my Progress Evaluation and for his very helpful suggestions. I thank Professor Fernanda Estevan, from the Sao Paulo School of Economics of Fundação Getúlio Vargas (FGV), by her valuable opinions on my study during my Progress Evaluation. I am thankful to Professor Denisard Alves for the comments on my study, for giving me the opportunity to learn and to develop my knowledge and for believing in my capabilities.

I also thank the Hamburg Center for Health Economics and my colleagues (specially to my friend Shushanik Margaryan) for receiving me as a research visitor during my Research Internship Abroad. I thank professors Thomas Siedler (Hamburg University), Stefan Boes (University of Lucerne) and Timo Goeschl (University of Heidelberg), the participants of the Master Seminar at the University of Lucerne and the participants of the Regional Environmental Economics Seminar at the universities of Heidelberg and Mannheim for the opinions that were very useful to improve this dissertation. And I thank Professor Danilo Igliori for the recommendation made to Professor Timo Goeschl.

I highlight that the opinions, hypotheses and conclusions or recommendations expressed in this material are the responsibility of the authors and do not necessarily reflect the views of the professors and FAPESP.

Last and most importantly, I thank my family and my friends for the support, the love and the friendship during this journey. You were the foundation of my existence and the reason of my persistence: Iloir, Hildegard and William Steffens; Lony Lange; Iris and Jorge Mohr; Júlia Kraemer, Júlia Paludo, Pedro Oliveira, Betina Iser, Stella Carneiro, Fernando Couto, Daniela Amaral, Isaac Verdu and Luise Holly. 



\section{Abstract}

Approximately 135,000 Brazilians die from smoking-related diseases every year (ERIKSEN et al., 2015). Due to the relevance of smoking as a public health problem, some states and municipalities implemented restrictive smoke-free environments from 2008 onwards. The national regulation became effective only in 2014. In this paper we explore the regional differences in the adoption of this policy to evaluate its impacts on cigarette consumption in Brazil. We propose a difference-in-differences approach to estimate the effects throughout the years on the smoking behavior of two age groups: adults and youths. We also estimate the impacts according to different levels of enforcement among states. We have built our panel using micro data from the National Health Research, collected by the Brazilian Bureau of Statistics (IBGE) in 2013. Our results indicate that smoking bans reduced daily cigarette consumption among young individuals in $7 \%$ on average, by reducing smoking initiation. This impact increases to $10 \%$ when considering higher enforced smoking bans, and vanishes when the law is not enforced. No impacts were found on smoking initiation and on smoking prevalence among adults, but high enforced smoking bans are related to $1.2 \%$ smoking cessation rate. Robustness tests show that the results are consistent. Our paper contributes to the literature providing evidences to developing countries on the effects of tobacco control policies.

Key-words: health economics. cigarette economics. smoking. impact evaluation. smoking bans. 



\section{Resumo}

Aproximadamente 135.000 brasileiros morrem por doenças relacionadas ao tabagismo anualmente (ERIKSEN et al., 2015). Devido à relevância do tabagismo como um problema de saúde, alguns estados e municípios adotaram áreas totalmente livres de fumo a partir de 2008. A legislação nacional passou a vigorar apenas a partir de dezembro de 2014 . Nesse estudo, exploramos a variação regional da adoção dessa política para avaliar seus impactos no consumo de cigarro no Brasil. Para tanto, adotamos uma abordagem de diferenças-em-diferenças para estimar os efeitos ao longo dos anos de introdução das leis no comportamento de fumantes em dois grupos etários: adultos e jovens. Os impactos também foram estimados considerando diferentes níveis de aplicação das leis entre os estados. Construímos um painel utilizando microdados da Pesquisa Nacional da Saúde (PNS), coletada pelo Instituto Brasileiro de Geografia e Estatística (IBGE) em 2013. Os resultados indicam que a criação de áreas livres de fumo reduziu, na média, em 7\% o consumo de cigarro entre jovens, e isso ocorreu através do desincentivo à iniciação ao tabagismo. Esse impacto aumenta para 10\% quando consideramos leis efetivamente aplicadas, e desaparecem quando a aplicação é baixa. Não foram encontrados efeitos em iniciação ao tabagismo e em consumo de cigarro entre adultos, mas leis fortemente aplicadas estão relacionadas a uma taxa de cessação do fumo de 1,2\%. Testes de robustez mostram que os resultados são consistentes. Esse estudo contribui para a literatura sobre os efeitos das políticas de controle do tabagismo ao apresentar evidências para países em desenvolvimento.

Palavras-chave: economia da saúde. economia do cigarro. fumo. avaliação de impacto. áreas livres de tabaco. 



\section{List of Figures}

Figure 1 - Trajectory of Smoking Bans in Brazil . . . . . . . . . . . . . . . . 23

Figure 2 - Brazilian Map of local smoking bans adopted from 2008 to 2012 . . . . . . . . . 25

Figure 3 - Enforcement level of Brazilian local smoking bans adopted from 2008 to 2012 . . . 27

Figure 4 - Database scheme . . . . . . . . . . . . . . 36

Figure 5 - Prevalence of Smokers per age groups in 2008 and 2013 . . . . . . . . 39

Figure 6 - Trajectory of smoking prevalence among adults (18-64 years old), 2007-2013 . . . 40

Figure 7 - Trajectory of smoking prevalence among youths (15-29 years old), 2007-2013 . . . 40

Figure 8 - Trajectory of smoking initiation among adults (18-64 years old), 2006-2013 . . . 41

Figure 9 - Trajectory of smoking initiation among youths (15-29 years old), 2006-2013 . . . 41

Figure 10 - Cumulative distribution of smoking initiation age . . . . . . . . . . . 41

Figure 11 - Trajectory of smoking cessation among adults (18-64 years old), 2006-2013 . . . . 42

Figure 12 - Trajectory of smoking cessation among youths (15-29 years old), 2006-2013 . . . . 42

Figure 13 - Age density (in 2013) of people who changed smoking status from 2006 to 2013 . . 42

Figure 14 - Year of treatment for each Brazilian capital, represented by the respective state. . . 45

Figure 15 - Trajectory of smoking prevalence among adults (18-64 years old) in control and

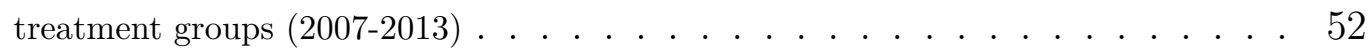

Figure 16 - Trajectory of smoking prevalence among youths (15-29 years old) in control and

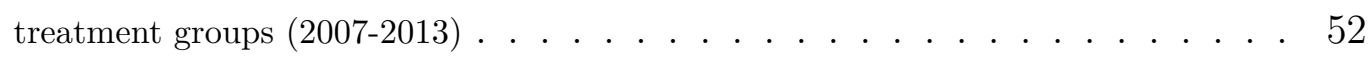

Figure 17 - Effects of smoking bans on smoking initiation among youths . . . . . . 55

Figure 18 - Effects of smoking bans on smoking cessation among 2007 young adults

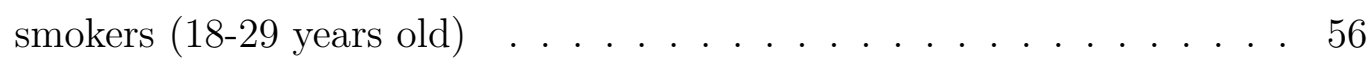

Figure 19 - Effects of smoking bans on smoking cessation among 2007 adults smokers

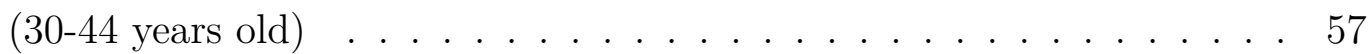

Figure 20 - Effects of smoking bans on smoking cessation among 2007 adults smokers (45-64 years old $) \ldots \ldots \ldots . \ldots . \ldots . \ldots 57$

Figure 21 - Higher enforced smoking bans impacts on smoking prevalence among adults . . . . . . . . . . . . . . . . . 5 59

Figure 22 - Higher enforced smoking bans impacts on smoking prevalence among

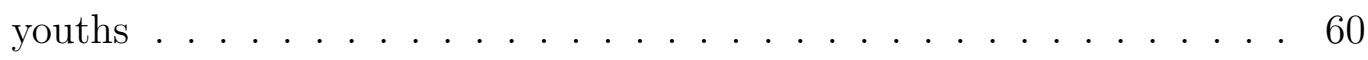

Figure 23 - Higher enforced smoking bans effects on smoking initiation among youths 61

Figure 24 - Higher enforced smoking bans effects on smoking quitting among adults 61

Figure 25 - Density of smoking starting age . . . . . . . . . . . . . 78

Figure 26 - Density of smoking starting age to restrained sample . . . . . . . . . . 78

Figure 27 - Density of smoking quitting time (in years) . . . . . . . . . . . . . . . 79

Figure 28 - Density of smoking quitting time (in years) . . . . . . . . . . . . . . 79

Figure 29 - Density of current daily smokers' smoking time . . . . . . . . . . . . . 79 
Figure 30 - Density of daily smokers current age . . . . . . . . . . . . . . . . 79

Figure 31 - Evolution in the proportion of capital's residents for unities with and without smoking bans $(1960-2010) \ldots \ldots . \ldots . \ldots . \ldots 81$

Figure 32 - Proportion of young individuals (15 - 29 years old) in treatment and control group 85

Figure 33 - Proportion of young individuals ( 15 - 29 years old) in control and treatment group by enforcement level . . . . . . . . . . . . . . . . . . . . 85

Figure 34 - Population in treatment and control group (million) . . . . . . . . . . . 86

Figure 35 - Population in control and treatment group by enforcement level (million) . . . . . 86

Figure 36 - GDP in treatment and control group (billion US\$) . . . . . . . . . . . . . . 86

Figure 37 - GDP in control and treatment group by enforcement level (billion US\$) . . . . . . 86

Figure 38 - Proportion of Health expenditure in total municipal expenditure (\%) . . . . . . . 86

Figure 39 - Proportion of Health expenditure in total municipal expenditure by enforcement level $(\%) \ldots \ldots \ldots$. . . . . . . . . . . . . . 86

Figure 40 - Trajectory of smoking prevalence among adults (18-64 years old) in control, low enforced and high enforced treatment groups, 2007-2013 . . . . . . . . . . 87

Figure 41 - Trajectory of smoking prevalence among youths (15-29 years old) in control, low enforced and high enforced treatment groups, 2007-2013 . . . . . . . . . . 87

Figure 42 - The state of selected tobacco control policies in the world in 2016 . . . . . . . . . 99

Figure 43 - Smoke-free environments - highest achieving countries and territories in 2016 . . 99

Figure 44 - Evolution of cigarette box's prices from 2010 to 2013 in Control and All Treatment Groups . . . . . . . . . . . . . . . . . . 100

Figure 45 - Evolution of cigarette box's prices from 2010 to 2013 in Control and High Enforcement Treatment Groups . . . . . . . . . . . . . . . . . . . 100

Figure 46 - Series of Price Index related to cigarette box from 2006 to 2017 in Control and Treatment Groups . . . . . . . . . . . . . . . . 100

Figure 47 - Distribution of price paid per cigarette pack by adults in 2013 in Control and All Treatment Groups . . . . . . . . . . . . . . . . . . . 101

Figure 48 - Distribution of price paid per cigarette pack by youths in 2013 in Control and All Treatment Groups . . . . . . . . . . . . . . . . . . . 101

Figure 49 - Distribution of price paid per cigarette pack by adults in 2013 in Control and High Enforcement Treatment Groups . . . . . . . . . . . . . . . . . . . . 101

Figure 50 - Distribution of price paid per cigarette pack by youths in 2013 in Control and High Enforcement Treatment Groups . . . . . . . . . . . . . . . . . . . 101 


\section{List of Tables}

Table 1 - States' Smoking Bans . . . . . . . . . . . . . . . . . . . . . . 24

Table 2 - State capitals' Smoking Bans . . . . . . . . . . . . . . . . . 24

Table 3 - Year of treatment for each treated unity . . . . . . . . . . . . 44

Table 4 - Mean differences for covariates, $2008 \ldots \ldots \ldots \ldots$

Table 5 - Mean differences in 2013 sample . . . . . . . . . . . . . . . 51

Table 6 - Smoking Bans impacts on smoking prevalence over time . . . . . . . 53

Table 7 - Smoking Bans impacts on smoking prevalence by enforcement level over time . . . . . . . . . . . . . . . . . . . . 59

Table 8 - Price, Smuggling and Cessation Programs in 2013 . . . . . . . . . 64

Table 9 - Price, Smuggling and Cessation programs in 2013 by enforcement level . 65

Table 10 - Smoking bans description and enforcement levels . . . . . . . . . . 75

Table 11 - Statistics to the whole sample . . . . . . . . . . . . . 77

Table 12 - Mean differences between capital states with and without smoking bans - PETab $2008 \ldots \ldots \ldots$. . . . . . . . . . . . . . . 81

Table 13 - State capitals in treatment and control groups . . . . . . . . . . 83

Table 14 - Covariates' mean differences between treatment and control group by enforcement level, $2008 \ldots \ldots \ldots$

Table 15 - Smoking bans impacts on selected covariates (2007-2013) _ . . . . . 87

Table 16 - Smoking Bans impacts on smoking initiation and cessation over time . . 88

Table 17 - Enforcement level smoking bans impacts on smoking initiation and cessation over time . . . . . . . . . . . . . . . . . . 89

Table 18 - Smoking Bans impacts on smoking prevalence over time: all treated . . 91

Table 19 - Smoking Bans impacts on smoking initiation over time: all treated . . . 92

Table 20 - Smoking Bans impacts on smoking cessation over time: all treated . . . 92

Table 21 - Smoking Bans impacts on smoking prevalence over time: 3 months threshold 93

Table 22 - Smoking Bans impacts on smoking initiation over time: 3 months threshold 94

Table 23 - Smoking Bans impacts on smoking cessation over time: 3 months threshold 94

Table 24 - Smoking Bans impacts on smoking prevalence over time: 9 months threshold 95

Table 25 - Smoking Bans impacts on smoking initiation over time: 9 months threshold 96

Table 26 - Smoking Bans impacts on smoking cessation over time: 9 months threshold 96

Table 27 - Coefficient and respective p-values for Cluster Robust Standard Deviation (CRVE)

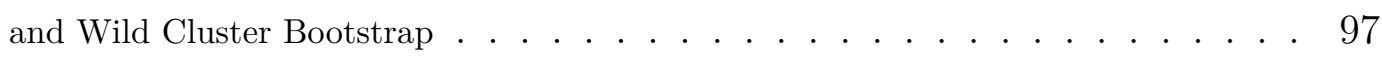

Table 28 - Statistics on Cigarette Prices (box with 20 cigarettes) _ . . . . . . . . 100 



\section{Contents}

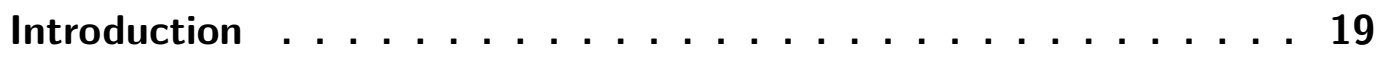

1 INSTITUTIONAL BACKGROUND $\ldots \ldots \ldots 23$

1.1 Smoking Bans in Brazil . . . . . . . . . . . . . . . 23

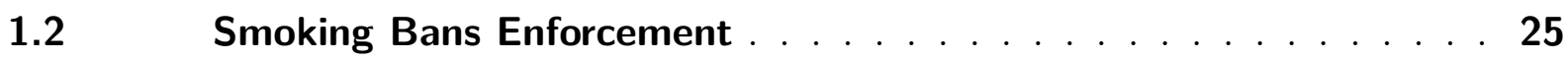

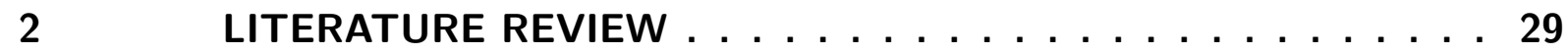

2.1 International Literature . . . . . . . . . . . . . . . . 29

$2.2 \quad$ Brazilian Literature . . . . . . . . . . . . . . . . . 31

2.3 Theoretical Approach to Cigarette Consumers Behavior . . . . . . 32

3 DATA AND DESCRIPTIVE STATISTICS . . . . . . . . . 35

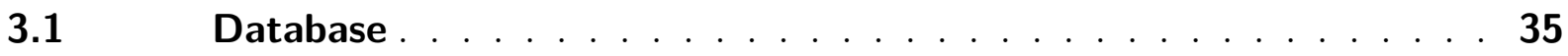

$3.2 \quad$ Descriptive Statistics . . . . . . . . . . . . . . . 38

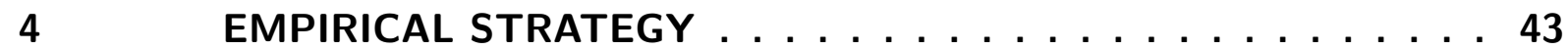

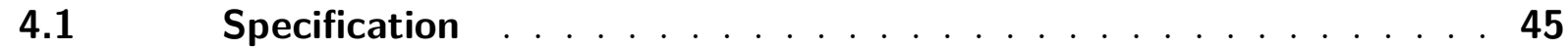

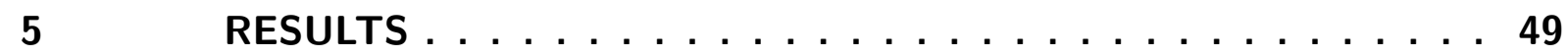

$5.1 \quad$ Mean differences and trend . . . . . . . . . . . . 49

$5.2 \quad$ Average Treatment Effects of Smoking Bans . . . . . . . . . . 52

5.2.1 Average impacts on Smoking Prevalence . . . . . . . . . . . . . 53

5.2.2 Average impacts on Smoking Initiation and Cessation . . . . . . . . . . 54

$5.3 \quad$ Impacts of Smoking Bans by Enforcement Levels . . . . . . . . 57

5.3.1 Enforcement-level impacts on Smoking Prevalence . . . . . . . . . . 58

5.3.2 Enforcement-level Impacts on Smoking Initiation and Cessation . . . . . . 60

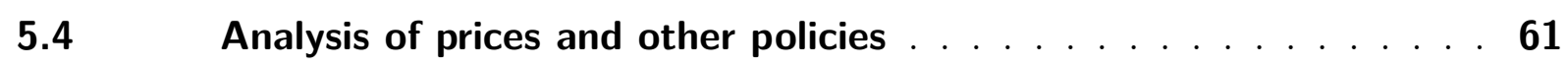

Concluding remarks $\ldots \ldots \ldots \ldots \ldots$

REFERENCE LIST $\ldots \ldots \ldots \ldots \ldots \ldots$

$\begin{array}{ll}\text { APPENDIX } & 73\end{array}$

APPENDIX A-SMOKING BANS DESCRIPTION . . . . . . 75

APPENDIX B - RETROSPECTIVE DATA FIT . . . . . . 77 
APPENDIX C - DESCRIPTIVE STATISTICS . . . . . . . . . 81

APPENDIX D - EMPIRICAL STRATEGY . . . . . . . . . . 83

APPENDIX E - RESULTS . . . . . . . . . . . . . 85

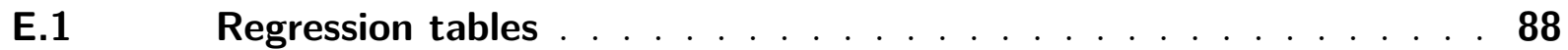

APPENDIX F - ROBUSTNESS . . . . . . . . . . . . . . . 91

F.1 Including all unities: 2008, 2009, 2010 and 2011 treated . . . . . . . 91

F.2 Changing the month threshold of smoking quitting time . . . . . . 93

F.2.1 3 months threshold . . . . . . . . . . . . . . . . . 93

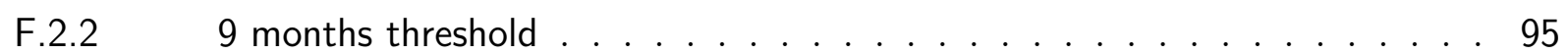

F.3 Wild Cluster Bootstrap . . . . . . . . . . . . . . . . . 97

APPENDIX G - PRICE AND OTHER POLICIES ANALYSIS . . . 99 


\section{Introduction}

Smoking is the main cause of preventable deaths worldwide according to the World Health Organization (WHO, 2015). It is estimated that more than 134,800 deaths are caused by tobacco related diseases in Brazil per year, which represented $12.8 \%$ of male and 9.4\% of female deaths in 2010 (ERIKSEN et al., 2015). Among these diseases, there are several types of cancers, cardiovascular diseases, emphysema and cerebrovascular accidents (WHO, 2008).

In addition to the adverse effects of tobacco on the health of smokers, it also impairs the health of those who did not choose to smoke. Passive smoking is related, for instance, to the incidence of respiratory diseases in children and to a lower fetal development (ADDA; CORNAGLIA, 2010). Estimates for 2011 indicated that 16,920 deaths per year in Brazil are related to passive smoking and perinatal causes (PINTO; PICHON-RIVIERE; BARDACH, 2015). Several studies ${ }^{1}$ evidence and explain the relationship between cigarette smoke and the development of pulmonary obstructions, heart diseases, asthma, lung cancer and respiratory symptoms, included in passive smokers.

As a consequence, smoking generates costs for the individuals and for the health system (PINTO; UGÁ, 2010). The direct costs generated for the Brazilian health system were estimated at more than US\$ 6 billion in 2011, including hospitalizations and other procedures for diseases such as stroke, heart disease, pneumonia and lung cancer (PINTO; PICHON-RIVIERE, 2012).

In this way, public policies that aim to reduce smoking are justified under two economic arguments of market failures: negative externalities and asymmetric information (RIZZIERI, 2008; LAMPREIA et al., 2015). Negative externalities are related to the adverse effects of smoking in passive smokers' health condition. Public intervention occurs by the restriction of the use of tobacco in indoor public places. Asymmetric information would help explain why smoking is still a common practice, despite the solid documentation of its adverse effects: $16.6 \%$ of men and $11.1 \%$ of women smoked daily in 2013 in Brazil (ERIKSEN et al., 2015). Intervention occurs with the objective of improving smokers knowledge on the health consequences of smoking (e.g.: advertisement bans, warning labels, mass media campaigns).

In order to reduce these failures, anti-smoking policies have been adopted in Brazil and worldwide in recent years. According to WHO, about $40 \%$ of the world's population was covered by at least one tobacco control policy at the highest level of achievement

\footnotetext{
(2014).

${ }^{1}$ See Bohadana, Teculescu and Martinet (2004), Tamimi, Serdarevic and Hanania (2012), Kim et al.
} 
in 2014. Among these policies, smoking bans are the most common, affecting 1.3 billion people in 2014 (WHO, 2015).

In Brazil, smoke-free environments were introduced in 1996 at the national level. Nonetheless, this law allowed the creation of smoking exclusive areas in indoor public places. In order to intensify tobacco control, several states and some municipalities introduced more restrictive smoking bans between 2008 and 2012. They prohibited smoking areas in all closed or partially opened public places. This restriction was nationally adopted in Brazil only in December 2014.

However, the international literature ${ }^{2}$ is not conclusive about the impacts of smoking bans on cigarette consumption and on smoking prevalence. If no impacts are observed, this policy can have adverse effects on passive smokers' health, as people might smoke more at private places (ADDA; CORNAGLIA, 2010). This finding draws attention to the importance of evaluating the effects of smoking bans on consumers behavior.

Aiming to provide more evidence to developing countries, our paper evaluates the impacts of smoking bans on the prevalence of daily smoking among adults and youths in Brazil. We focus on the laws which forbidden smoking specific areas, exploring regional and timing differences in their implementation between states and municipalities. We use the difference-in-differences approach to capture heterogeneous impacts of the bans over the years of coverage. Despite the existence of more lenient smoke-free environments legislation, we will refer as smoking bans only to the ones that prohibit smoking in closed or partially closed indoor public places.

Even though there are evaluations of smoking bans worldwide, they strongly prevail in developed countries. In this sense, our paper contributes to the international literature ${ }^{2}$ providing evidence of smoking bans impacts on countries with institutional and financial specificities and distinct smoking prevalence.

Developing countries have lower-quality institutions and scarcity of public resources, which can threaten the implementation of policies. The reason is that the enforcement of laws requires allocation of resources to surveillance and political will to publicize and to penalize transgressors. In this paper we consider different levels of enforcement of smoking bans to identify those specificities.

Moreover, developing countries have, on average, lower smoking prevalence when compared to developed ones. Cigarette use in most countries from Americas and Africa is under the global average, while most European countries are distributed over this average (WHO, 2017a). It does not mean, nevertheless, that smoking is not a concern in less developed nations: in absolute values, the number of smokers is not insignificant, due to the high population; and smoking-related diseases incur costs to public health in countries

2 See Chaloupka and Wechsler (1995), Adda and Cornaglia (2010), Anger, Kvasnicka and Siedler (2011), Boes, Marti and Maclean (2015), Jones et al. (2015), Vuolo, Kelly and Kadowaki (2016). 
with already overwhelmed health system and lack of resources.

This paper also contributes to the literature ${ }^{2}$ in what concerns to the measurement of longer run effects. Some international evaluations ${ }^{3}$ related the absence of impacts of smoking bans to the short term analysis and the addiction aspect of tobacco. Our empirical strategy allows the comprehension of the smokers' response to this policy over the time of exposure to the bans. The temporal difference between the introduction of local laws and the implementation of the national smoking ban in Brazil also allows the analysis of the effects of this policy in a longer term.

One difficulty in studying smoking policies in Brazil is the lack of panel data about individuals' cigarette consumption. In order to deal with it, we build a panel using cross-sectional micro data collected by the Brazilian Bureau of Statistics (IBGE): 2013 National Health Research (PNS). This survey contains information of the age in which individuals start smoking and also of the time they quit smoking, if so. We then create our longitudinal data based on the retrospective information about cigarette consumption, according to Boes, Marti and Maclean (2015), Palali and Ours (2017a), Palali and Ours (2017b). We artificially observe the status of each individual as a smoker or not in the period of study. This strategy allow us to evaluate dynamic impacts both on smoking initiation and quitting due to smoking bans ${ }^{4}$.

Our results show that smoking bans are related to a reduction of around $7 \%$ of daily smoking prevalence among young adults over the time of implementation of the laws, especially after three years of exposure. When considering the level of enforcement, we find that the effects of smoking bans on daily consumption of cigarette among young adults were stronger in the unities where the laws were more policed and penalties were applied. Higher enforced laws are related to a decrease on smoking prevalence among youths of $10 \%$ in the longer term. This reduction represents more than 90 thousand young adults smokers in the high-enforced treatment group in 2009. On the other hand, no significant impacts were found on the unities where the laws were poorly enforced.

Our findings to youths are associated to lower smoking initiation. Among adults, we find evidence of $1.2 \%$ smoking cessation rate due to high-enforced bans. No impacts were found on adults' smoking prevalence and initiation.

The long run effects are consistent with international evidence on delayed effects of smoking bans (BOES; MARTI; MACLEAN, 2015). Finally, the impacts on young adults can be explained by the literature that found effects on people that are more exposed to the smoking bans (by going out more frequently to public places, such as restaurants, bars

\footnotetext{
${ }^{3}$ See Jones et al. (2015), Anger, Kvasnicka and Siedler (2011).

${ }^{4}$ In order to show that the creation of an individual panel from PNS was accurate, we compare the lagged PNS in 2008 to 2008 Tobacco Special Research (PETab) information. PETab is another cross-sectional micro data collected by the IBGE, which consisted of a supplement of the 2008 Household Sample Survey (PNAD) regarding tobacco use.
} 
and nightclubs) (ANGER; KVASNICKA; SIEDLER, 2011) and by the theory of smoking rational addiction (CHALOUPKA, 1991). We show that our findings are not explained by cigarette prices changes and by other tobacco control policies.

This dissertation is organized as following: chapter 1 presents the institutional background of smoking bans adoption in Brazil. A literature review is presented in chapter 2 , followed by database description (chapter 3). In the chapter 4 we explain the empirical strategy adopted to identify the effects. The results are presented in the chapter 5. Finally, the last chapter discusses the results and future investigations. 


\section{Institutional Background}

\subsection{Smoking Bans in Brazil}

Brazilian smoke-free areas were introduced in 1996 for the whole country. This national law prohibited smoking in closed indoor public places, although it allowed the creation of smoking exclusive areas. According to the legislation, these areas should be properly insulated from the common areas and with suitable ventilation.

However, it is common knowledge that the segregation of smoking areas did not happen in the way of effectively isolating smoke from common areas and avoiding the exposition of nonsmokers. Moreover, the 1996 legislation and its further regulation have not indicated the monitoring agencies and the penalties that could be applicable to transgressors.

As a consequence, overall, it is possible to argue that the creation of smoke-free areas was not actually enforced in Brazil until 2008. Therefore, with the objective of strengthening the creation of smoke-free areas, since 2008 some states and some municipalities have adopted regional smoking bans. These local laws prohibit smoking in closed or partially opened indoor public places, without the permission of smoking exclusive places.

After the initiative of local unities, a national smoking ban forbidding smoking areas was approved in 2011, replacing the 1996 legislation for the whole country. This national smoking ban got effective only in December, 2014, following its regulation by the federal executive branch. A summary regarding the Brazilian institutional background on smoking bans is exposed bellow.

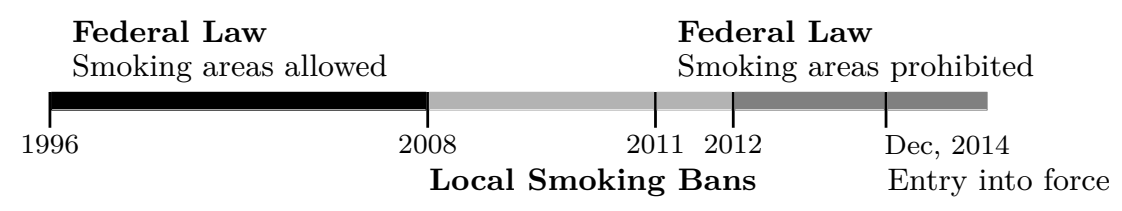

Figure 1 - Trajectory of Smoking Bans in Brazil

Source: Prepared by the authors.

Information about the adoption of smoking bans by municipalities and states were first obtained from the website of the non-governmental organization Tobacco Control Alliance (ACTBR, 2016). Then each legislation has been read in order to verify information about restrictions, effective date and enforcement. An Internet search has been also 
conducted to check changes of the listed laws or the existence of laws not cited by ACTBr $(2016)^{1}$.

Table 1 lists the States smoking bans and their effective dates. Table 2 lists state capital municipalities with regional restrictive smoking ban. Beyond state capitals listed in Table 2, other municipalities belonging to states with no smoking bans have adopted local restrictions, mainly in the states of Santa Catarina and Rio Grande do Sul. Brazil is a federative country with 26 states plus the federal district and with 5,570 municipalities. Because there is no centralized information regarding the adoption of laws at the municipal level and our data is not representative to non-capital municipalities, we focus only in the state capitals.

Table 1 - States' Smoking Bans

\begin{tabular}{c|c}
\hline State $^{2}$ & Effective date \\
\hline Rondônia (RO) & October, 2008 \\
São Paulo (SP) & August, 2009 \\
Roraima (RR) & November, 2009 \\
Paraíba (PB) & November, 2009 \\
Rio de Janeiro (RJ) & November, 2009 \\
Paraná (PR) & November, 2009 \\
Amazonas (AM) & December, 2009 \\
Cuiabá (MT) & June, 2011 \\
Alagoas (AL) & February, 2012 \\
Goiás (GO) & October, 2012 \\
\hline
\end{tabular}

Source: Prepared by the authors based on the cited laws and ACTBr (2016).

Table 2 - State capitals' Smoking Bans

\begin{tabular}{c|c}
\hline City/State $^{3}$ & Effective date $^{\text {Rio de Janeiro/RJ }}$ \\
May, 2008 \\
Curitiba/PR & November, 2009 \\
Belém/PA & November, 2009 \\
Aracaju/SE & December, 2009 \\
Salvador/BA & December, 2009 \\
Goiânia/GO & December, 2009 \\
Manaus/AM & December, 2009 \\
João Pessoa/PB & January, 2010 \\
Rio Branco/AC & February, 2010 \\
Campo Grande/MS & March, 2010 \\
Teresina/PI & November, 2010 \\
\hline
\end{tabular}

Source: Prepared by the authors based on the cited laws and ACTBr (2016).

As we can see from Table 1 and Table 2, most of local smoking bans have been adopted between 2009 and 2010. There are some capitals in which both the state and the

\footnotetext{
${ }^{1}$ Our findings are compatible with Furtado and Filho (2016).
} 
municipality introduced smoking bans. In the map showed in Figure 2, we present the distribution of these local smoking bans in the Brazilian territory, differentiating states that have adopted laws from those in which only the capital adopted its local law ${ }^{4}$. The red markers in the map indicate the location of each state capital. By the map, one can observe the existence of a regional variability in the adoption of smoking bans, since all Brazilian regions are represented by at least one State and city with local smoking bans.

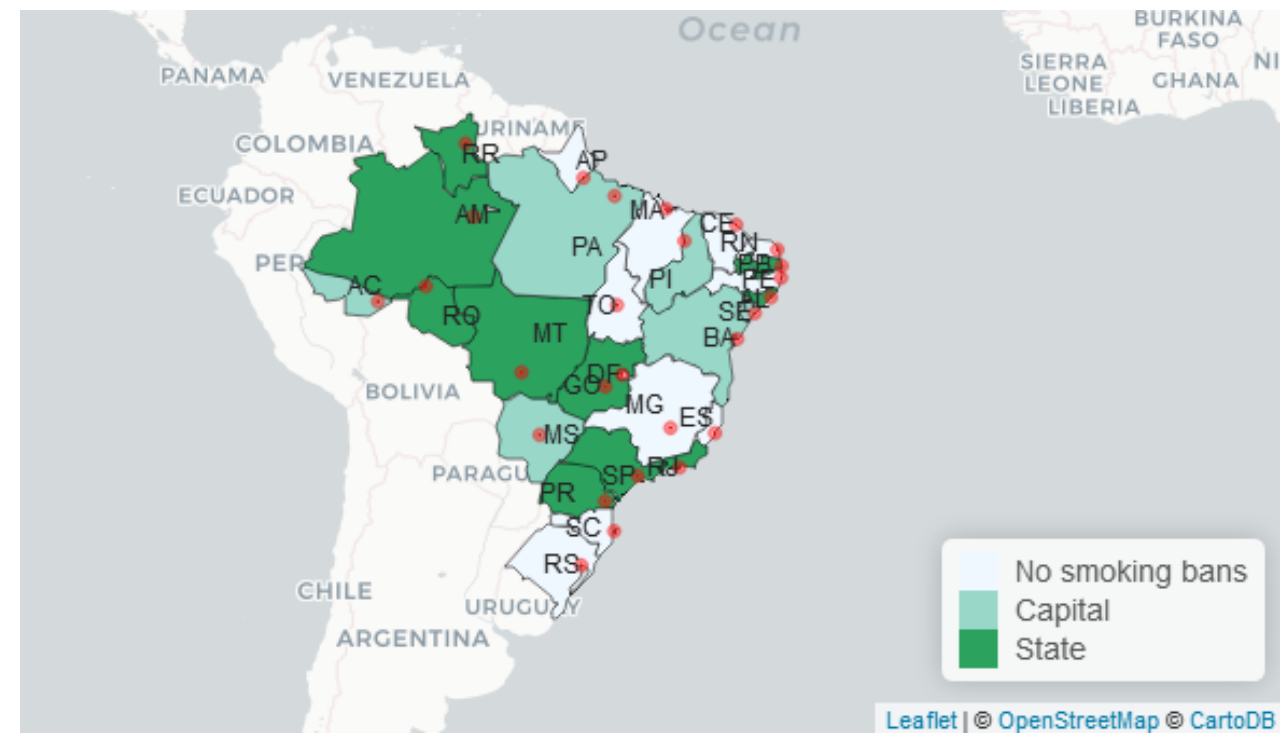

Figure 2 - Brazilian Map of local smoking bans adopted from 2008 to 2012

Note: The red markers indicated the location of the capital of the respective states, followed by state's acronyms. For easy viewing, the whole state was hatched by the representative color, even if the law was adopted only in the capital. Prepared by the authors.

Therefore, the regional Brazilian smoking bans represented a shift in the policy of smoke-free areas in two ways. Firstly, it established a formal complete prohibition of cigarette smoking in closed collective areas. Secondly, local legislations have laid down detailed rules for their enforcement. The next subsection contains information about these rules.

\subsection{Smoking Bans Enforcement}

Regarding the enforcement of local Brazilian smoking bans, each legislation define the monitoring agency and the punishment imposed to transgressors. Overall, the bans are executed by municipal health agencies related to Agência Nacional de Vigilância Sanitária

\footnotetext{
${ }^{4}$ There are some news concerning the validity of Rio de Janeiro municipal smoking ban, which had a claim of unconstitutionality. As it is not clear if the law was effectively applied, we request Rio de Janeiro's Agência Nacional de Vigilância Sanitária (ANVISA) for clarification. Until the moment, we did not have answer. Is this paper, we consider as effective date the moment from which the state law was adopted, since there is no evidence of enforcement of Rio de Janeiro municipality law, as we show better in the next subsection.
} 
(ANVISA) and to consumer protection agency (PROCON). When the law is adopted at the state level, the state agencies act together with the municipal ones.

The law offenders are the responsible for the establishments where smoking bans were not enforced. In private collective places, for instance, the offender would be the owner of the company. According to the legislations, in order to ensure the application of smoking bans, the collective places should contain warnings such as "Forbidden to Smoke in this place" and their responsible should advertise smokers and even call the police in the case smokers do not respect the bans. Rondônia law also provides penalties for smoker transgressors.

Anyone can report violation of the law for the monitoring agency, even anonymously. After that, one representative should check the reported place and, in case of disagreement with the law, apply the penalties. The penalties provided for the bans vary from warning to fines and, in the extreme case of recidivism, interruption of places.

However, the enforcement of smoking bans depends on the allocation of resources to surveillance, on the disseminating of the law among citizenships and the raising of public awareness in ensuring it, and on political will to penalize transgressors. There are not few situations in which the existence of some law does not guarantee its application, mainly in developing countries.

We requested the monitoring agencies information regarding the enforcement of the respective smoking bans, such as number of applied penalties and value of fines per year. We have had answers from the states of São Paulo (SP) and Rondônia (RO) and from the capitals Curitiba (PR), Campo Grande (MS), Goiânia (GO), Maceió (AL), Salvador (BA), João Pessoa (PB), Aracaju (SE) and Teresina (PI). We did not obtain any answers of the remaining unities. We have then complemented the obtained information with available news and data concerning the municipal expenditure in monitoring health agency. Information for each unity is summarized in Appendix A.

Maceió's monitoring agency informed they carried out awareness-raising activities when the law were adopted and never received any reports. Similar answer was received from Aracaju, but with respect to 2017 only. Salvador's monitoring agency informed that the system could not provide the required information. João Pessoa's consumer protection agency informed they are the responsible for supervising smoking bans, but did not provide further information. Rondônia's monitoring agency informed the law was still not enforced.

We then created a two-level index of enforcement, in which the higher level (number two) refers to smoking bans with high dissemination, surveillance and application of penalties. The lower level refers to smoking bans with dissemination and news regarding some surveillance, but no information regarding application of penalties (number one). Finally, Porto Velho, Rondônia's capital, received a zero-level indicator, due to the absence 
of enforcement which were confirmed by news and by the monitoring agency. Therefore, this municipality was dropped in our main estimations. Some specifications for the estimation of smoking bans impacts consider dosage impacts of smoking bans according with their level of enforcement showed in the Figure 3.

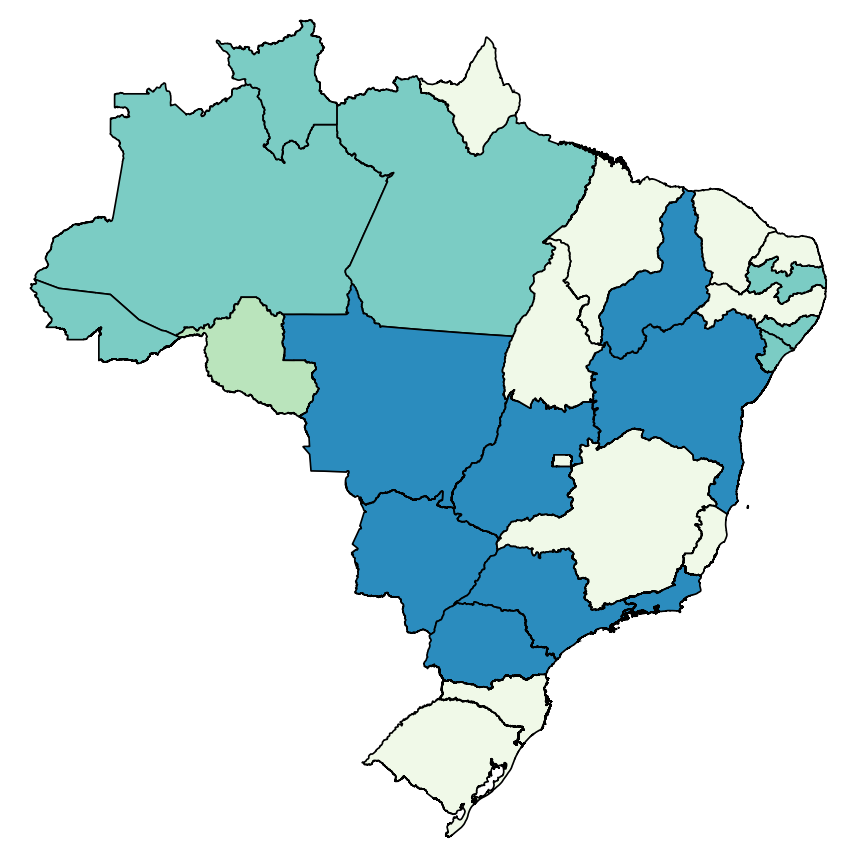

\section{$\square$ Higher enforcement $\square$ No enforcement Lower enforcement $\square$ No smoking bans}

Figure 3 - Enforcement level of Brazilian local smoking bans adopted from 2008 to 2012

Note: For easy viewing, the whole state was hatched by the representative color, even if the law was adopted only in the capital. Prepared by the authors.

It is necessary to highlight that, even in the absence of high observed enforcement, smoking bans can be applied by population monitoring. The fact that the legal offender would be the responsible of the establishment can encourage compliance by collective places and facilitate the claim by individuals. Finally, the restriction of the analysis to state capitals reduce the heterogeneity of the institutions and of information access, which can be higher distorted in small municipalities. 



\section{Literature Review}

Due to the proliferation of anti-tobacco policies in the world, several studies aimed to measure the effectiveness of such policies on reducing the prevalence and consumption of tobacco products and its health impacts. This chapter contains a review of the literature about evaluation of impacts on cigarette consumers' behavior, focusing on smoking bans. The first section summarizes the international literature on smoking bans impacts. In the sequence, we present Brazilian studies that were made in this area. As there are few studies regarding smoking bans in Brazil, we also discuss papers about other tobacco control policies, which were adopted as a baseline to our further analysis. Finally, in the last section, we introduce a brief view of the theory of rational addiction, widely adopted in the analysis of cigarette consumers' behavior.

\subsection{International Literature}

In one of the seminal papers on smoking bans evaluation, Chaloupka and Wechsler (1995) measured the effects of this policy on young individuals' smoking behavior, based on a 1993 survey with 17,592 students from 140 U.S. colleges and universities. They found that stricter bans reduced student participation rates on smoking and any kind of ban reduced average consumption. More recently, Vuolo, Kelly and Kadowaki (2016) verified that U.S. smoking bans had a significant impact on reducing occasional cigarette smoking but not on daily consumption among young individuals.

Some papers used differences-in-differences to measured the impacts of smoking bans. Anger, Kvasnicka and Siedler (2011) evaluated German smoking bans' impacts on the prevalence of smoking and on daily smoking quantity. They did not find significant impacts on the average cigarette consumption in the short term, but, analyzing for individuals who claimed to "going-out" to restaurants and bars more frequently, there was significant impact on the reduction of smoking.

With a similar empirical strategy, Boes, Marti and Maclean (2015) estimated progressive impacts of Swiss smoking bans along the years of exposure to the laws. They found that the policy reduced the prevalence of cigarette use, but only one year after its introduction. In addition, they observed that individuals who smoke more intensively were less likely to visit public places (such as bars, restaurants and nightclubs) after the bans.

Using this approach, there is also the paper of Jones et al. (2015) for the United Kingdom. They explored the temporal difference in the adoption of smoking bans in Scotland and England and found that the creation of smoke-free areas in the UK had 
little impact on smoking prevalence and on overall consumption. Therefore, no evidence of effectiveness of these policies in controlling tobacco use was found, although the authors emphasize that the study measured short-term impacts.

Adda and Cornaglia (2010) investigated the relation between the effects of smoking bans on consumers behavior and its consequences on health conditions of passive smokers. They found no evidence of causal effects between smoking bans and the prevalence and cessation of smoking in the US. As a result, contrary to expectations of the policy, the exposure of nonsmokers to cigarette smoke have increased in the US, mainly due to a shift in tobacco use from collective to private places.

Regarding other effects of smoking bans than cigarette use, Menzies et al. (2006) and Goodman et al. (2007) investigated the impacts on nonsmokers health condition in Scotland and Ireland, but just for bars workers. They found evidence of effects of the law on improving lung function and reducing respiratory inflammation among workers. Kim et al. (2016) measured a reduction of $73 \%$ on concentration of pollutants from tobacco smoke in bars after the introduction of smoking bans in South Korea.

Palali and Ours (2017a) investigated the impact of many tobacco control policies on smoking initiation in eleven European countries. They applied hazard models to longitudinal data at the individual level. In order to capture the dynamics of smoking throughout the years, they used individuals' onset age of cigarette use to "reconstruct the history of smoking initiation" (PALALI; OURS, 2017a, p.12). This study emphasizes the stylized fact that as individuals start smoking in early ages, the probability of starting to smoke after mid-20s is very low. Even thought no impact of the policies were found, the study gives light to the need of measures that focus on youths to avoid smoking initiation. They also highlight that the decision to start smoking is different from the decisions to continue or to quit smoking. Therefore, impacts evaluations should take it into account when identifying the effects of tobacco control policies.

As showed, international literature is not conclusive about the impacts of smoking bans on cigarette consumption and on smoking prevalence. Overall, no significant impacts were found in the short term, except when the analysis is restricted to groups that could me more exposed to the bans. There is some evidence of effects of smoking bans in the reduction of smoking prevalence in the medium term and to more restrictive laws. (ADDA; CORNAGLIA, 2010) draws attention to the importance of evaluating the effects of smoking bans on consumers behavior, since this policy can have adverse effects on passive smokers' health when not effective. 


\subsection{Brazilian Literature}

In Brazil, we are not aware of papers that evaluated the impacts of recent smoking bans on smoking behavior. But some papers studied the impacts of other tobacco control policies. For instance, Rizzieri (2008) estimated the effects of cigarette packs' warnings and advertising bans implemented in 2000 on smoking prevalence. He also measured a price elasticity of cigarette demand from -0.369 in the short term to -0.513 in the long term. The study applied Vector Autoregression using quarterly data from 1991/1 to 2006/4. He found no significant impacts of warnings and advertising bans on smoking prevalence, but observed that the price elasticity increased after those policies were implemented (to -0.3926). The study concluded that there was a shift of the competition through advertising to prices due to the bans (RIZZIERI, 2008).

Iglesias et al. (2016) measured the proportion of illegal cigarette consumption in the Brazilian market using data from PETab (2008) and PNS (2013). As smuggling is not observable, they defined price thresholds to the minimum price that cigarettes could be legally purchased in Brazil. Therefore, individuals who declared paying less than the this threshold for the cigarette pack would be considering as consuming from the illicit market. The study found an increase from $16.6 \%$ to $31.1 \%$ in the prevalence of illicit cigarette consumption in the period 2008-2013 in Brazil. The threshold for 2013 was defined according to the minimum price in force for the cigarette packs, which is established in Brazil since 2011.

The authors point out that the anti-smoking policies adopted in recent years in Brazil have been effective in reducing the prevalence of smoking among all socio-demographic groups. However, they emphasized the need to analyze and to restrain the cigarette illegal market, due to its harmful impacts on the effectiveness of the Brazilian tobacco control policy (IGLESIAS et al., 2016).

Concerning smoking bans, the study of Levy, Almeida and Szklo (2012) performed a simulation of the impacts of many anti-tobacco policies adopted in Brazil since 1989. They used SimSmoke Tobacco Control Policy Simulation Model and found that anti-smoking policies could reduce in 46\% the proportion of smokers between 1989 and 2010, of which 14\% would be due to smoke-free environments. However, this results should not be interpreted as casual effects, since no identification strategy were applied to identify the impacts of smoking bans.

Regarding health impacts, there is the paper of Furtado and Filho (2016) for more recent smoking bans. They evaluated the short and medium-term effects of the creation of smoke-free areas on the incidence of hospitalizations for smoking-related diseases (3 months and 7 months of exposure, respectively) using micro data of the Brazilian health system and the method of differences-in-differences combined with propensity-score. Overall, no 
significant impacts of smoking bans were found.

\subsection{Theoretical Approach to Cigarette Consumers Behavior}

Until the development of the Theory of Rational Addiction, consumers of addictive good were not seen as rationally behaving. Becker and Murphy (1988) applied the economics approach to show that addictive consumption could also be understood as a rational acting. In this theory, rationality is considered as the maximization of utility over time and addiction occurs when current consumption depends of past consumption (BECKER; MURPHY, 1988; CHALOUPKA, 1991).

Past consumption is included in the model in a cumulative way, producing the stock of the addictive good. Addiction is decomposed in three effects: reinforcement, tolerance and withdrawal. Reinforcement means that past consumption raises current and future consumption of the addictive good, since it increases its marginal productivity in the production of its benefits (relaxation). Tolerance means that a given level of current consumption generates less utility with higher level of addictive stock. Withdrawal is related to the negative effects on individuals' utility due to the cessation of an addictive good consumption. Cigarette is considered, then, as an addictive good and, under this theory, its consumption can be viewed as a rational behavior (BECKER; MURPHY, 1988; CHALOUPKA, 1991).

Therefore, the utility function of an individual at time $t$ can be summarized as follows (BECKER; MURPHY, 1988; CHALOUPKA, 1991).:

$$
U(t)=u[x(t), c(t), S(t)]
$$

where $\mathrm{x}(\mathrm{t})$ are the non-addictive good; $\mathrm{c}(\mathrm{t})$ is an addictive good, which in our study is cigarette; and $\mathrm{S}(\mathrm{t})$ is the accumulated stock of the addictive good. The marginal utility of cigarette is positive (withdrawal) and the marginal utility $S$ is negative (by tolerance). Reinforcement means that the derivative of the marginal utility of cigarette in relation to the stock is positive. Rational individuals maximize the lifetime utility (discounted by a time preference rate $\sigma$ ) subject to their lifetime budget constraint (BECKER; MURPHY, 1988; CHALOUPKA, 1991).

Based on this maximization, Chaloupka (1991) derived a demand function of the consumption of the addictive good:

$$
c(t)=\phi_{0}+\phi_{1} P_{c}(t)+\phi_{2} P_{c}(t+1)+\phi_{3} c(t+1)+\phi_{4} S(t)
$$

According the theoretical approach, it would be expected $\phi_{1}<0, \phi_{2}>0$ and $\phi_{3}>0$, since $c$ is an addictive good. The effect of $S(t)$ in the current consumption of $c$ 
depends of the strength of two opposite effects: by one hand, higher $S$ increases $c$ due to reinforcement; by the other hand, higher $S$ increases $c$ shadow price, as part of $c$ price take into account its harmful effect on future utility. Assuming a time discount rate equal the interest rate $(r)$, Chaloupka (1991) estimated this equation using U.S micro data and found evidence that $\phi_{4}>0$. It means that, under $\sigma=r$, reinforcement effect prevailed for the sample.

According to Becker and Murphy (1988) model, the net effect of the addiction stock on the current consumption depends, among other factors, on the rate of time preference. For individuals with higher preference for the present (higher $\sigma$ ), the shadow price is smaller. Therefore, the effect of stock in the current consumption is positive and stronger. Present-oriented individuals would be more potentially addicted. It explains why youngsters are more likely to get addicted compared to older counterparts.

With regards to cigarette use, according to Becker and Murphy (1988), smoking initiation, which consists in $c(t)>0$ when $S_{0}=0$, can be related both to high $\sigma$ and to events that cause an accumulation in the addictive stock to a given level such that reinforces future consumption. Some events are stress and peer pressure, which also explain smoking initiation among young individuals (BECKER; MURPHY, 1988).

Differently from initiation, smoking quitting also depends on the level of the individual addictive stock. Becker and Murphy (1988) argues that more addictive individuals are more likely to quit smoking, since larger stocks are related to higher degree of adjustment in future consumption. Therefore, there is a given level of addictive stock $(\hat{S})$ at which the relation of $c$ to $S$ is discontinuous, similar to an unstable steady-state. Under that level, consumption falls to zero over time. Above that level, if some event reduces $S$ under $\hat{S}$, then addiction is also ended. However, if the level of stock is so large that this event is not adequate to take $S$ under the discontinuity point, then addiction is not ceased.

According to Becker and Murphy (1988), as ending the consumption of addictive goods is painful (by withdrawal), a person decides to quit smoking when his loss in the short run is smaller than the long term benefits of smoking cessation. Palali and Ours (2017a) interpreted smoking quitting and initiation decision as the comparison among marginal costs $(M C)$ to marginal benefits $(M B)$. When $\mathrm{MC}$ is higher than $\mathrm{MB}$, then cigarette consumption should decrease. For instance, cessation treatments and informational policies can influence smoking quitting by reducing costs and increasing benefits, respectively. Smoking bans can have both effects: it increases the long term benefits of smoking cessation, due to peer pressure ans social interaction; and it increases the costs of smoking by restraining places where individuals can smoke.

In another study, Palali and Ours (2017b) checked the peer effects on the decision to quit smoking based on married couples in the Netherlands. They found no significant spousal peer effect, mainly due to the addictive characteristics of smoking. They argue 
that smoking quitting requires "a much stronger motivation and determination" (PALALI; OURS, 2017b, p.9) than avoiding smoking initiation. This study also highlights the necessity of data with enough youths observations when there is the aim to evaluate initiation impacts, since it prevails on early ages.

Hence, both empirical and theoretical literature address the importance of considering smoking prevalence apart from initiation and quitting when studying effects on cigarette consumption behavior. In addition, the Theory of Rational Addiction give support to the analysis of smoking under the economics approach. 


\section{Data and Descriptive Statistics}

\subsection{Database}

One of the limitations of studying smoking policies in Brazil is the absence of individual panel data on cigarette consumption. We have created an individual panel with smoking status using cross-sectional micro data from the 2013 National Health Research (PNS), collected by the Brazilian Bureau of Statistics (IBGE). This survey contains smoking information of a representative sample of the population of each Brazilian state and Brazilian state capitals.

We have identified if each individual smokes at the moment of the survey or if he has already smoked. We have also observed the age that the individual started smoking on a daily basis (even if he was not smoking anymore) and for how long the individual had quit smoking, if so. However, we can not observe when casual smokers started smoking and neither when the individual quit smoking on a daily basis and became a casual smoker ${ }^{1}$. We then dropped their observations, limiting our data to daily and former daily smokers. Casual smokers and former casual smokers represent around $6 \%$ of the PNS sample $(2 \%$ of current and $4 \%$ of former smokers), while daily ones represent almost $25 \%$. Casual smokers consist in around $19 \%$ of total current smokers. There is no statistical significant difference in these proportions among the sample of capitals with and without local smoking bans.

Using retrospective information of PNS, we created an individual panel with smoking status through the years of 2006 - 2013, in accordance with Boes, Marti and Maclean (2015), Palali and Ours (2017b), Palali and Ours (2017a). For each individual, we artificially observe their status as a regular smoker or not in the period of study. A person is considered a daily smoker in a specific year $(\mathrm{t})$ if their smoking time (the difference between their current age and the smoking starting age) is greater or equal the difference between 2013 and the year t. If this person was not a daily smoker in 2013, we also consider their smoking quitting time and compare it with the difference between 2013 and the year of analysis (t).

To illustrate, consider three individuals: A (never smoker), B (current smoker) and $\mathrm{C}$ (former smoker). $A$ will be considered as non-smoker in all the years of the panel (dummy zero). If $B$ is forty years old and answered he has started smoking by the age 35 , then $B$ will be considered as smoker in 2013 and in the five years prior to 2013: 2012, 2011, 2010, 2009 and 2008. So he will not be considered as smoker in 2007 and before. Finally,

\footnotetext{
${ }^{1}$ Daily smokers are individuals who reported smoking cigarette on a daily basis. On the other hand, casual smokers are defined as individuals who reported consuming cigarette, but not on a daily basis.
} 
consider $\mathrm{C}$ is also forty years old and started smoking by the age 35, but quit smoking 2 years before the survey (then 2011). Then C also started smoking in 2008, but will not be considered as smoker in 2013 and 2012. A simplified scheme can be seen in Figure 4.

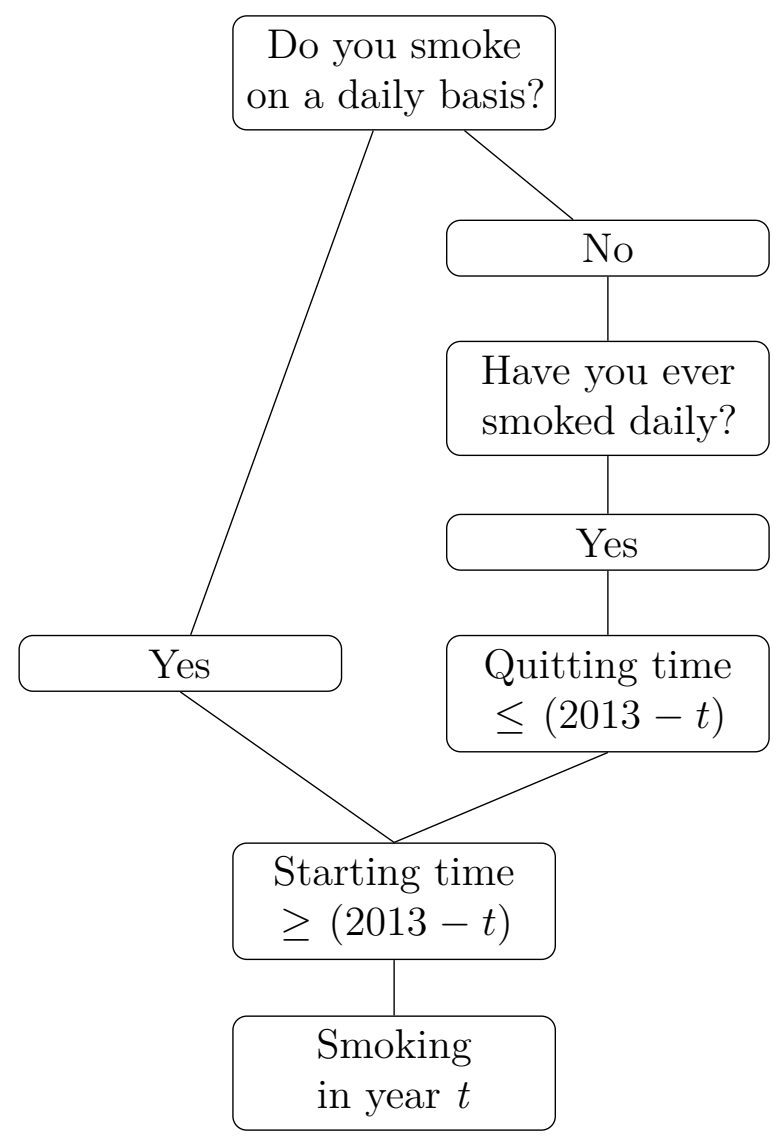

Figure 4 - Database scheme

Source: Prepared by the authors based on PNS 2013 dictionary.

Regarding smoking quitting time, individuals could have answered both year and month (i.e 1 year and 3 months, or just 6 months). Individuals who quit smoking for less than six months have been considered as smokers in the year of analysis. If they quit smoking for more than six months, they have been considered smoking quitters in the previous year or in the beginning of the current year (so a former smoker in the year of analysis). As an illustration, consider four individuals and their respective quitting time: A (5 months), B (9 months), C (1 year and 3 months) and D (1 year and 8 months). A received a null quitting time and, for this reason, was not considered as a former smoker in 2013. B was considered 1 year smoking quitter. Consequently, B was a former smoker in 2013, but was smoking in 2012. The same for C. Finally, D received a 2 years smoking quitting time and was smoking, then, until 2011. We highlight that our results are robust to the change of this threshold for three and for nine months. ${ }^{2}$

\footnotetext{
${ }^{2}$ We have used six months as a threshold because the survey was not applied in the end of 2013, but
} 
In order to verify if the retrospective information about smoking was well estimated by the procedure explained above, we have compared some statistics of the lagged PNS for 2008 with the 2008 Tobacco Special Research (PETab) information ${ }^{3}$. The comparison is showed in Appendix B. Overall, the results indicate a good fit of the 2008 lagged PNS and show evidence that the created panel can be used to achieve the objectives proposed in this thesis.

Concerning other database manipulations, we have restrained our study to individuals living in Brazilian state capitals. One reason is that PNS is not representative to non-capital municipalities. Second, there is no centralized information of local smoking bans for each Brazilian municipalities, as explained in chapter 1. Besides that, using this strategy, we can keep the whole country in the analysis and we can obverse more institutional homogeneity among municipalities.

The sample of state capital's residents consists in around $45 \%$ of PNS individuals. Even thought it represents $25 \%$ of Brazilian population (more than 31 million adults in 2013) ${ }^{4}$, it is representative to Brazilian urban areas. Moreover, it covers most of the target population, since a significant fraction of formal jobs, public services and closed cultural and leisure activities' places are concentrated in the state capitals in Brazil.

There is a higher proportion of adults living in state capitals in the group of smoking bans adopters compared to the non-adopters one ${ }^{5}$. However, we argue that this difference (which is not statistically significant) is captured by regional specific effect, since there is no evidence of distinct evolution over time ${ }^{6}$.

We have also restricted the panel to individuals aged 18 through 64 years old in the adults' analysis and, in the youths' analysis, to individuals aged 15 to 29 years old in each year of the panel. The youths' boundaries are in accordance to the age's limits established by the Brazilian legislation ${ }^{7}$.

As the PNS smoking survey was only applied to individuals from 18 years old on,

in September. The results for three and nine months as threshold are shown in Appendix F.2. With three months, both A, B and C would be 1 year smoking quitters - so they would be smoking only until 2012. And D would be a 2 years smoking quitting (former smoker in 2013 and 2012). In the 9 months analysis, both A and B would be considered as smokers in 2013. C and D would be considered as smokers in 2012 (only 1 year of smoking quitting time).

${ }^{3}$ We have maintained the whole sample of adults from 15 years old to make the comparison, in order to keep the representativeness of the surveys.

${ }^{4}$ Obtained when using survey weights.

${ }^{5}$ The proportion is almost $28 \%$ in the unities with bans and almost $20 \%$ in the remaining ones.

${ }^{6}$ Checking data of the Brazilian Census from 1960 to 2010, also collected by IBGE, we have observed no difference in the evolution of the proportion of capital's residents over the last decade between unities with and without smoking bans. Even thought there is a slightly different trend between most groups in the last 50 decades, we argue this difference is not significant in one decade, mainly in the period of the adoption of smoking bans. The evolution in the proportion of residents in Brazilian capitals for both groups is showed in Figure 31 in Appendix C.

${ }^{7}$ National Law n. 12852, from August 2013, which establishes the Youth Statute and provides the rights of young people and the principles and guidelines of public policies for youth. 
we have checked the proportion of individuals in the age ranges 18 to 64 and 18 to 29 years old. The first range represents more than $87 \%$ of PNS and there is no difference among capitals with and without local smoking bans. Individuals from 18 to 29 years old represent $26.6 \%$ of the observations in the group of capitals without local smoking bans and $25.1 \%$ in the capitals with bans. This difference is not statistical significant.

In the Table $12^{8}$, we present the same statistics analyzed above, but regarding the period before the implementation of local smoking bans using PETab 2008. Previous conclusions do not change ${ }^{9}$.

Overall we argue that the sample restrictions do not generate selection concerns. The reason is that they do not affect the state capitals that adopted and did not adopt smoking bans in a different way. One advantage of the retrospective strategy we have used is that it allows the evaluation of dynamic impacts both on smoking initiation and quitting due to smoking bans (PALALI; OURS, 2017a; PALALI; OURS, 2017b). One limitation is that we do not observe time-varying individuals' covariates.

Finally, we have collected covariates at municipal level from 2006 to 2013, such as: GDP, Health Expenditure, Population and Health control agency expenditure. These data were obtained from the Brazilian Accounting Data of Municipalities (FINBRA) of the National Treasury and the Survey of Basic Municipal Information (MUNIC) of IBGE. To corroborate that our following results are not driven by differences in price evolution, we have obtained data regarding cigarette price from 2010 to 2013 for each Brazilian state. These prices were provided by the Federal Revenue Bureau.

\subsection{Descriptive Statistics}

The proportion of daily smokers in Brazil was around 17\% in 2008 (PETab) among individuals from 15 years old and 14.8\% in 2013 (PNS) among individuals from 18 years old ${ }^{10}$. Comparing the prevalence of smokers between youth and adults in 2008 and 2013 in Brazil (Graph 5), one can observe that a reduction in smoking prevalence happened in both groups in this period. For young adults, the proportion of daily smokers decreased

\footnotetext{
${ }^{8}$ Appendix C

${ }^{9}$ We highlight that, as PETab is not representative to state capitals, for some unities we had to select the metropolitan area of the capital or the urban area of the state as a proxy to the capital. That is one explanation why the proportion of the restricted sample of individuals living in capital regions is higher in PETab.

${ }^{10}$ We measured the proportions of daily smokers using sample weights of individuals selected for tobacco surveys in 2008 and 2013. According to IBGE (b), in 2008, the proportion of smokers was $17.2 \%$ and the proportion of daily smokers was $15.1 \%$ among individuals from 15 years old. The proportion of smokers was $10.7 \%$ for the age range $15-24$ years old; $18.3 \%$ for the age range $25-44$; and $22.7 \%$ for the age range 45-64 years old in 2008. In 2013, the proportion of tobacco users was $15 \%$ among individuals from 18 years old. It was distributed by age ranges as follows: $10.7 \%$ for 18 to 24 years old range; $13.2 \%$ for 25 to $39 ; 19.4 \%$ for 40 to 59 ; and $13.3 \%$ for the age range of individuals from 60 years old (IBGE, a). There is no official statistics regarding the exact sample and information we have used.
} 
from $13 \%$ in 2008 to $10.4 \%$ in 2013 . In the age range from 30 to 64 years old, the proportion of daily smokers decreased from $21 \%$ in 2008 to $16.8 \%$ in 2013. The prevalence of smoking among youths from 15 to 18 years old was less than $5 \%$ in $2008^{11}$.

Graph 5 - Prevalence of Smokers per age groups in 2008 and 2013

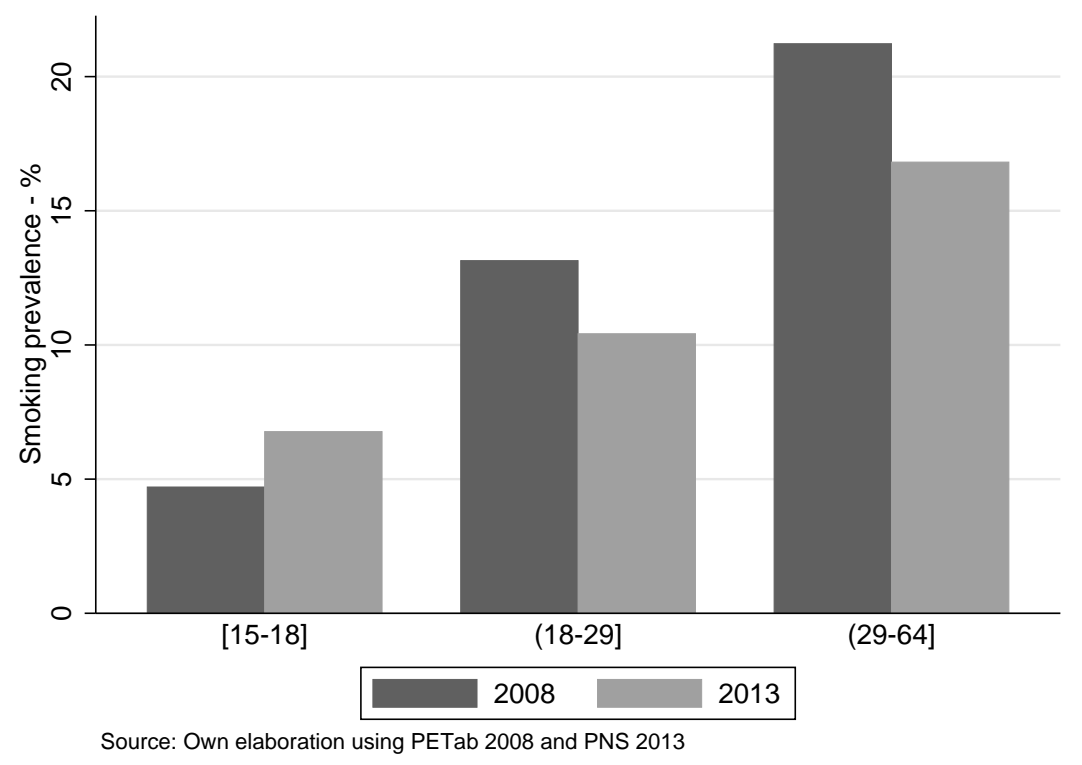

Source: Prepared by the authors using PETab 2008 and PNS 2013.

When inserting Brazil in a global perspective, one can observe that its prevalence of smokers is under the global average, which was more than $20 \%$ in 2015. Observing by continents, on one hand, America is between those regions which have more countries under the global average than above, along with the African continent. On the other hand, most European countries are distributed over this average (WHO, 2017a).

Even thought the Brazilian prevalence of smokers is not high in a global perspective, the quantity of smokers is not insignificant in absolute values: Brazil had more than 17.5 million daily smokers among persons from 18 to 64 years old in 2013, according to PNS. Moreover, Brazilian prevalence of smokers is similar to many developing countries and it is even similar to the US (WHO, 2017a).

When restraining to state capital's residents, the proportion of daily smokers was around $16.5 \%$ among adults and $12.4 \%$ among individuals from 15 to 29 years old in 2007 12. The prevalence of smokers is lower in the state capitals when compared to the whole country. However, the quantity of daily smokers was more than 10 million in 2008 and almost 9 million in 2013. In Graphs 6 and 7 we show the decreasing trajectory of smoking prevalence for both cohorts from 2007 to 2013.

\footnotetext{
${ }^{11}$ We highlight that, as PNS 2013 only applied the smoking survey to individuals from 18 years old, the age range $15-18$ is more limited in 2013 . However, we included this range in our analysis because we
} 
Graph 6 - Trajectory of smoking prevalence among adults (18-64 years old), $2007-2013$

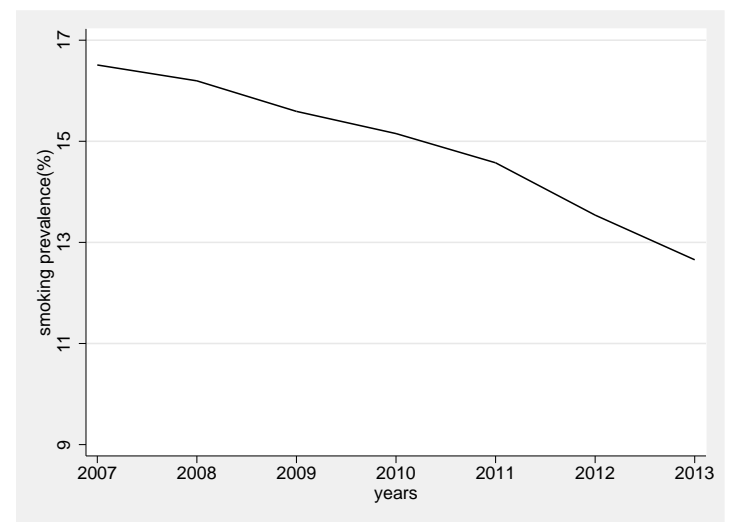

Source: Prepared by the authors using PNS 2013.
Graph 7 - Trajectory of smoking prevalence among youths (15-29 years old), 2007-2013

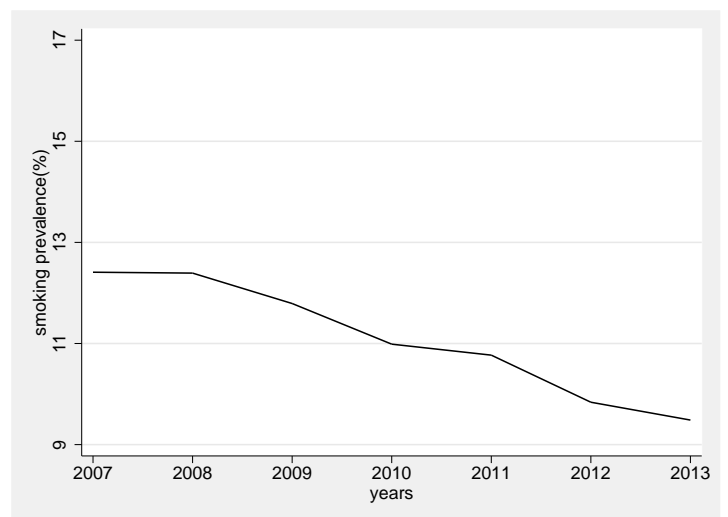

Source: Prepared by the authors using PNS 2013.

Regarding the dynamics of smoking behavior, around $2 \%$ of adults and more than $5 \%$ of youths in our sample became smokers from 2006 to 2013 (Graphs 8 and 9 respectively $)^{13}$. The low incidence of smoking initiation can be explained by the early ages people start smoking: in Graph 10, one can observe that more than $73 \%$ of the individuals started smoking until the age of 18 years old. Therefore, the restriction of our sample of adults to people from 18 years old limits the measurement of the effects on smoking initiation on this age range (PALALI; OURS, 2017b; PALALI; OURS, 2017a).

The cessation dynamic from 2006 to 2013 was higher: more than $25 \%$ among adults as well as young individuals (Graphs 11 and 12 respectively) ${ }^{14}$. By Graph 13, one can observe that most individuals who start smoking from 2006 to 2013 were younger than 29 years old in $2013^{15}$. Smoking cessation was more distributed around ages, with a peak between 30 and 50 years old.

can observe those individuals back in the panel.

${ }^{12}$ Both prevalences were measured using lagged PNS and sample weights

${ }^{13}$ We have measured the proportion of new smokers (i.e, initiation) in the sample of individuals who were not smokers in 2005.

${ }^{14}$ We have measured the proportion of smoking quitters (i.e, cessation) in the sample of individuals who were smoking in 2005.

${ }^{15}$ We remember that the smoking section of PNS was applied just to individuals from 18 years old on. As this graph consists in the age density of individuals in 2013, its lower bound in restrained to this limit. 
Graph 8 - Trajectory of smoking initiation among adults (18-64 years old), 2006-2013

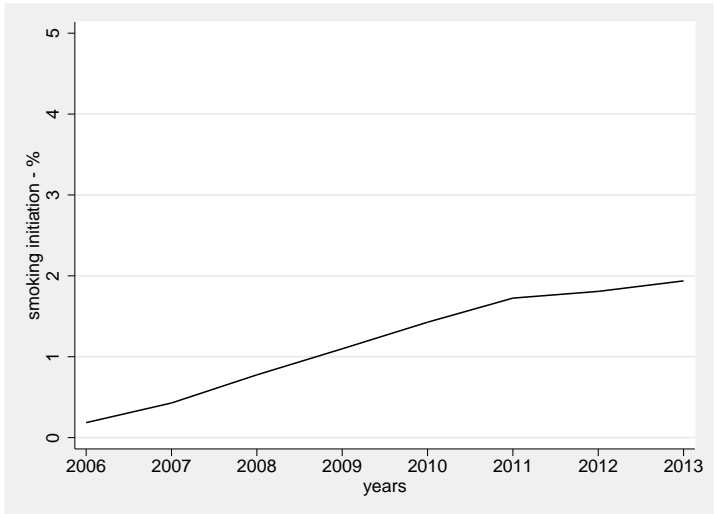

Note: Proportion of new smokers (i.e, initiation) measured in the sample of individuals who were not smokers in 2005. Prepared by the authors using PNS 2013.
Graph 9 - Trajectory of smoking initiation among youths (15-29 years old), 2006-2013

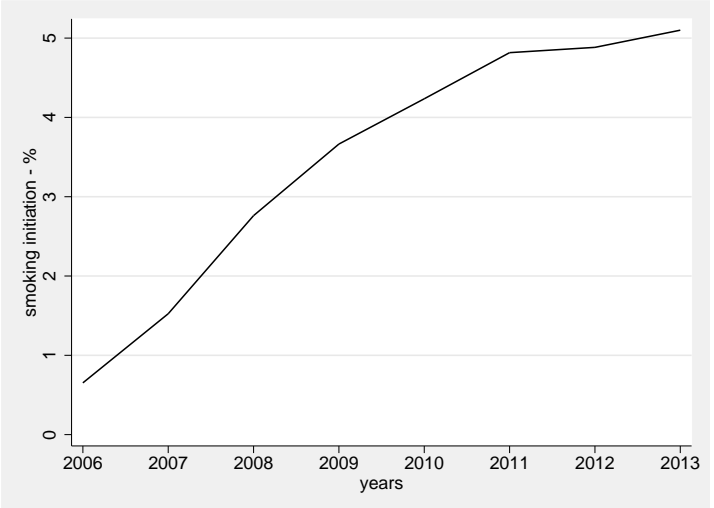

Note: Proportion of new smokers (i.e, initiation) measured in the sample of individuals who were not smokers in 2005. Prepared by the authors using PNS 2013.

Graph 10 - Cumulative distribution of smoking initiation age

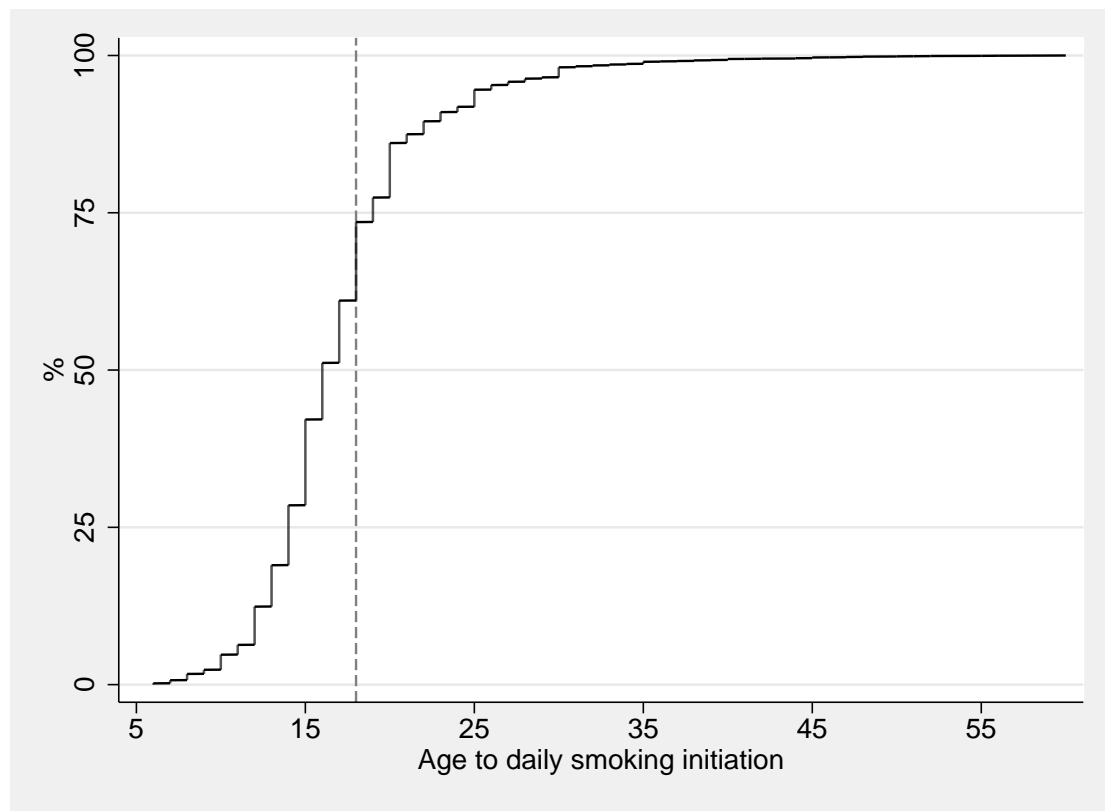

Source: Prepared by the authors using PNS 2013. 
Graph 11 - Trajectory of smoking cessation among adults (18-64 years old), 2006-2013

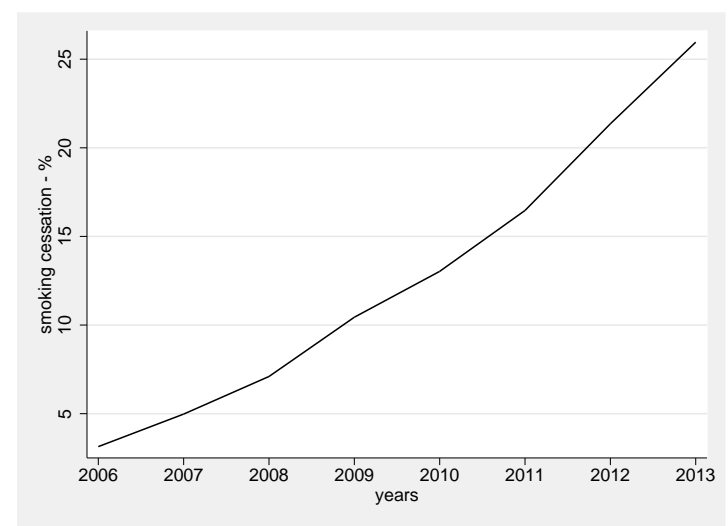

Note: Proportion of former smokers (i.e, quitters) measured in the sample of individuals who were smoking in 2005. Prepared by the authors using PNS 2013.
Graph 12 - Trajectory of smoking cessation among youths (15-29 years old), 2006-2013

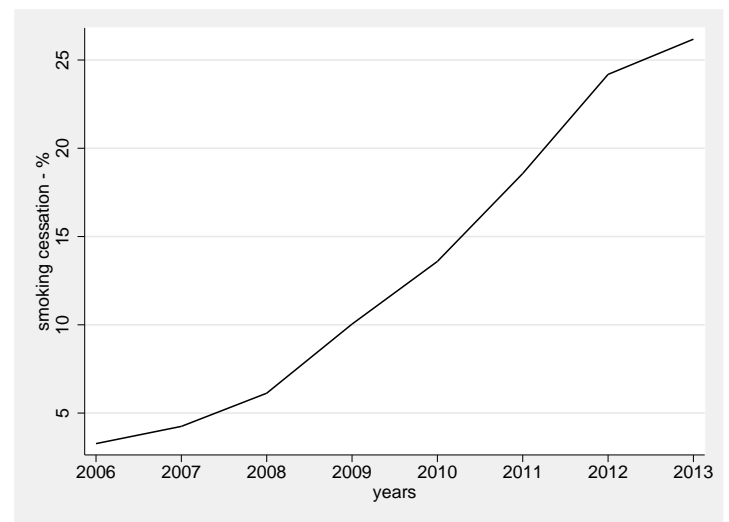

Note: Proportion of former smokers (i.e, quitters) measured in the sample of individuals who were smoking in 2005. Prepared by the authors using PNS 2013.

Graph 13 shows the age distribution, in 2013, of individuals who start smoking and who quit smoking from 2006 to 2013. It suggests that, if there is any effect of smoking bans on smoking behavior, then we would expect it to stand out on smoking initiation among youths and smoking cessation among adults. In the next section we present the empirical strategy we have adopted to measure the impacts of local Brazilian smoking bans on smoking behavior.

Graph 13 - Age density (in 2013) of people who changed smoking status from 2006 to 2013

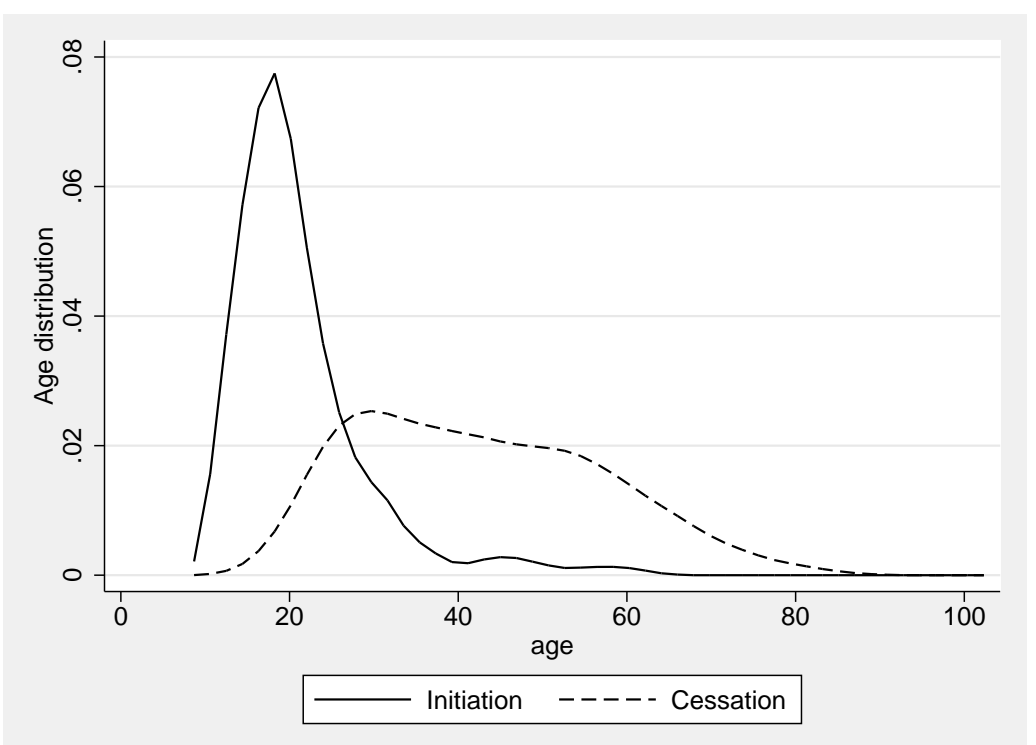

Note: Age in 2013. For initiation, we have considered individuals who had the sum of the smoking dummy from 2006 to 2013 different from zero. For cessation, this sum should be smaller than 8 . Prepared by the authors using PNS 2013. 


\section{Empirical Strategy}

We estimate the impacts of Smoking Bans ${ }^{1}$ adopted by some states and some capitals in Brazil since 2008 on the prevalence of smoking among adults (18-64 years old) and among young adults (15-29 years old). As cigarette is considered to be an addiction good, it's reasonable to believe that smokers with lower addictive stock are more likely to quit smoking (JARVIS, 2004; CHALOUPKA, 1991). Moreover, since most smokers started smoking before age 18 (Graph 10), the analysis to youngsters allows us to measure the effects of smoking bans on the cohort of age that is supposed to be more influenced by the restrictions. Therefore, based on theoretical approach and on the results we showed in the previous chapter, we also estimate dynamical impacts of smoking bans on smoking cessation and initiation.

In order to achieve our aims, the method we have used is differences-in-differences, which allows the measurement of the impact of a given policy by comparing the control and treatment groups in many periods before and after the policy (ANGRIST; PISCHKE, 2009). When considering local smoking bans as the treatment, we would have the following situations: (i) treated municipalities in non-treated states; (ii) treated capitals in non-treated states; (iii) treated municipalities and treated capitals in non-treated states; (iv) treated states (we then consider all cities as treated); and (v) non-treated states without any treated municipality.

As explained in chapters 1 and 3, we focus on individuals living in capital municipalities. It is justified by data representativeness and by the inviability of checking local laws to all Brazilian municipalities.

Therefore, the treatment group contains the capitals belonging to states with local smoking bans (Table 1) and the capitals with municipal law (Table 2). Our data is composed of 27 groups in total (26 state capitals and Brasília, which is the capital of the Federal District). Treated and control groups are listed in Table 13 in Appendix D. They have, respectively, 16 and 11 municipalities.

This strategy avoid spillover effects of the treatment over non-treated municipalities due to the high distance from each Brazilian state capitals ${ }^{2}$. Since migration is costly in Brazil (MORTEN; OLIVEIRA, 2016), it is likely to expect that neither people nor companies move from one state capital to another because of smoking bans. For these

\footnotetext{
${ }^{1}$ As mentioned in the Introduction, we consider as smoking bans the less lenients restrictions that prohibited the creation of smoking exclusive areas inside collective places. Then states and municipalities that introduced some smoking ban similar to the 1996 federal law (allowing for smoking areas) are not considered as treated unities in our analysis.

${ }^{2}$ It can be seen in the Figure 2 in chapter 1 , in which the red markers in the map represent the location of each state capital.
} 
reasons, we can consider that non-treated capitals represent a good control group to the treated ones.

Furthermore, as the time of adoption of the laws is different across treated municipalities, we have estimated heterogeneous impacts of smoking bans according to the time of exposure to the law in each year of analysis. As an illustration, for capitals in which the effective date of the restrictions were by the end of 2009, we assign 2009 as the year of treatment and, consequently, 2010 as one year after treatment and 2008 as one year before treatment. When the effective date of the law was in the beginning of some year, we consider this year as one year of exposure and the previous year as the treatment time $^{3}$. For the capitals with local law that belong to states that adopted smoking ban, we consider as the effective date the first one. It changed the treatment year just for Goiânia/GO, which was considered as treated in $2009^{4}$. We included Rio de Janeiro as treated in 2009, since the municipal law was not implemented. These information are shown in Table 3.

Table 3 - Year of treatment for each treated unity

\begin{tabular}{l|c|c}
\hline Treated Unities & Effective date & Treatment time \\
\hline Porto Velho/RO & October, 2008 & 2008 \\
São Paulo/SP & August, 2009 & 2009 \\
Boa Vista/RR & November, 2009 & 2009 \\
Curitiba/PR & November, 2009 & 2009 \\
Belém/PA & November, 2009 & 2009 \\
João Pessoa/PB & November, 2009 & 2009 \\
Rio de Janeiro/RJ & November, 2009 & 2009 \\
Aracaju/SE & December, 2009 & 2009 \\
Salvador/BA & December, 2009 & 2009 \\
Goiânia/GO & December, 2009 & 2009 \\
Manaus/AM & December, 2009 & 2009 \\
Rio Branco/AC & February, 2010 & 2009 \\
Campo Grande/MS & March, 2010 & 2009 \\
Teresina/PI & November, 2010 & 2010 \\
Cuiabá/MT & June, 2011 & 2011 \\
Maceió/AL & February, 2012 & 2011 \\
\hline \multicolumn{2}{c}{ Source: Prepared by the authors. }
\end{tabular}

Figure 14 contains consolidated treatment years for each capital in the treatment group. Capitals without smoking bans are included in the control group for the whole period of analysis. By this map, one can observe that most municipalities were treated in 2009. It was the year of treatment for 12 of the total 16 treated unities. Besides that, two capitals were treated in 2011 (Maceió/AL and Cuiabá/MT), one capital was treated in

\footnotetext{
${ }^{3}$ It's the case of Rio Branco/AC and Campo Grande/MS, which introduced the laws on February, 2010 and March, 2010 respectively, but were allocated to 2009 treatment time; and Maceió/AL, in which the effective date of smoking ban was February, 2012, but the treatment time assigned is 2011.

${ }^{4}$ The municipal law was adopted in 2009 and the state law in 2012.
} 
2008 (Porto Velho/RO) and another one in 2010 (Teresina/PI). We highlight that, from those capitals treated other year than 2009, Porto Velho and Maceió's smoking bans had a low level of enforcement (as showed in Figure 3, chapter 1).

For this reason, our main results consider only the state capitals treated in 2009 in the treatment group and the capitals with no smoking bans in the control group (total of 12). Robustness checks include the remaining municipalities.

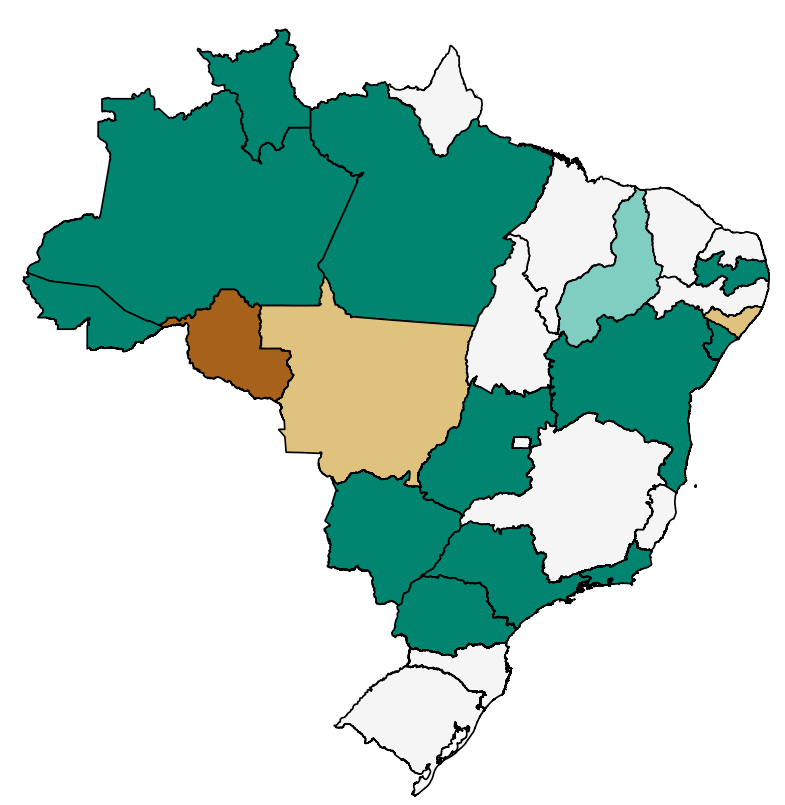

Figure 14 - Year of treatment for each Brazilian capital, represented by the respective state.

Note: For an easier visualization, we have hatched the whole state by the respective color, even if the law was adopted only by the capital. Prepared by the authors.

\subsection{Specification}

Our main specification is based on the following equation:

$$
\text { (1) } y_{i s t}=\alpha+\sum_{e} \beta_{e} S B_{s t}^{e}+\mu_{i}+d_{t}+\gamma X_{i s t}+\epsilon_{i s t}+u_{s t}
$$

where $y_{i s t}$ is the observed result for individual $i$ residing in the unit $s$ in the year $t$ (smokes or does not smoke); $S B_{s t}^{e}$ is a binary variable that assumes 1 if individuals residing in the unit $s$ are exposed to smoking ban for $e$ periods of time in year $t$, even for $e<0 ; \mu_{i}$ is the 
individual fixed effect; $d_{t}$ is the year fixed effect; $X_{i s t}$ are the covariates at state capital or individual level; $\epsilon_{i s t}$ is an individual random error term; and $u_{s t}$ is a cluster error term.

We also estimate equation (1) using dosage effects of smoking bans according to enforcements levels presented in Figure 3 of chapter 1 and Table 10 in Appendix A. This strategy aims to find out impacts of smoking bans according to effective adoption of the laws (in the way of surveillance and penalties). The equation considering dose treatment follows:

(2) $y_{i s t}=\alpha+\sum_{s l} E_{l} * \sum_{e} \beta_{e} S B_{s t}^{e}+\mu_{i}+d_{t}+\gamma X_{i s t}+\epsilon_{i s t}+u_{s t}$

where $E_{l}$ is a dummy variable that assumes 1 for individuals residing in the unit $s$ that implemented a smoking ban with the level of enforcement $l$, with $l=$ lower and higher.

As already explained, the approach we have used to create the database restrains the dependent variable to daily smoking. The identification strategy is based on the hypothesis that control and treatment groups do not need to be equal before treatment, but have a similar evolution in the prevalence of cigarette smoking in the absence of treatment (hypothesis of parallel trends). It means that, if $S B_{s t}^{e}=0$, the observed differences for two individuals in different states would be captured by the time-invariant state and individual effects, the time effect and other observed characteristics differences (ANGRIST; PISCHKE, 2009).

According to Angrist and Pischke (2009), we can investigate the parallel trend assumption by using data in many periods. Therefore, if laws were randomly introduced (and not due to some previous trajectory), then the following condition would be true (ANGRIST; PISCHKE, 2009; KLINE, 2011):

(3) $\beta_{e}=0 \forall e<0$

Under (3), the coefficients $\beta_{e}$ estimated by equations (1) and (2) represent the average impacts of smoking bans on the probability of smoking in individuals treated by the law. In order to avoid perfect multicollinearity, $\beta_{0}=0$. That is, we normalized the parameter of the treatment year to zero (which means we assumed no contemporary impact of the laws).

In order to take into account the correlation of the treatment dummy and of the unobserved characteristics within each state's capital (which can underestimate standard deviation if not considered), we estimated (1) with Cluster Robust Variance Estimator (CRVE). Because the number of clusters is small (27 in total and 16 in the treatment group) and the number of individuals in each cluster is not balanced, we verify the significance of 
ours estimations by Wild Cluster Bootstrap (BERTRAND; DUFLO; MULLAINATHAN, 2004; CAMERON; MILLER, 2015; MACKINNON; WEBB, 2016) ${ }^{5}$

\footnotetext{
${ }^{5}$ The results are shown in Appendix F.3.
} 



\section{Results}

This chapter applies the empirical strategy previously described to measure the amount of the decrease in the use of cigarette related to smoking bans. The first section presents some descriptive statistics comparing the treatment and control groups. The second section shows average effects of smoking bans on smoking prevalence. The impacts by enforcement level are shown in the third section. The fourth section contains the impacts on initiation and cessation. Finally, section five analyses other policies that could be confounding our findings on smoking bans.

\subsection{Mean differences and trend}

As we showed in chapter 4, the identification hypothesis means that, in the absence of treatment, the prevalence of cigarette smoking in the control and treatment groups have to change in the same way. When we add covariates to the model, the counter-factual result in the absence of the treatment would be as follows (ANGRIST; PISCHKE, 2009):

(4) $E\left[y_{0 i s t} \mid i, s, t, X_{i s t}\right]=\alpha+\mu_{i}+d_{t}+\gamma X_{i s t}$

In this section, we present some statistics comparing the treatment and the control groups to identify potential control variables ${ }^{1}$. We also present the unconditional trend of smoking prevalence in control and treatment group for the two age ranges. However, we underline that the unconditional trend do not need to be the same in both groups, according to (4).

Table 4 shows tests of mean differences for some variables at the capital level that could be related to local adoption of tobacco control policies. We have chosen 2008 in order to compare pretreatment characteristics of municipalities with and without local bans. The proportion of young adults was similar between control and treated capitals (close to 35\%). Average population, GDP and the proportion of health expenditure in the municipal expenditure ${ }^{2}$ were higher in the treatment group compared to the control group ${ }^{3}$. GDP is almost twice higher in the treatment group. However, none of these differences are statistically significant.

\footnotetext{
${ }^{1}$ We have dropped Porto Velho/RO in our main results, since this capital has approved a smoking ban, but has never applied it (see Table 10 in Appendix A). But we highlight that overall our findings do not change with the inclusion of this municipality.

${ }^{2}$ The importance of taking health expenditure into account is due to the fact that, as the public health system is decentralized in Brazil, the municipalities are responsible to most executive attributions.

${ }^{3}$ The reason is that the capitals with local smoking bans are more heterogeneous in these characteristics
} 
Table $14^{4}$ shows the same statistics, considering the treatment group in two enforcement levels. We observe that the proportion of young individuals is higher in the low-enforcement treatment group and lower in the group with higher-enforcement. On the other hand, average population and GDP are strongly higher in the treatment group with high-enforced smoking bans. However, only the difference in average population is significant (at 10\%).

Overall, the differences in the covariates are not statistically significant due to the small number of observations (26 state capitals) that generates a high standard deviation. In Graphs 32 to $39^{4}$, we show the trend of these covariates comparing both control and treatment group. The differences in the population and the proportion of youths do not change over time. The GDP has increased more in the higher-enforcement treatment group compared to the other groups (Graph $37^{4}$ ). The proportion of the municipal expenditure to public health varies more in the treatment group than in the control one (Graph 38 and $39^{4}$ ). Table $15^{4}$ shows evidence of no significant differences in the trajectory of these variables between control and treatment groups that could confound the effects of Smoking Bans. We highlight that level differences are capture by fixed effects in our diff-in-diff models.

Table 4 - Mean differences for covariates, 2008

\begin{tabular}{lccc} 
Variables & Control & Treatment & Difference \\
\hline Youth proportion & $34.68 \%$ & $34.81 \%$ & -0.14 \\
Population & $1,226,700$ & $2,075,822$ & $-849,122$ \\
GDP $^{a}$ & 7.68 & 13.62 & -5.95 \\
Health Exp. & $23 \%$ & $26.2 \%$ & -3.2 \\
\hline Observations & $\mathbf{1 1}$ & $\mathbf{1 5}$ & $\mathbf{2 6}$ \\
\hline
\end{tabular}

Note: We have dropped Porto Velho/RO, but the results are robust when considering it. For inference: *** $1 \%$ significant; ** $5 \%$ significant; * $10 \%$ significant. ${ }^{a}$ GDP measured in US $\$$ billion. Prepared by the authors using PNS, Munic(IBGE) and FINBRA.

Table 5 compares characteristics at the individual level for the treatment and the control group using data from PNS. As those information are just observed in 2013, we are not able to control all of them in our regressions, but most of its effects are captured by individual fixed effects. One can observe that the average age among all individuals and among smokers, the age individuals reported to have started smoking and the time they have been smoking and that they have quit smoking are not different between treatment and control groups ${ }^{5}$.

We have also check measurement errors that could generate report bias in our study. First, we have checked if individuals round the time they have quit smoking differently in

\footnotetext{
${ }^{4}$ See Appendix E.

${ }^{5}$ We have dropped Porto Velho/RO, but the findings do not change to the inclusion of this capital in the treatment group.
} 
both groups. The proportion of former smokers that round the quitting time to 5 years ${ }^{6}$ is around $4.5 \%$ and there is no significant difference between treatment and control groups. We have also checked the proportion of mistakes in reporting quitting and smoking time. It has been considered mistake when the individual answered a quitting time higher than smoking time. This proportion is around $1.8 \%$ in the treatment group and the difference to the control group is not statistically significant. Therefore, we have not evidence of report bias in our data

When considering the treatment by levels of enforcement, we have found no significant difference in the proportion of rounding the quitting time and mistakes. But the average age is around 0.8 years higher in the high-enforcement group and around 1.1 lower in the low-enforcement group at $10 \%$ and $5 \%$ respectively. The difference in smokers' age, starting age and smoking time is only significant to the low-enforcement group (respectively $0.3,1.95$ and 1.33 lower compared to the control group). We control some of our regressions to the age and the square of the age of the individuals.

Table 5 - Mean differences in 2013 sample

\begin{tabular}{lccc} 
Variables & Control & Treatment & t statistic \\
\hline Age & 38.26 & 38.72 & -0.91 \\
Smokers' age & 41.48 & 40.94 & 1.54 \\
Starting age & 17.15 & 17.06 & 0.52 \\
Smoking time & 6.23 & 6.4 & -0.21 \\
Quitting time & 12.59 & 12.44 & 0.33 \\
Quitting round & \\
Mistake $^{b}$ & $4.71 \%$ & $4.45 \%$ & 0.35 \\
\hline Observations & $1.08 \%$ & $1.79 \%$ & -1.43 \\
\hline
\end{tabular}

Note: Statistics for 2013 measured using the sample of individuals aged from 18 to 64 years old in PNS, after dropping Porto Velho/RO. Our results do not change to the inclusion of this capital. For inference: $* * * 1 \%$ significant; $* * 5 \%$ significant; ${ }^{*} 10 \%$ significant. ${ }^{a}$ proportion of former smokers that answer to have quit for 5 years. ${ }^{b}$ proportion of former smokers that answer quitting time higher than smoking time. Prepared by the authors.

One can see in Graphs 15 and 16 that the prevalence of smokers was lower for the whole period in the treatment groups when compared to many of the control groups, except for the 2009 treated. This group contains most of the treated unities and its smoking prevalence trend is the most similar to the control group one. One first analysis based on Graph 15 would indicate no effect of smoking bans on the prevalence of cigarette consumption among adults.

In Graph 16, one can observe some evidence of decrease in smoking prevalence among young adults related to the implementation of smoking bans by the 2009 treated unities, mainly in 2012 and 2013. An overall look also indicate a similar pretreatment

\footnotetext{
${ }^{6}$ This is the only relevant rounding in our study.
} 
Graph 15 - Trajectory of smoking prevalence among adults (18-64 years old) in control and treatment groups (2007-2013)

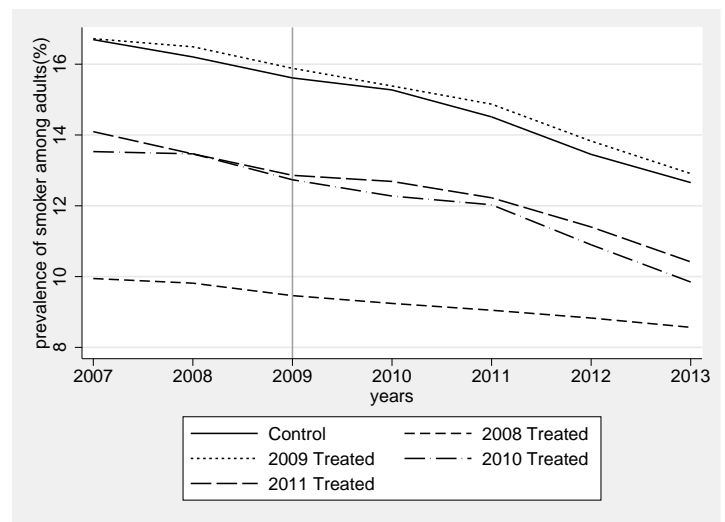

Source: Prepared by the authors using PNS 2013.
Graph 16 - Trajectory of smoking prevalence among youths (15-29 years old) in control and treatment groups (2007-2013)

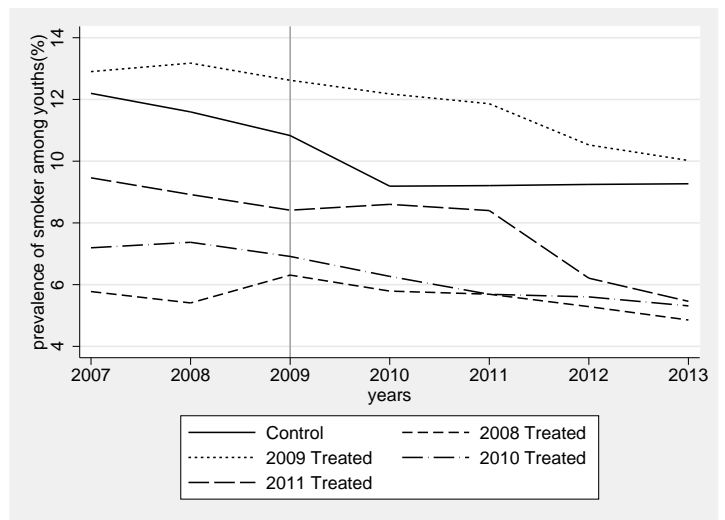

Source: Prepared by the authors using PNS 2013.

trend among control and 2009-treatment group. Graphs 40 and $41^{7}$ show the trend of smoking prevalence to control group and to low and high enforcement treatment groups. We can not refute the pretreatment parallel trend among control and high enforcement treatment group. As mentioned, however, the unconditional trend do not need to be equal, since we control for individual and state specific and varying characteristics and time fixed effects. Therefore, no casual effect can be conclude by those graphical analysis. In order to check the causality of these findings, the following sections present additional tests.

\subsection{Average Treatment Effects of Smoking Bans}

Our main results consider in the treatment group only the municipalities treated in 2009, since the graphical analysis indicates a similar pretreatment trend and level of smoking prevalence on this group compared to the control one. We have dropped the capitals treated in 2008, 2010 and 2011, which are, respectively, Porto Velho/RO, Teresina/PI, Cuiabá/MT and Maceió/AL. Only Cuiabá/MT highly enforced its smoking ban among these unities; and Porto Velho/RO not even implemented it. Moreover, $75 \%$ of the capitals in the treatment group adopted local ban in 2009. Nevertheless, alternative results including all treated municipalities are shown in Appendix F.1. Appendix F.2 shows the results considering three and nine months as threshold for yearly smoking quitting time. All the estimations consider individual and year fixed effects and cluster robust standard errors. We have clustered at the state capital level. Results with Wild Cluster Bootstrap are shown in Appendix F.3.

We first estimate the average treatment effects on 2009 treated not considering

\footnotetext{
${ }^{7}$ In Appendix E
} 
enforcement groups. In the sequence, we show the impacts taking the enforcement of the bans into consideration. Our estimates include four lags and two leads. The estimated coefficients of the leads can support the identification hypothesis.

\subsubsection{Average impacts on Smoking Prevalence}

Estimated coefficients of smoking bans impacts on adults' smoking prevalence are shown in models (1), (2) and (3) of Table 6. In model (2), we have included the age and the square age of individuals. In model (3), we have also added state capital level covariates: natural logarithm of GDP and population and proportion of youths.

There is evidence of the identification hypothesis, since no pretreatment effects of the laws were found, what can be seen by the absent of significance of $\beta_{e}, \forall e<0$ (i.e., $\beta \_2$ and $\beta \_1$ ). No significant impacts of the law were found on the prevalence of daily smoking among the whole sample of adults.

Table 6 - Smoking Bans impacts on smoking prevalence over time

\begin{tabular}{l|ccc|ccc} 
& \multicolumn{5}{c}{ Adults } & \multicolumn{3}{c}{ Youths } \\
& $(1)$ & $(2)$ & $(3)$ & $(4)$ & $(5)$ & $(6)$ \\
\hline \multirow{4}{*}{$t_{-2}$} & 0.0001955 & 0.000134 & $-7.12 \mathrm{e}-06$ & -0.00591 & -0.00619 & -0.00634 \\
$t_{-1}$ & $(0.00293)$ & $(0.00299)$ & $(0.00295)$ & $(0.00480)$ & $(0.00494)$ & $(0.00502)$ \\
& 0.0006646 & 0.000615 & 0.000776 & -0.00300 & -0.00320 & -0.00338 \\
$t_{1}$ & $(0.00196)$ & $(0.00199)$ & $(0.00198)$ & $(0.00419)$ & $(0.00430)$ & $(0.00430)$ \\
& $2.97 \mathrm{e}-05$ & $6.52 \mathrm{e}-05$ & 0.000181 & 0.00366 & 0.00360 & 0.00339 \\
$t_{2}$ & $(0.00169)$ & $(0.00167)$ & $(0.00171)$ & $(0.00391)$ & $(0.00392)$ & $(0.00368)$ \\
& -0.000470 & -0.000406 & -0.000234 & 0.00379 & 0.00426 & 0.00407 \\
$t_{3}$ & $(0.00193)$ & $(0.00189)$ & $(0.00202)$ & $(0.00343)$ & $(0.00357)$ & $(0.00344)$ \\
& -0.000963 & -0.000870 & -0.000843 & $-0.00635^{* *}$ & $-0.00582^{*}$ & -0.00583 \\
$t_{4}$ & $(0.00289)$ & $(0.00280)$ & $(0.00260)$ & $(0.00294)$ & $(0.00288)$ & $(0.00366)$ \\
& -0.00293 & -0.00280 & -0.00319 & $-0.00951^{* * *}$ & $-0.00894^{* *}$ & $-0.00875^{*}$ \\
age & $(0.00346)$ & $(0.00334)$ & $(0.00310)$ & $(0.00331)$ & $(0.00330)$ & $(0.00448)$ \\
& & $0.00286^{*}$ & 0.000987 & & $0.0324^{* * *}$ & $0.0327^{* * *}$ \\
age ${ }^{2}$ & & $(0.00138)$ & $(0.00227)$ & & $(0.00996)$ & $(0.0115)$ \\
& & $-6.78 \mathrm{e}-05^{* * *}$ & $-6.78 \mathrm{e}-05^{* * *}$ & & $-0.000662^{* * *}$ & $-0.000660^{* * *}$ \\
Const. & $0.164^{* * *}$ & $(1.31 \mathrm{e}-05)$ & $(1.32 \mathrm{e}-05)$ & & $(0.000201)$ & $(0.000201)$ \\
& $(0.001935)$ & $(0.0424)$ & $(0.381)$ & $(0.00405)$ & $(0.123)$ & $(0.456)$ \\
\hline Cov. & No & No & Yes & No & No & Yes \\
Obs. & 131,431 & 131,431 & 131,431 & 46,024 & 46,024 & 46,024 \\
Ind. & 20,518 & 20,518 & 20,518 & 8,596 & 8,596 & 8,596 \\
\hline
\end{tabular}

Note: Cluster Robust standard errors in parentheses. For inference: ${ }^{* * *} \mathrm{p}<0.01,{ }^{* *} \mathrm{p}<0.05,{ }^{*} \mathrm{p}<0.1$. Estimations only for 2009 treated. Porto Velho/RO, Maceió/AL, Cuiabá/MT and Teresina/PI were dropped. Models include individual and year FE and cluster at capital level. Models (1), (2) and (3) were estimated to individuals from 18 to 64 years old and models (4), (5) and (6), from 15 to 29 years old. The covariates included in models (3) and (6) are the natural logarithm of GDP and Population and the proportion of youths.

Considering the sample of young individuals (15 to 29 years old) in each period of analysis - models (4), (5) and (6)-, we have found that smoking bans reduced smoking 
prevalence among young adults in around 0.6 percent points and 0.9 percent points in the treatment groups, respectively, three and four years after they were implemented. These impacts are significant at 5\% significance level. As around $12.5 \%$ of young people were daily smokers in 2009, this result represents from $5 \%$ to $7 \%$ of reduction in smoking prevalence among this group due to smoking bans. We cannot refute pretreatment parallel trend hypothesis, which reinforce the causal interpretation of the results.

We have kept in our estimations to youths all individuals from 15 years old and up to 29 years old in each year of analysis, resulting in an unbalanced panel for this group ${ }^{8}$. The results in Model (6) also consider the covariates at the capital level. We highlight that the variation of those variables is not significant to explain the variation in smoking prevalence. As explained in chapter 3, they don't change over time between treatment and control groups. For this reason, our preferred specification only includes the covariates at the individual level (age and squared age).

Our findings to young individuals are compatible with international evidence about delayed impacts of smoking bans, which can be explained by the adjustment of public places, of enforcements and of people habits both in enforcing the law and reporting irregularities as in changing smoking use (BOES; MARTI; MACLEAN, 2015). They are also consistent with addiction characteristic of cigarette consumption (CHALOUPKA, 1991). As we saw in Graph 10, once most smokers started smoking before age 30, age is positive related to smoking time. Since addiction is supposed to be cumulative over time of smoking, because of addiction stock, and positive related to current consumption (CHALOUPKA, 1991), it's therefore reasonable to presume that smoking bans would affect more young adults smoking behavior than older individuals.

In addition, these results are supported by peer effects of smoking among youngsters (RIZZIERI, 2008) and by findings of smoking bans impacts over people that "go out" to public places (such as pubs and restaurants) more frequently (ANGER; KVASNICKA; SIEDLER, 2011). The reason is that young individuals use to be more influenced by social pressure over addiction behavior that are related to social integration. They also use to frequent public place where these influences and practices are more common.

\subsubsection{Average impacts on Smoking Initiation and Cessation}

As we found evidence of impacts of smoking bans on young adults smoking prevalence, it would be interesting to verify whether those impacts are due to decrease in smoking initiation or to smoking quitting. Palali and Ours (2017a) called attention to the

\footnotetext{
${ }^{8}$ We have restrained our regressions to this age range in each year of analysis. So individuals near to the limits "drop" the panel in different years. As we can only observe, in 2013, individuals from 18 years old, we have chosen the use of the unbalanced panel in order to keep more observations in the sample of youths. This strategy allows the study of smoking initiation, since we can observe changes in smoking behavior over the youth cohort throughout the time.
} 
importance of evaluating the impacts of tobacco control policies on smoking dynamics. With the aim to achieve this, we estimated the effects of smoking bans both on daily smoking initiation and quitting among adults and young adults. Detailed results to impacts on initiation and cessation can be seen in Appendix E.1 -Table 16.

Impacts on initiation to daily smoking were measured by restraining PNS sample for non-smokers in 2005 and then limiting data from 2007 to 2013. $t_{-2}$ and $t_{-1}$ are the estimated coefficients of the dummies variable assigning 1 to two and one year pretreatment (so 2007 and 2008), respectively. Graph 17 shows the coefficients of the estimated impacts of smoking bans on young individuals' initiation. We found a significant impact three and four years after the implementation of the bans of almost 0.008 and 0.01 percent points respectively. It represents from $20 \%$ to $25 \%$ less initiation in the treatment group compared to the initiation rate in the absence of the bans (around 60 thousand smokers). Our previous results on smoking prevalence among youths are explained by the reduction of the initiation to cigarette use in this cohort.

Graph 17 - Effects of smoking bans on smoking initiation among youths

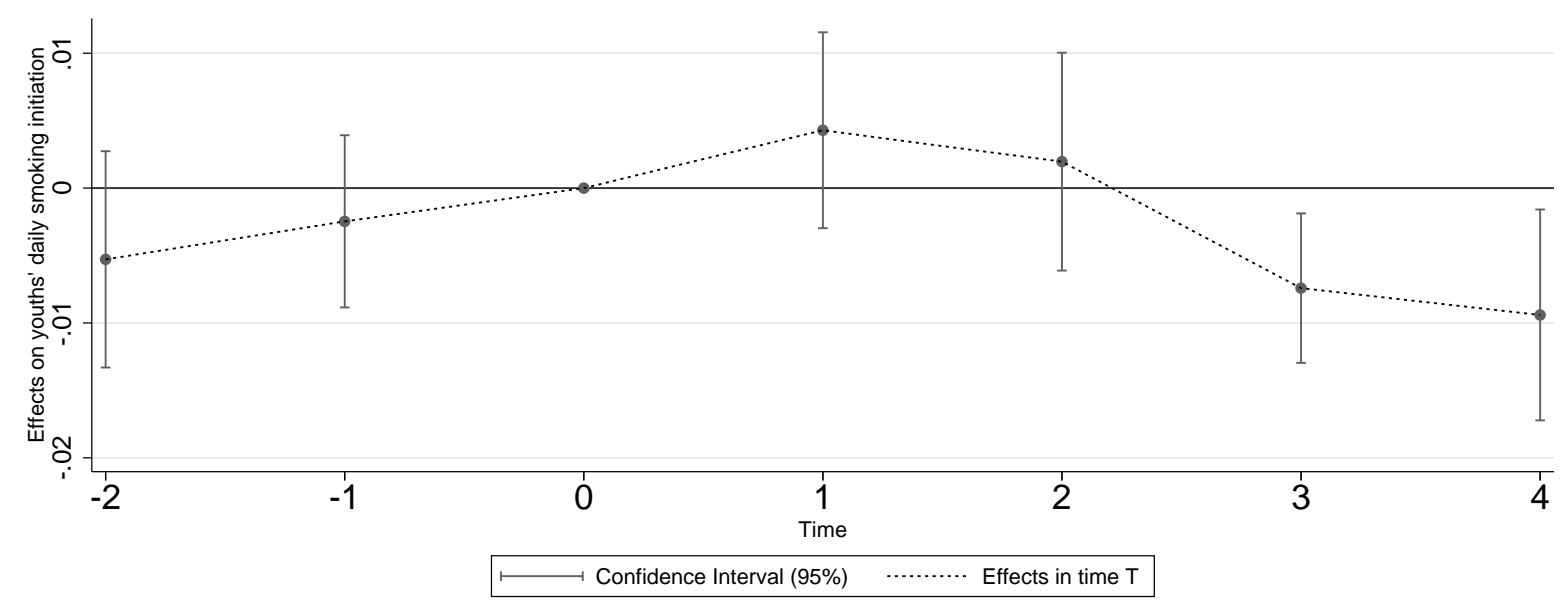

Source: Prepared by the authors.

No impact was found on smoking initiation among adults due to smoking bans. The absence of results to smoking initiation is expected because there is not a lot of variation in smoking status from non-smokers to smokers in our sample, since $73 \%$ of smokers started smoking before 18 years old (Graph 10). In addition, these findings are compatible with Palali and Ours (2017a) paper, which found no impacts of tobacco control policies (including smoking bans) in smoking initiation in eleven European countries.

Impacts on cessation to daily smoking were measured by restraining the sample to smokers in 2005 and then limiting PNS data from 2007 to 2013. $t_{-2}$ and $t_{-1}$ are the estimated coefficients of the dummies variable assigning 1 to two and one year pretreatment (so 2007 and 2008), respectively. We found no impacts of smoking bans on adults and on 
youths daily smoking cessation. This absence of impact for the overall sample of adults be explained by smoking addiction characteristic, which difficult smoking quitting by persistent smokers (CHALOUPKA, 1991).

In order to observe whether or results are compatible with the theory of rational addiction, we made the cessation analysis for three cohorts: young adults (18-29 years old) (Graph 18); adults from 30 to 44 years old (Graph 19); and adults from 45 to 64 years old (Graph 20). One can observe significant impacts on smoking cessation one and two years after the implementation of smoking bans among adults from 30 to 44 years old (Graph 19). This effect represents a decrease of around $5 \%$ of cigarette use among adults.

Our findings on smoking cessation are compatible with the literature regarding smoke addiction, addictive stock and their consequent reduction in the probability to quit smoking throughout the time of cigarette consumption (CHALOUPKA, 1991).

Graph 18 - Effects of smoking bans on smoking cessation among 2007 young adults smokers (18-29 years old)

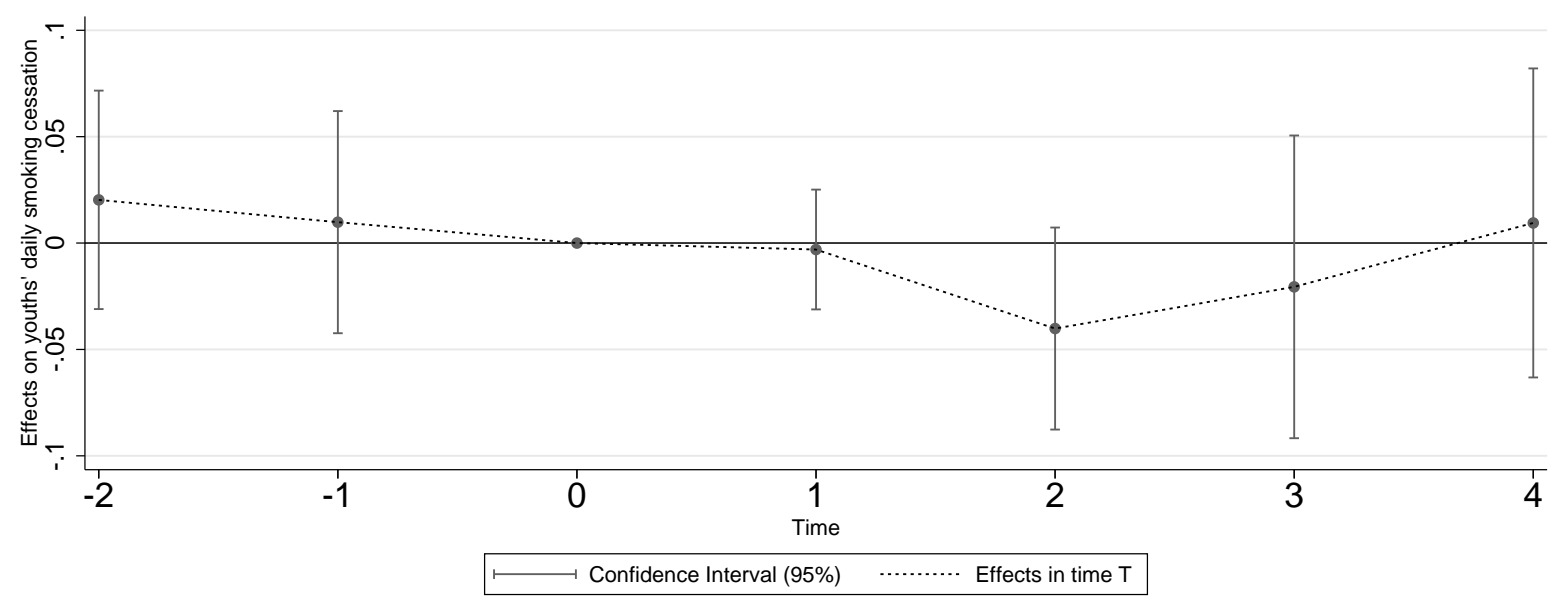

Source: Prepared by the authors. 
Graph 19 - Effects of smoking bans on smoking cessation among 2007 adults smokers (30-44 years old)

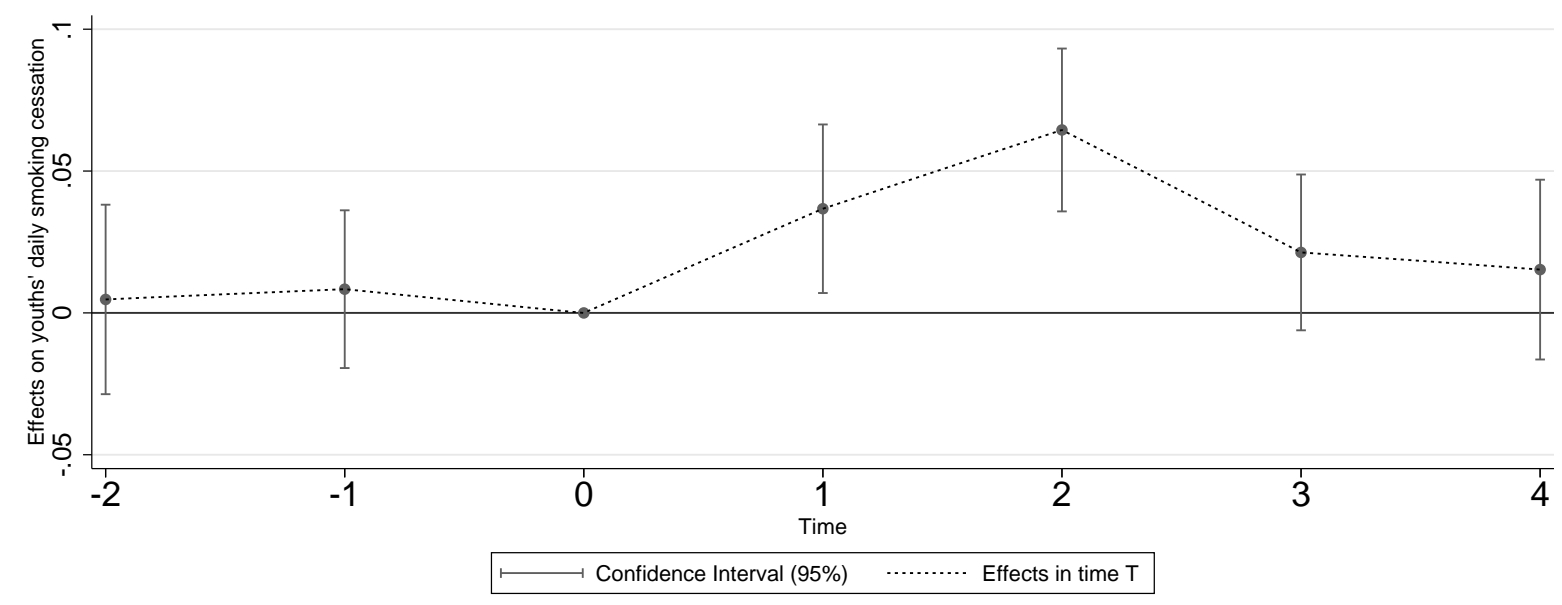

Source: Prepared by the authors.

Graph 20 - Effects of smoking bans on smoking cessation among 2007 adults smokers (45-64 years old)

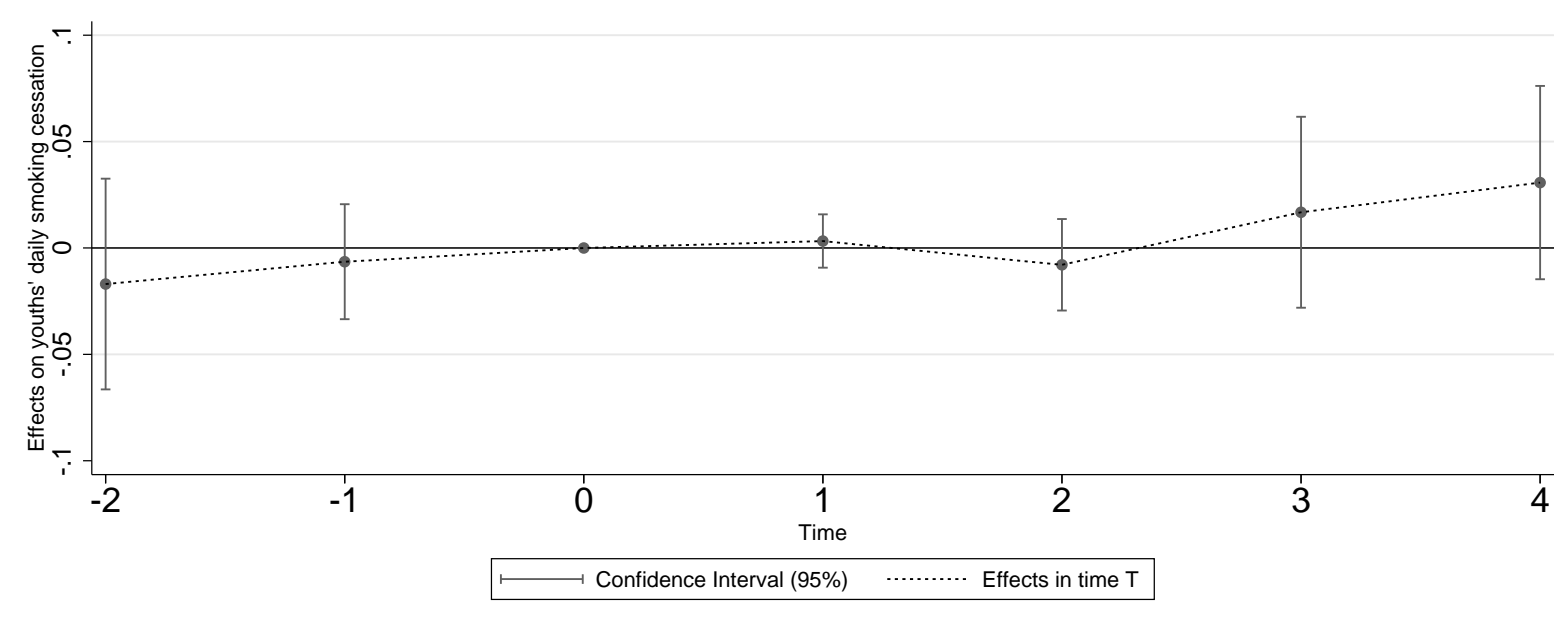

Source: Prepared by the authors.

\subsection{Impacts of Smoking Bans by Enforcement Levels}

As previously explained, one limitation to the effectiveness of public regulations can be related to the lack of their enforcement. Policy-evaluators should be concerned about this, especially in developing countries, which are known to have weaker institutions. In order to take into account the actual application of smoking bans, we estimate equation (2) by considering two levels for the treatment, according to Figure $3^{9}$ : higher and lower enforcement.

\footnotetext{
${ }^{9}$ In chapter 1.
} 
After dropping the unities that were treated in another year but 2009, the treatment group remains with 12 unities, of which 6 have applied higher enforced smoking bans (with surveillance, companies inspections and penalties application); and 6 unities have applied lower enforced smoking bans (with some surveillance only). The results are robust to the inclusion of 2010 and 2011 treated unities ${ }^{10}$.

\subsubsection{Enforcement-level impacts on Smoking Prevalence}

The estimated impacts on smoking prevalence considering the treatment by two levels of enforcement are shown in Table 7. The results for the lower level of enforcement are shown in models (1) and (2) for adults and young individuals respectively. It is possible to observe a positive difference on smoking prevalence after the adoption of smoking bans in the low-enforcement treated unities when compared to non-treated ones. It means that low enforced bans are related to an increase in smoking prevalence among adults. More research is needed to understand this finding. One possible explanation is that smoking bans were publicized, but not enforced. Therefore, they could have an effect on making people talk more about cigarettes that they would in the absence of the bans, reducing the incentives to quit smoking. For young individuals, there was no significant difference after the adoption of smoking bans.

The results for the higher enforced bans are shown in models (3) and (4) of Table 7 for adults and youths respectively. No significant effects of smoking bans were found on the overall sample of adults. But it is possible to observe, in (Graph 21), an increasing trend of difference in smoking prevalence.

When considering higher-enforcement treatment, there are also impacts of smoking bans on the reduction of cigarette use among young individuals three and four years after the adoption of smoking bans. But the effects are stronger when compared to the average treatment effects: almost 0.9 percent points after three years; and more than 1.2 percent points four years after the law got effective (Graph 22). They are significant at $1 \%$ level. These findings represent from around $7 \%$ to $10 \%$ of decrease of smoking prevalence after the adoption of the bans in the longer time. It represents more than 90 thousand smokers among young individuals.

\footnotetext{
${ }^{10}$ This robustness is shown in Appendix F.1. We have dropped Porto Velho/RO in all the estimations which consider enforcement level, since there was no enforcement of the law in this municipality.
} 
Table 7 - Smoking Bans impacts on smoking prevalence by enforcement level over time

\begin{tabular}{lcccc} 
& \multicolumn{2}{c}{ Low } & \multicolumn{2}{c}{ Higher } \\
Variables & Adults & Youth & Adults & Youth \\
\hline$t_{-2}$ & 0.00158 & -0.00869 & -0.000148 & -0.00566 \\
& $(0.00311)$ & $(0.00553)$ & $(0.00310)$ & $(0.00510)$ \\
$t_{-1}$ & 0.00253 & -0.000137 & 0.000243 & -0.00390 \\
& $(0.00215)$ & $(0.00345)$ & $(0.00206)$ & $(0.00478)$ \\
$t_{1}$ & $0.00229^{* *}$ & 0.00531 & -0.000352 & 0.00322 \\
& $(0.00105)$ & $(0.00376)$ & $(0.00182)$ & $(0.00425)$ \\
$t_{2}$ & 0.00430 & 0.00887 & -0.00131 & 0.00322 \\
& $(0.00359)$ & $(0.00722)$ & $(0.00175)$ & $(0.00390)$ \\
$t_{3}$ & 0.00654 & 0.00636 & -0.00230 & $-0.00865^{* * *}$ \\
& $(0.00435)$ & $(0.00614)$ & $(0.00267)$ & $(0.00261)$ \\
$t_{4}$ & $0.00853^{* *}$ & 0.00631 & -0.00501 & $-0.0125^{* * *}$ \\
& $(0.00403)$ & $(0.00743)$ & $(0.00294)$ & $(0.00256)$ \\
Const. & $0.159^{* * *}$ & $-0.258^{* *}$ & $0.159^{* * *}$ & $-0.258^{* *}$ \\
& $(0.0425)$ & $(0.124)$ & $(0.0425)$ & $(0.124)$ \\
\hline Cov. & Yes & Yes & Yes & Yes \\
Obs. & 131,431 & 46,024 & 131,431 & 46,024 \\
Ind. & 20,518 & 8,596 & 20,518 & 8,596 \\
\hline
\end{tabular}

Cluster Robust standard errors in parentheses

Inference: ${ }^{* * *} \mathrm{p}<0.01,{ }^{* *} \mathrm{p}<0.05,{ }^{*} \mathrm{p}<0.1$

Note: Estimations only for 2009 treated. Porto Velho/RO, Maceió/AL, Cuiabá/MT and Teresina/PI were dropped. Models include individual and year FE and cluster at capital level. The covariates included in all models are age and age squared.

Graph 21 - Higher enforced smoking bans impacts on smoking prevalence among adults

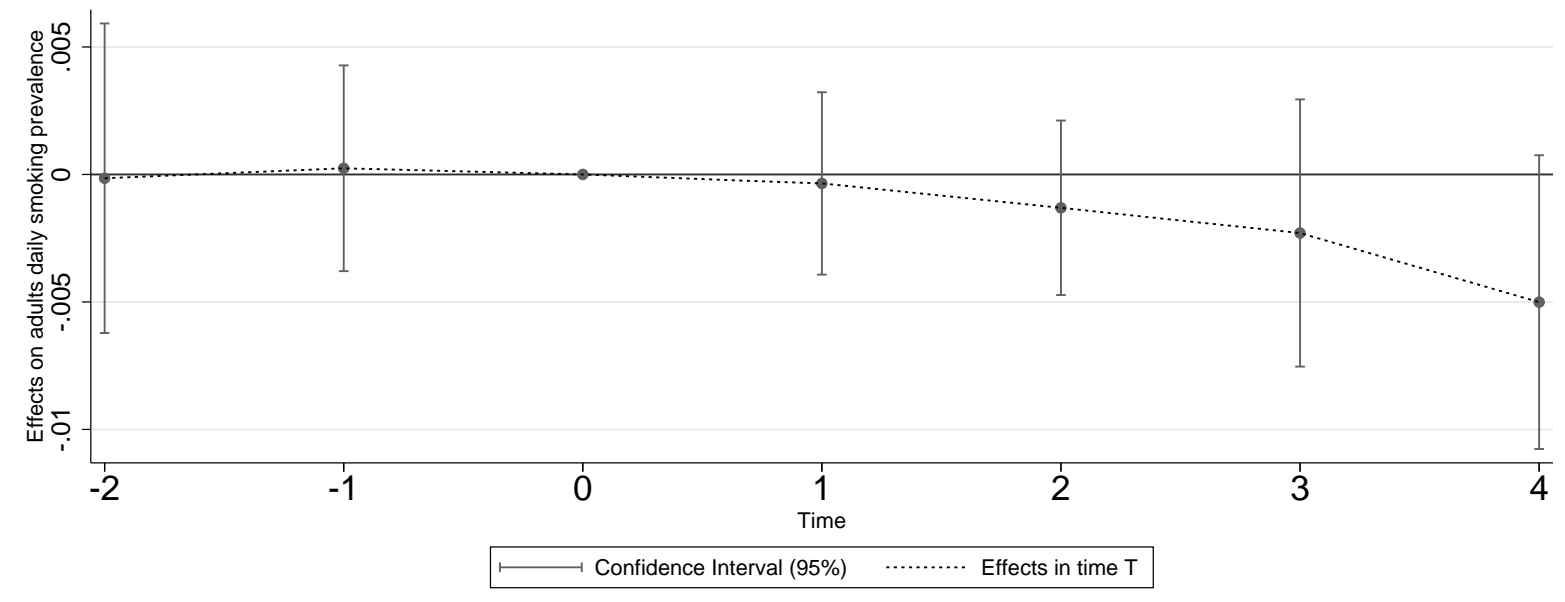

Source: Prepared by the authors. 
Graph 22 - Higher enforced smoking bans impacts on smoking prevalence among youths

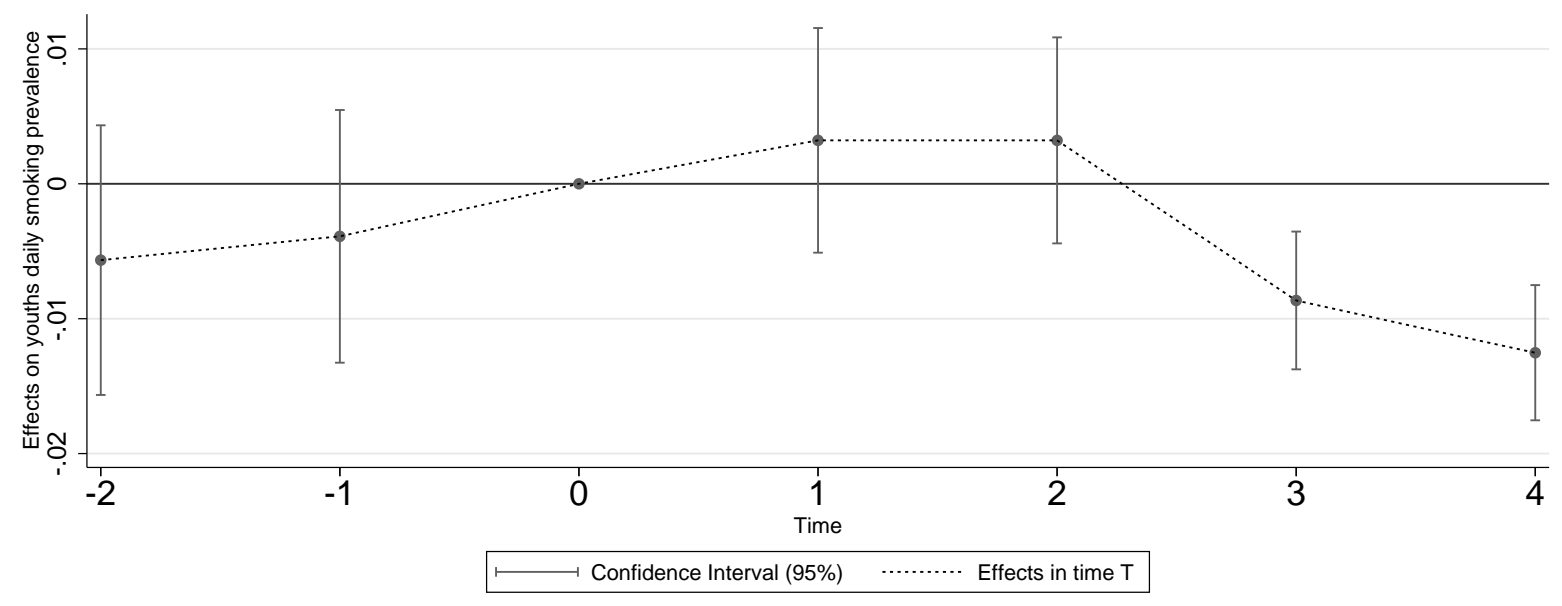

Source: Prepared by the authors.

\subsubsection{Enforcement-level Impacts on Smoking Initiation and Cessation}

In this section we show the estimated dosage effects of smoking bans on smoking initiation and cessation according to enforcement levels. Detailed results are shown in Table $17^{11}$. Overall, no impacts were found on smoking initiation among adults and on smoking cessation among young individuals.

As the average treatment effect, the impacts of the higher enforced smoking bans on young individuals are explained by the lower initiation in the treated capitals. As there was no impacts on the capitals that adopted the bans with low enforcement, the effects of the high-enforced laws are higher than the average treatment effects: from 1 percent point after three years of adoption of the bans (Graph 23). These impacts are significant at $1 \%$ level and represent almost $34 \%$ of lower initiation in the group that highly enforced smoking bans compared to the control group (more than 80 thousand smokers).

No significant impacts (at 5\%) were found on smoking cessation among youths both for lower and higher enforced smoking bans. Regarding adults, there were significant impacts of high-enforced smoking bans on smoking cessation two years after the law got effective (Graph 24). This impact represent a smoking cessation rate around $1.2 \%$ higher (and more than 50 thousand individuals that quit cigarette use due to highly enforced smoking bans).

\footnotetext{
${ }^{11}$ Appendix E.1
} 
Graph 23 - Higher enforced smoking bans effects on smoking initiation among youths

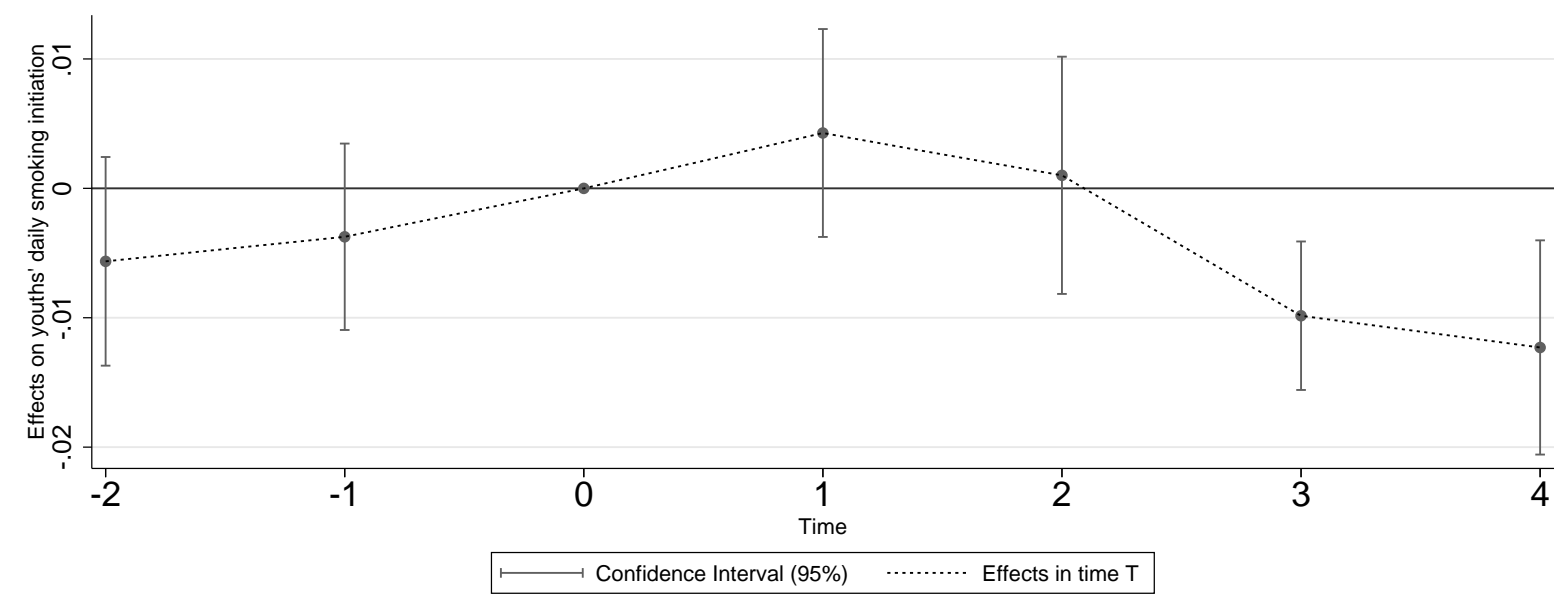

Source: Prepared by the authors.

Graph 24 - Higher enforced smoking bans effects on smoking quitting among adults

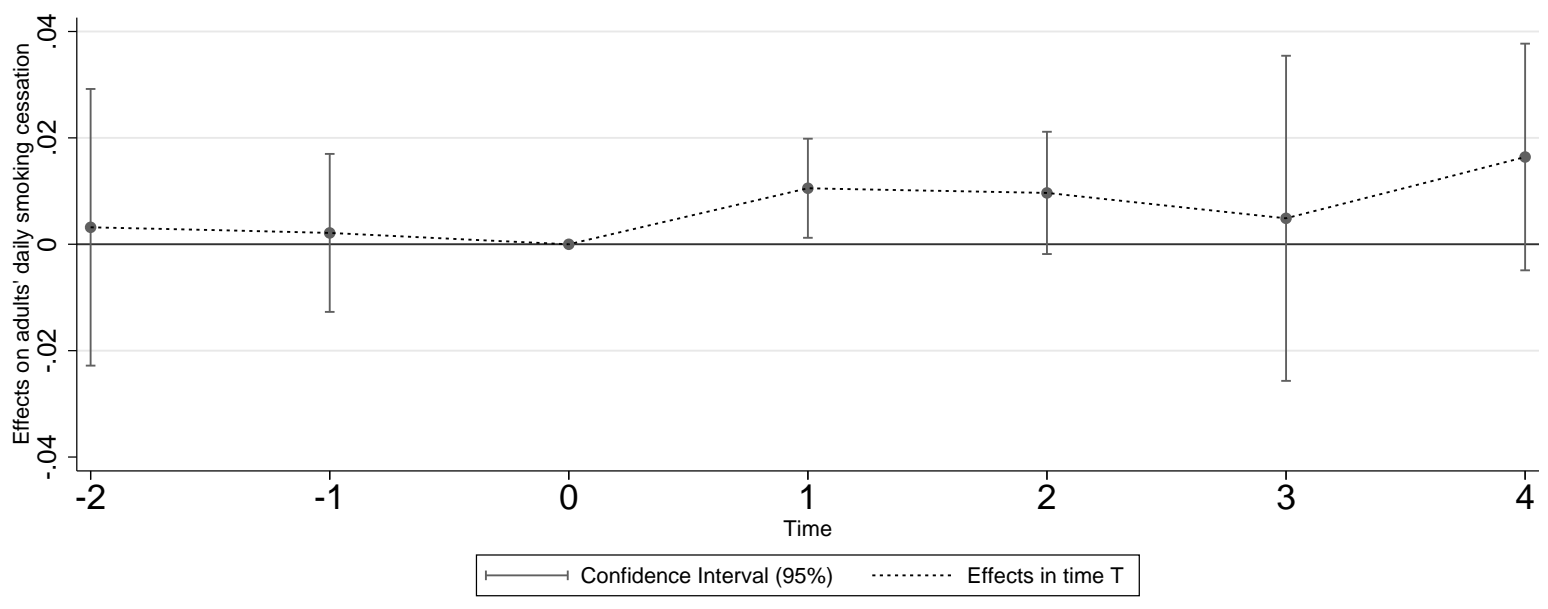

Source: Prepared by the authors.

\subsection{Analysis of prices and other policies}

Brazil has been implementing policies to reduce cigarette consumption since the 1980s, under the establishment of the National Tobacco Control Program (INCA, 2016). After the ratification of the WHO Framework Convention on Tobacco Control in 2006, the obligations and guiding principles of this treaty became part of Brazil's anti-smoking program $^{12}$. WHO guideline contains six measures ${ }^{13}$, which are: monitoring; smoke-free

\footnotetext{
${ }^{12}$ According to (WHO, 2015), this Framework "and its guidelines provide the foundation for countries to implement and manage tobacco control"

${ }^{13}$ These measures are denominated MPOWER: Monitoring tobacco use and policies; Protect people from smoke by smoke-free environments; Offer help to quit smoking by cessation programs; Warning about
} 
environments; warning (labels and mass media campaigns); advertising bans; taxation and cessation programs.

Brazil has adopted all these measures over the years. One could concern that the effects of smoking bans we have found are driven by other policies or by differences in prices changes. In this section, we argue that it does not explain our results.

The current WHO Report on Tobacco (WHO, 2017b) cites Brazil as a successful example of tobacco monitoring since the introduction of the 2008 PETab. According to WHO (2017b), the implementation of the National Health Survey in 2013 (PNS), containing a smoking behavior questionnaire, and the intention to carry it out every five years, consolidate this monitoring system. Even thought these information are useful to supervise tobacco control indicators (WHO, 2017b), we do not expect them to impact the behavior of smokers. If so, the related impact should not be different between municipalities treated and not treated by local smoking bans, since the monitoring system is a measure nationally applied by IBGE and the Ministry of Health.

Warning labels were introduced on the side of cigarette packages in 1996 in Brazil. They were expanded in order to mention the harmful effects of tobacco on packages and advertising materials in 2000. Finally, since 2011, warning labels must also cover 30\% of cigarette packages' front side. Advertising bans were also implemented in 1996 by restricting cigarette advertising on radio and television to $9 \mathrm{pm}$ to $6 \mathrm{am}$ with the inclusion of warnings about the harmful effects of smoking. In 2000, advertisings were restricted to posters and panels inside the places of sale. Distribution of gifts or samples, merchandising, advertising by electronic means and sponsor of cultural or sport activity were forbidden in the same year. In 2011, every types of advertising were forbidden, except the exposure of the products at their place of sale containing warnings.

The measures concerning warnings and advertising bans should not affect municipalities differently, since they were applied at the national level. Moreover, to the best of knowledge, we are not aware of local mass-media campaigns.

Regarding prices differences, they would overestimate smoking bans impacts if prices increased more in the municipalities that adopted Smoking Bans after 2008 comparing to the control ones. We argue that prices differences do not explain our results. First, since 2012, a federal minimum price is in force in Brazil. The minimum price for cigarette has been the same around the country, at least three and four years after the adoption of Smoking Bans (period in which we have found the main impacts).

However, there may be differences in prices above the minimum. In Appendix G, we show some evidences that the evolution in cigarette prices was not significantly different

the dangers of tobacco by cigarette labels and media campaigns; Enforce bans on tobacco advertising; and Raise taxation on tobacco. WHO's figure in Appendix G shows the number of countries that implemented each measure by levels of achievement. 
between treatment and control capitals. Data regarding cigarette prices were obtained from 2010 to 2013 for each Brazilian state. The Federal Revenue Bureau provided prices of different brands and kinds of cigarette packs ${ }^{14}$. We had access to the prices from 2010 to 2013, but only for the pack branded Free, produced by Souza Cruz, which is the main producer in Brazil. Free is among the main cigarette packs consumed in Brazil.

In Table 28, Appendix G, we show some statistics regarding reported prices of Free cigarette pack for each Brazilian state. One can observe no difference in maximum and minimum prices between control and treatment groups throughout the period. However, the average price was higher in the group of 2009-treated in the years 2012 and 2013. It is also observable in the Graph 44. From 2011 to 2012, cigarette price increased around $37.5 \%$ in the control group and almost 39\% in the treatment one. But it decreased in 2013 in the treatment group, while it increased in the control one. So some price effect would be happening 3 years after the treatment. Cigarette price-elasticity was estimated from -0.4 to -0.5 to Brazil (RIZZIERI, 2008), and it is in accordance to international estimates. Therefore, a decrease in cigarette consumption of $15 \%$ in the control group and of $15.6 \%$ in the treatment group would be related to price changes. It represents a difference of 0.6 percent points, widely lower than our estimated impacts of smoking bans, in the order of 6 percent points. From 2012 to 2013, the estimated difference associated to price would be even lower, around 0.2 percent points. In Graph 45, it is possible to observe no significant difference between the evolution of price between the control and the high-enforcement treatment group.

As our previous price analysis was limited to one kind of cigarette, we have collected the Price Index related to cigarette pack from 2006 to 2017 from IBGE. One can observe, in Graph 46, Appendix G, that the evolution of the cigarette price index was very similar between control and treatment group. It was narrowly higher in the treatment group during the pretreatment period and, after the treatment, it was around 1.8 percent points higher in the treatment group when compared to the control one. This difference would represent a decrease in cigarette consumption from 0.7 to 0.9 percent points in the treatment group related to price changes, when considering the elasticity of -0.4 and -0.5 respectively. Therefore it is still widely lower than the estimated impacts we have found in this paper.

One limitation of our paper is related to the absence of official data on cigarette smuggling over the years. If the prevalence of smuggling is higher in the control group, then non-treated smokers could have a higher access to cigarettes under the minimum prices. Therefore, the effect of smoking bans would be overestimated: the treatment group would also be "treated" by a higher actual price when comparing to the control group. In the opposite situation, our findings would be underestimated.

\footnotetext{
${ }^{14}$ Before 2012, it was not mandatory to the producers to inform the prices of cigarette to the Federal Revenue Service. After that, they have to inform the prices to consumers of all kinds of packs in each federal unity.
} 
We have measured the prevalence of smuggling as the percentage of cigarette packs purchased below the 2013 minimum price (3.5 Brazilian reais - around 1 dollar), according to the strategy used by Iglesias et al. (2016) to measure the size of illicit cigarette consumption in Brazil ${ }^{15}$. The prevalence of smuggling is lower when considering only capitals (around 18\%, compared to $30-32 \%$ of the Brazilian average ${ }^{16}$ ). Table 8 shows the 2013 prevalence of smuggling among adults and young adults on control and treatment groups (all treated and 2009 treated. The prevalence of smuggling when considering all individuals from 18 to 64 years is not statistically significant between control and treatment groups. This prevalence is around 17\% (in control, all treated, 2009 treated and higher-enforcement treated groups) and almost $23 \%$ in the lower-enforcement treatment group (Table 9). The higher prevalence of smuggling in the municipalities that adopted low-enforced smoking bans (although not significant) can be one explanation to the positive difference found on the prevalence of smoking among adults on this group.

Table 8 - Price, Smuggling and Cessation Programs in 2013

\begin{tabular}{lccccc} 
Price & Control & All Treated & t-value & 2009 Treated & t-value \\
\hline Adults & 5 & 4.95 & 0.27 & 4.94 & 0.31 \\
Young Adults & 4.96 & 4.78 & 0.79 & 4.75 & 0.87 \\
\hline
\end{tabular}

\section{Smuggling}

\begin{tabular}{lccccc}
\hline Adults & $17.71 \%$ & $17.54 \%$ & 0.04 & $17.3 \%$ & 0.09 \\
Young Adults & $14.23 \%$ & $25.11 \%$ & $-2.08^{* *}$ & $26 \%$ & $-2.13^{* *}$ \\
\hline
\end{tabular}

Cessation Programs

\begin{tabular}{lccccc}
\hline Adults & $14.01 \%$ & $9.41 \%$ & $1.78^{*}$ & $9.99 \%$ & 1.57 \\
Adults $\left(\mathrm{SUS}^{a}\right)$ & $37.17 \%$ & $57.38 \%$ & $-1.91^{*}$ & $57.34 \%$ & $-1.9^{*}$ \\
Young Adults & $5.37 \%$ & $1.39 \%$ & $1.86^{*}$ & $1.24 \%$ & $1.91^{*}$ \\
\hline
\end{tabular}

Note: Smuggling estimated as the percentage of cigarette packs purchased below the 2013 minimum price (3.5 Brazilian reais - around 1 dollar) according to the strategy used by Iglesias et al. (2016) to measure the size of illicit cigarette consumption in Brazil. Regarding Cessation Programs, the survey asked individuals whether they have appealed on treatment to quit smoking and, if so, whether this treatment was supplied by the Public Health System (SUS ${ }^{a}$ ). 162 individuals in our sample have appealed on treatment, from which 64 on SUS. Among young adults, only 12 individuals in our sample have appealed on treatment to quit smoking, with no observation on SUS. Prepared by the authors based on data from PNS 2013.

\footnotetext{
${ }^{15}$ The creation of the price variable was based in two questions of the 2013 PNS: the quantity of cigarettes bought in the last purchase; and the price paid by this purchase.

${ }^{16}$ Our measure is consistent with the $31.1 \%$ estimated by Iglesias et al. (2016).
} 
Table 9 - Price, Smuggling and Cessation programs in 2013 by enforcement level

\begin{tabular}{lccccc} 
Price & Control & Low-enforced & t-value & Higher-enforced & t-value \\
\hline Adults & 5 & 5.28 & -0.75 & 4.9 & 0.52 \\
Young Adults & 4.96 & 5.14 & -0.32 & 4.7 & 1.02 \\
\hline
\end{tabular}

\section{Smuggling}

\begin{tabular}{lccccc}
\hline Adults & $17.71 \%$ & $22.74 \%$ & -0.73 & $16.66 \%$ & 0.24 \\
Young Adults & $14.23 \%$ & $26.2 \%$ & -1.41 & $25.93 \%$ & $-1.94^{*}$ \\
\hline
\end{tabular}

Cessation Programs

\begin{tabular}{lccccc} 
Adults & $14.01 \%$ & $12.69 \%$ & 0.31 & $9.63 \%$ & 1.7 \\
Adults $\left(\mathrm{SUS}^{a}\right)$ & $37.17 \%$ & $45.37 \%$ & -0.63 & $59.6 \%$ & $-2^{*}$ \\
Young Adults & $5.38 \%$ & $0.5 \%$ & $2.29^{* *}$ & $1.37 \%$ & $1.84^{*}$ \\
\hline
\end{tabular}

Note: Smuggling estimated as the percentage of cigarette packs purchased below the 2013 minimum price (3.5 Brazilian reais - around 1 dollar) according to the strategy used by Iglesias et al. (2016) to measure the size of illicit cigarette consumption in Brazil. Regarding Cessation Programs, the survey asked individuals whether they have appealed on treatment to quit smoking and, if so, whether this treatment was supplied by the Public Health System (SUS ${ }^{a}$ ). 162 individuals in our sample have appealed on treatment, from which 64 on SUS. Among young adults, only 12 individuals in our sample have appealed on treatment to quit smoking, with no observation on SUS. Prepared by the authors based on data from PNS 2013.

Regarding the prevalence of cigarette smuggling among young adults, one can observe it was significantly higher in the treatment group: $26 \%$ in 2009 treated and higher-enforcement treated compared to around $14 \%$ in the control group (Tables 8 and 9). As young adults in the treatment group have had a higher access to cigarettes by prices below the national minimum price, we would expect them to quit smoking less often. The price and smuggling effects were acting in an opposite direction to the smoking bans. Therefore, these effects would underestimate our findings.

Another measure adopted in Brazil since 2004 are the cessation programs, which consist in the public supply of treatment to help to quit smoking. They were introduced by the Ministry of Health, with the execution assigned to the municipalities. All Brazilian capitals offer public treatments to cigarette dependents in hospitals and basic health units. The treatment ranges from counseling to drug use and lasts around one year.

We could not get access to data concerning the quantity of individuals that received treatment to quit smoking in the Brazilian state capitals over the years. However, PNS 2013 asked individuals whether they have appealed on treatment to quit smoking and, if so, whether this treatment was supplied by the Public Health System (SUS). 162 individuals in our sample have appealed on treatment, from which 64 on SUS. Among young adults, only 12 individuals in our sample have appealed on treatment to quit smoking, with no observation on SUS. Tables 8 and 9 compare the prevalence of individuals who answer 
have appealing to cessation programs on control and treatment groups and by levels of enforcement, respectively. There was a higher prevalence of individuals who have appealed on cessation treatment on the control group compared to treatment ones. Therefore, these results indicate that cessation programs might not explain our findings or, if so, might be underestimating the impacts of smoking bans.

Based on the exposed in this section, we can argue that there is no evidence of different trajectory in prices and in the other covariates that would confound our results. Even considering the price difference in 2012 and 2013, an impact of over 5 percent points would remain explained by smoking bans. Overall, the other tobacco control policies implemented in Brazil do not explain our finding on smoking bans. Smuggling and cessation programs effects would underestimate our findings. 


\section{Concluding remarks}

Following a worldwide trend of expanding tobacco control, Brazil implemented, in 2014, a national smoking ban that prohibit cigarette consumption in closed and partially closed indoor public places. Before this national law, however, a few states and municipalities adopted local smoking bans. These restrictions got effective in different locations at different moments from 2008 to 2012.

Exploring these regional and timing differences of smoking bans implementation, this thesis evaluate the impacts of such bans on the prevalence of cigarette consumption among adults and youngsters. We use a difference-in-difference approach to estimate heterogeneous impacts throughout the time of exposure to the restrictions.

Our results show that smoking bans are related to a reduction of around $7 \%$ of daily smoking prevalence among young adults, mainly three years after their adoption. When considering the level of enforcement, we found that the effects of smoking bans on daily consumption of cigarette among young adults were stronger in the unities where the laws were more policed and penalties were applied. Higher enforced laws are related to a decrease on smoking prevalence among youths around $10 \%$ in the longer term, which represents 90 thousand less smokers among individuals between 15-29 years. However, in the unities where the laws were poorly enforced, no significant impacts were found among young adults.

Furthermore, the impacts on young adults are associated with the reduction of smoking initiation from $20 \%$ to almost $35 \%$ for highly-enforced bans. It means that around 80 thousand young individuals have not started using cigarette due to smoking bans.

No impact was found on smoking cessation among youths. Among adults, highly enforced smoke bans are related to a smoking cessation rate $1.2 \%$. It means that almost 30 thousand individuals have quit cigarette use due to these bans. When considering different age ranges, we have shown that there is no impact on smoking quitting among people from 18 to 29 years old and from 45 to 64 years old. However, smoking bans had an estimated average impact of $5 \%$ on smoking cessation among adults from 30 to 44 years old. This finding is compatible with theory of rational addiction, in which the effects of shocks are related the accumulated addiction stock (CHALOUPKA, 1991)

Our findings are also in accordance with international evidence of delayed effects of smoking bans (BOES; MARTI; MACLEAN, 2015) and their effects on the more exposed people (which go more frequently to public places, such as restaurants, bars and nightclubs) (ANGER; KVASNICKA; SIEDLER, 2011). These results indicate that, even in the absence of expressive impacts on persistent smokers, public policies can be effective in reducing 
the incentives to smoking initiation among young adults.

This paper contributes to the literature about smoking bans impacts in developing countries, which are less widespread. We also show that these bans can have a long term effect on adapting young adults smoking behavior. Most of international evidences were limited to short term evaluation of smoking bans, whose impacts may not be significant due to the need of time to enforce the laws and to the addiction aspect of tobacco and its consequent slow adjustment.

In addition, our paper contributes to the literature on policy evaluation by empirically showing the importance of taking into account enforcement levels. Average treatment effects can hide differences related to the way policies are implemented. We have shown that the consequence can be the absence of impacts when policies are not enforced and higher impacts when policies are implemented in a more effective way.

Besides that, our paper is the first one that uses national representative longitudinal data on cigarette consumption in Brazil. It is due to the strategy of creating individual panel data base on cross-sectional micro data and using retrospective information about smoking, inspired in Boes, Marti and Maclean (2015), Palali and Ours (2017a), Palali and Ours (2017b).

One limitation of our analysis is the lack of retrospective information about casual smoking in PNS. We understand the importance of verifying the impacts of smoking bans on casual cigarette consumption, since it can respond differently to smoke-free areas creation. We have tried two-periods difference-in-difference estimations (comparing PETab and PNS), but the identification hypothesis could not be verified.

Our results are robust to sensibility tests. We have also shown that our findings are not explained by differences in cigarette prices evolution and by the adoption of other tobacco control policies. 


\section{Reference List}

ACTBR. Legislação. 2016. Aliança de Controle do Tabagismo do Brasil. Available from Internet: <www.actbr.org.br/biblioteca/legislacao>. Cited 2 times on pages 23 and 24 .

ADDA, J.; CORNAGLIA, F. The effect of bans and taxes on passive smoking. American Economic Journal: Applied Economics, American Economic Association, v. 2, n. 1, p. 1-32, 2010. Cited 3 times on pages 19, 20, and 30.

ANGER, S.; KVASNICKA, M.; SIEDLER, T. One last puff? public smoking bans and smoking behavior. Journal of health economics, Elsevier, v. 30, n. 3, p. 591-601, 2011. Cited 6 times on pages 20, 21, 22, 29, 54, and 67.

ANGRIST, J. D.; PISCHKE, J.-S. Mostly harmless econometrics: an empiricist's companion. : Princeton University Press: Princeton, 2009. v. 1. Cited 3 times on pages 43, 46 , and 49 .

BECKER, G. S.; MURPHY, K. M. A theory of rational addiction. Journal of political Economy, The University of Chicago Press, v. 96, n. 4, p. 675-700, 1988. Cited 2 times on pages 32 and 33 .

BERTRAND, M.; DUFLO, E.; MULLAINATHAN, S. How much should we trust differences-in-differences estimates? The Quarterly journal of economics, Oxford University Press, v. 119, n. 1, p. 249-275, 2004. Cited 2 times on pages 47 and 97.

BOES, S.; MARTI, J.; MACLEAN, J. C. The impact of smoking bans on smoking and consumer behavior: Quasi-experimental evidence from switzerland. Health economics, Wiley Online Library, v. 24, n. 11, p. 1502-1516, 2015. Cited 7 times on pages 20, 21, 29, $35,54,67$, and 68 .

BOHADANA, A.; TECULESCU, D.; MARTINET, Y. Mechanisms of chronic airway obstruction in smokers. Respiratory medicine, Elsevier, v. 98, n. 2, p. 139-151, 2004. Cited on page 19.

CAMERON, A. C.; MILLER, D. L. A practitioner's guide to cluster-robust inference. Journal of Human Resources, University of Wisconsin Press, v. 50, n. 2, p. 317-372, 2015. Cited 2 times on pages 47 and 97.

CHALOUPKA, F. Rational addictive behavior and cigarette smoking. Journal of political Economy, The University of Chicago Press, v. 99, n. 4, p. 722-742, 1991. Cited 7 times on pages $22,32,33,43,54,56$, and 67 .

CHALOUPKA, F. J.; WECHSLER, H. Price, tobacco control policies and smoking among young adults. 1995. Cited 2 times on pages 20 and 29.

ERIKSEN, M. et al. The tobacco atlas. : American Cancer Society, 2015. Cited 3 times on pages 9,11 , and 19 .

FURTADO, I. B.; FILHO, G. A. da S. Lei antifumo no brasil: Impactos do banimento do fumo em ambientes coletivos sobre a ocorrência de internações hospitalares. In: 
Proceedings of the 42ndd Brazilian Economics Meeting. : ANPEC-Brazilian Association of Graduate Programs in Economics, 2016. Cited 2 times on pages 24 and 31.

GOODMAN, P. et al. Effects of the irish smoking ban on respiratory health of bar workers and air quality in dublin pubs. American journal of respiratory and critical care medicine, Am Thoracic Soc, v. 175, n. 8, p. 840-845, 2007. Cited on page 30.

IBGE. Pesquisa Nacional de Saúde, 2013. Instituto Brasileiro de Geografia e Estatística, 2015. Available from Internet: <www.ibge.gov.br/home/estatistica/populacao/pns/2013/>. Cited on page 38.

IBGE. Pesquisa Nacional por Amostra de Domicílios: Tabagismo, 2008. Instituto Brasileiro de Geografia e Estatística, 2009. Available from Internet: </www.ibge.gov.br/ home/estatistica/populacao/trabalhoerendimento/pnad2008>. Cited on page 38.

IGLESIAS, R. M. et al. Estimating the size of illicit tobacco consumption in brazil: findings from the global adult tobacco survey. Tobacco control, BMJ Publishing Group Ltd, p. tobaccocontrol-2015, 2016. Cited 3 times on pages 31, 64, and 65.

INCA, I. N. d. C. Observatório da Política Nacional de Controle do Tabaco. 2016. Available from Internet: <http://www2.inca.gov.br/wps/wcm/connect/observatorio controle_tabaco/site $>$. Cited on page 61 .

JARVIS, M. J. Why people smoke. BMJ, v. 328, n. 7434, p. 277-279, 2004. Cited on page 43.

JONES, A. M. et al. Do public smoking bans have an impact on active smoking? evidence from the uk. Health economics, Wiley Online Library, v. 24, n. 2, p. 175-192, 2015. Cited 3 times on pages 20, 21, and 29 .

KIM, J. et al. Impact of partial and comprehensive smoke-free regulations on indoor air quality in bars. International journal of environmental research and public health, Multidisciplinary Digital Publishing Institute, v. 13, n. 8, p. 754, 2016. Cited on page 30.

KIM, W. J. et al. The effects of secondhand smoke on chronic obstructive pulmonary disease in nonsmoking korean adults. The Korean journal of internal medicine, v. 29, n. 5, p. 613-619, 2014. Cited on page 19.

KLINE, P. The impact of juvenile curfew laws on arrests of youth and adults. American Law and Economics Review, Am Law Econ Assoc, p. ahr011, 2011. Cited on page 46.

LAMPREIA, S. et al. Tabagismo no brasil: estimação das elasticidades preço e renda na participação e na demanda por cigarros industrializados. Instituto de Pesquisa Econômica Aplicada (Ipea), 2015. Cited on page 19.

LEVY, D.; ALMEIDA, L. M. de; SZKLO, A. The brazil simsmoke policy simulation model: the effect of strong tobacco control policies on smoking prevalence and smoking-attributable deaths in a middle income nation. PLoS Med, Public Library of Science, v. 9, n. 11, p. e1001336, 2012. Cited on page 31.

MACKINNON, J. G.; WEBB, M. D. Wild bootstrap inference for wildly different cluster sizes. Journal of Applied Econometrics, Wiley Online Library, 2016. Cited 2 times on pages 47 and 97. 
MENZIES, D. et al. Respiratory symptoms, pulmonary function, and markers of inflammation among bar workers before and after a legislative ban on smoking in public places. Jama, American Medical Association, v. 296, n. 14, p. 1742-1748, 2006. Cited on page 30 .

MORTEN, M.; OLIVEIRA, J. The effects of roads on trade and migration: Evidence from a planned capital city. NBER Working Paper, v. 22158, 2016. Cited on page 43.

PALALI, A.; OURS, J. C. V. The Impact of Tobacco Control Policies on Smoking Initiation in Europe. 2017. CEPR Discussion Papers. Cited 9 times on pages 21, 30, 33, $35,38,40,54,55$, and 68 .

PALALI, A.; OURS, J. C. V. Love conquers all but nicotine: Spousal peer effects on the decision to quit smoking. Health Economics, p. n/a-n/a, 2017. ISSN 1099-1050. Hec.3489. Available from Internet: <http://dx.doi.org/10.1002/hec.3489>. Cited 7 times on pages $21,33,34,35,38,40$, and 68 .

PINTO, M.; PICHON-RIVIERE, A. Carga das doenças tabaco-relacionadas para o brasil. Rio de Janeiro: ACT, 2012. Cited on page 19.

PINTO, M.; UGÁ, M. A. D. Os custos de doenças tabaco-relacionadas para o sistema único de saúde. Cadernos de Saúde Pública, SciELO Public Health, v. 26, n. 6, p. 1234-1245, 2010. Cited on page 19.

PINTO, M. T.; PICHON-RIVIERE, A.; BARDACH, A. Estimativa da carga do tabagismo no brasil: mortalidade, morbidade e custos. Cad. Saúde Pública, v. 31, n. 6, p. 1283-1297, 2015. Cited on page 19.

RIZZIERI, J. A demanda brasileira de cigarros e o efeito da restrição para a veiculação de sua publicidade em meios de comunicação de massa. 2008. FIPE: Texto para discussão n. 11. Cited 4 times on pages 19, 31, 54, and 63 .

TAMIMI, A.; SERDAREVIC, D.; HANANIA, N. A. The effects of cigarette smoke on airway inflammation in asthma and copd: therapeutic implications. Respiratory medicine, Elsevier, v. 106, n. 3, p. 319-328, 2012. Cited on page 19.

VUOLO, M.; KELLY, B. C.; KADOWAKI, J. Independent and interactive effects of smoking bans and tobacco taxes on a cohort of us young adults. American journal of public health, American Public Health Association, v. 106, n. 2, p. 374-380, 2016. Cited 2 times on pages 20 and 29.

WHO. WHO Report on the Global Tobacco Epidemic: the MPOWER Package. 2008. World Health Organization. Cited on page 19.

WHO. WHO Report on the Global Tobacco Epidemic: Raising taxes on tobacco. 2015. World Health Organization. Cited 3 times on pages 19, 20, and 61.

WHO. Global Health Observatory Data Repository. 2017. World Health Organization. Available from Internet: < http://apps.who.int/gho/data/node.main.Tobacco?lang=en $>$. Cited 2 times on pages 20 and 39 .

WHO. WHO Report on the Global Tobacco Epidemic: Monitoring tobacco use and prevention policies. 2017. World Health Organization and others. Cited 2 times on pages 62 and 99. 

Appendix 



\section{APPENDIX A - Smoking bans description}

Table 10 - Smoking bans description and enforcement levels

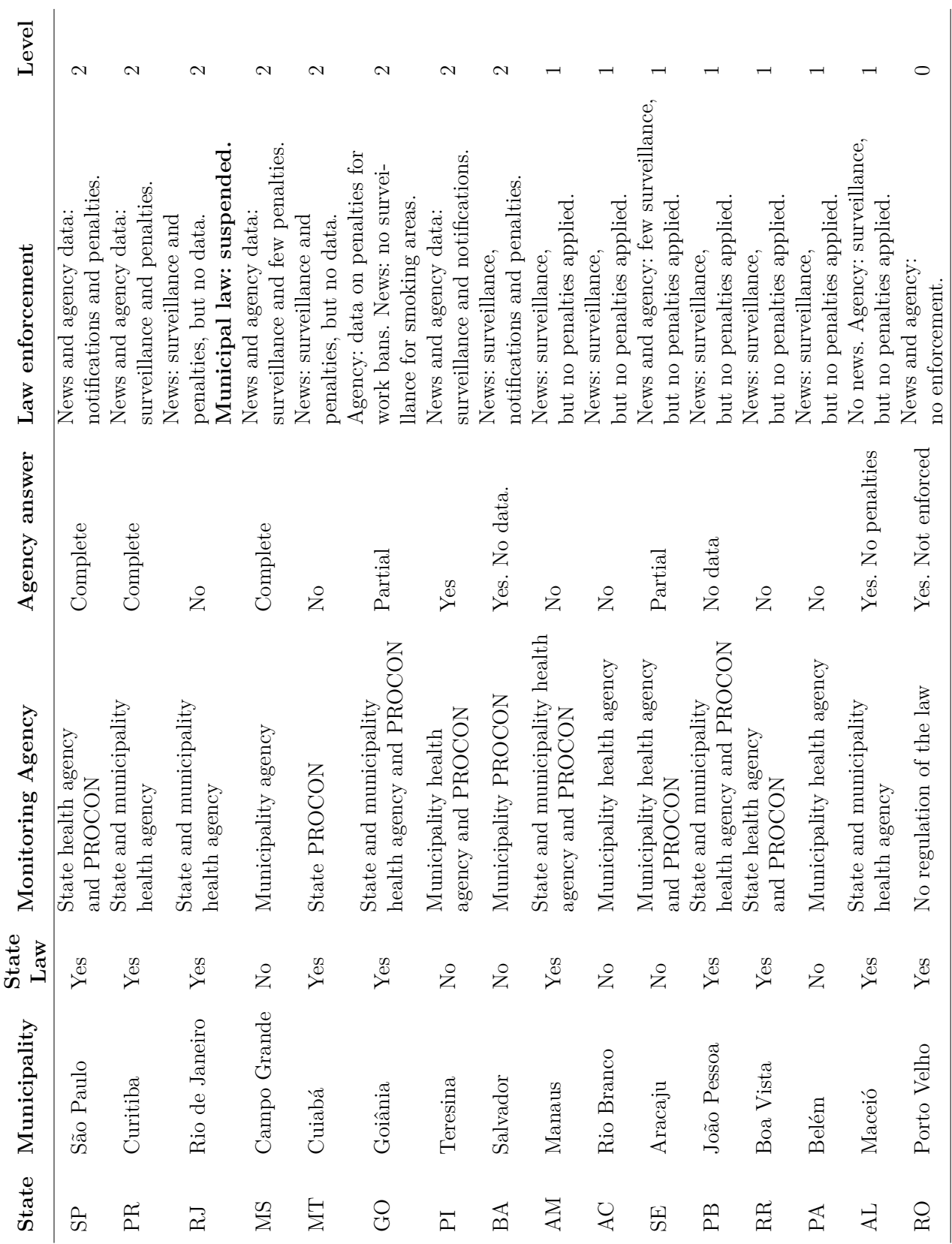

Note: the columns are described in the following order: (i) acronym of the State; (ii) name of the state capital; (iii) whether the unity is treated or not by a state level law; (iv) agency responsible by the enforcement of the law; (v) whether the monitoring agency answered to our requirement; (vi) description of the enforcement; (vii) level of enforcement, where (0) represents not enforced smoking bans; (1) lower enforced smoking bans; and (2) higher enforced smoking bans. Prepared by the authors using local laws and enforcement information provided by the responsible organizations. In the absence of response, the enforcement information were obtained on news. 



\section{APPENDIX B - Retrospective data fit}

In order to verify if the retrospective information about smoking was well estimated by the procedure explained above, we compared some statistics of the lagged PNS for 2008 with PETab. To make both samples comparable, we restrained lagged PNS to individuals from 15 years old in 2008, since PETab was applied from this age. We present these results in Table 11. All the tests of mean difference were estimated using cluster robust standard deviation on states and sample weights.

Table 11 - Statistics to the whole sample

\begin{tabular}{lccc} 
Variables & PETab & PNS & Difference \\
\hline Men & $47.63 \%$ & $46.37 \%$ & $1.26^{* * *}$ \\
Age & 39.90 & 39.20 & $0.70^{* * *}$ \\
Rural residents & $15.49 \%$ & $13.60 \%$ & $1.89^{* * *}$ \\
Smokers & $16.81 \%$ & $17.37 \%$ & -0.56 \\
Ex-smokers & $17.18 \%$ & $13.4 \%$ & $3.78^{* * *}$ \\
Smoking quitting years $^{a}$ & 14.33 & 15.27 & $0.94^{* *}$ \\
Starting Smoking age $^{*}$ & 17.81 & 16.99 & $0.82^{* * *}$ \\
Starting Smoking age $^{b}$ & 19.66 & 18.94 & 0.72 \\
Smoking time $^{c}$ & 28.48 & 27.78 & $0.7^{* *}$ \\
Daily smokers' age $^{c}$ & 42.89 & 41.04 & $1.85^{* * *}$ \\
\hline Observations $^{\text {Obs }}$ & $\mathbf{3 6 , 7 7 4}$ & $\mathbf{5 4 , 2 3 9}$ & $\mathbf{9 1 , 0 1 3}$ \\
\hline
\end{tabular}

Note: Statistics for 2008 measured using PETab and lagged PNS. Sample of individuals aged from 15 years old. Samples weights were used to calculate the means. T-test estimated using cluster robust standard deviation. For inference, consider: *** $1 \%$ significant; ** $5 \%$ significant; * $10 \%$ significant.

${ }^{a}$ Difference measured by quitting time of 0 years. ${ }^{b}$ Difference measured by dropping who smokes for more than 20 years and former smokers who quit more than 15 years ago. ${ }^{c}$ Smoking time is defined as the difference between the current age and smoking initiation age, considering only daily smokers.

As we can see in Table 11, the proportion of daily smokers is not statistically different between lagged PNS and PETab. However, the proportion of former daily smokers is higher in PETab, which can be a limitation in our study. It can be in part explained because all individuals who declared, in 2008, quitting smoking for more than three months were considered as ex-smokers in PETab sample.

Average age and the proportion of males and rural residents are higher in PETab. However, even if these differences are statistically significant, they are not concerning. The difference in the average age is very small, less than one year, and can be explained because oldest individuals are older in PNAD comparing to lagged PNS, once individuals had five years reduction in PNS 2013. If we restrain the sample for individuals up to 80 years old, the difference decreases to 0.37 and is not statistically significant. The proportion of males is lower in PNS due to the selection of householders aged 18 or more to answer questions 
about smoking. In PETab this selection were more balanced. Regarding rural residents, it can express a reduction in rural households during the five years between both surveys.

The average of smoking quitting time (measured in years) of former smokers and the starting age for former and current daily smokers is slightly different among both samples (less than 1 year). In Graph 25 we show that the distributions of the initiation age are very similar. And when we drop individuals who started smoking more than 20 years ago and/or quit smoking for more than 15 years, the age of smoking initiation is not statistically different among the samples. Those individuals would not have a change in the smoking status in our period of analysis and they are more likely to report smoking information whit error due to memory concerns. The distribution with this sample restriction is showed in Graph $26^{1}$

Graph 25 - Density of smoking starting age

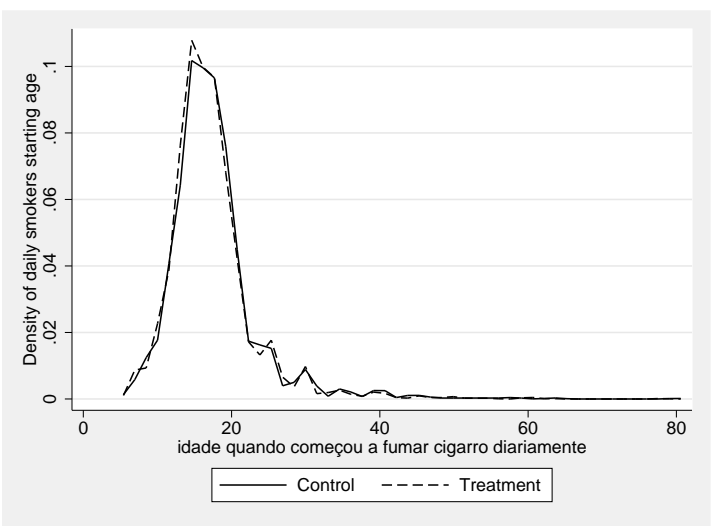

Source: Prepared by the authors.
Graph 26 - Density of smoking starting age to restrained sample

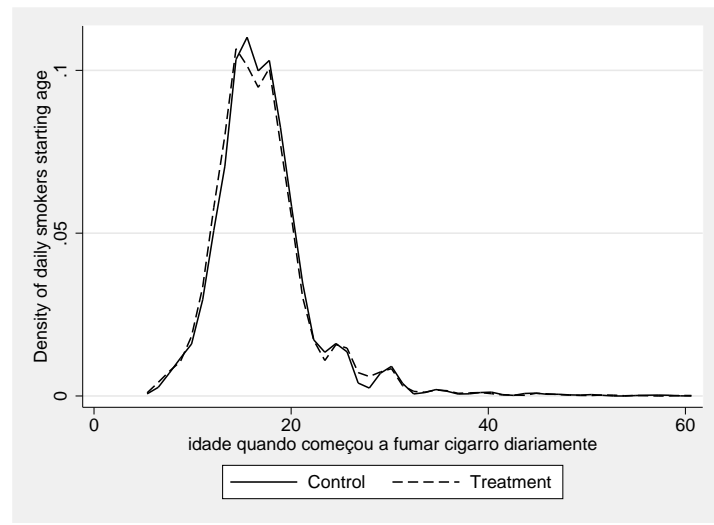

Source: Prepared by the authors.

Regarding the distributions of smoking quitting time, it's possible to check that, overall, they are similar among both samples (Graph 27), except by the higher quantity of observations on zero-year in PNS. The reason is that individuals use to round up the quitting time to 5 years, 10 years, and so on. The 5 -years rounding up is more relevant to our analysis, since it is related to zero quitting time, in 2008, for individuals from PNS. Considering only quitting time from 1 year on, the distributions are very similar (Graph 28). We take rounding up into consideration in robustness tests.

Considering only 2008 daily smokers, smoking time, defined as the difference between the current age of smokers and the age to smoking initiation, is less than one year higher in PETab. The distributions are very similar in both samples (Graph 29). When we restrain to individuals that smoke up to 20 years, smoking time is, on average, 10 years and not statistically different among the samples. The average age of daily smokers in 2008 was higher in PETab, even thought the distributions are similar (Graph 30). This

\footnotetext{
${ }^{1}$ Sample restricted by dropping smokers who started smoking more than 20 years ago and former smokers who started smoking more than 20 years ago and quit smoking for more than 15 years.
} 
Graph 27 - Density of smoking quitting time (in years)

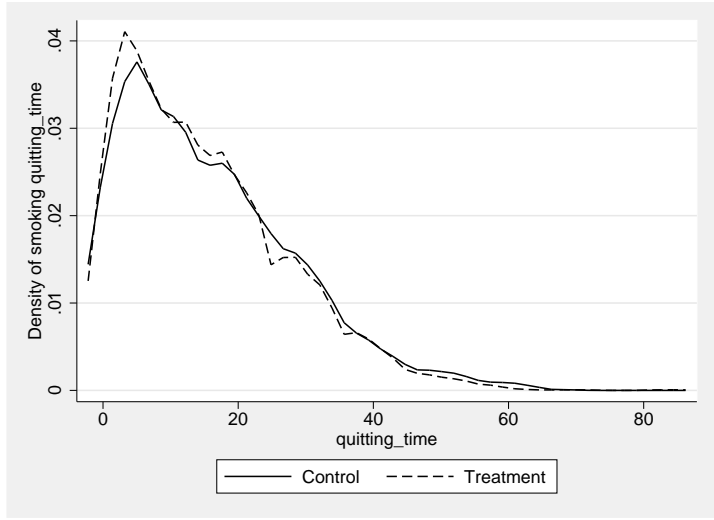

Source: Prepared by the authors.
Graph 28 - Density of smoking quitting time (in years)

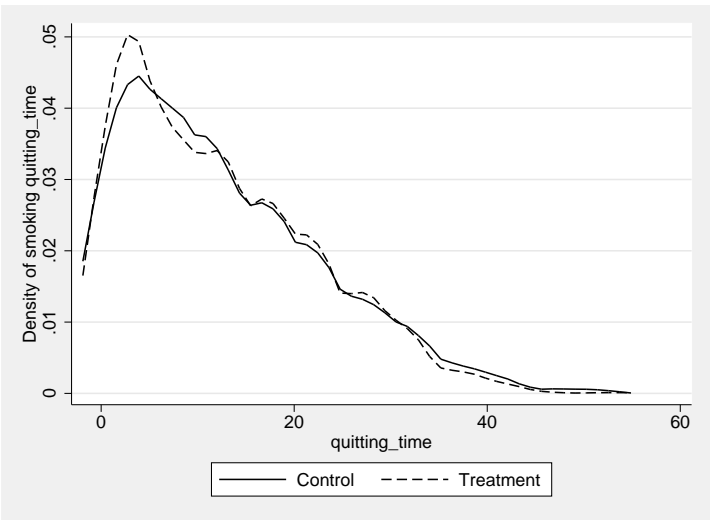

Source: Prepared by the authors.

difference decreases to less than 1 year when considering the sample of individuals up to 64 years old (which is the sample we use in this study).

Graph 29 - Density of current daily smokers' smoking time

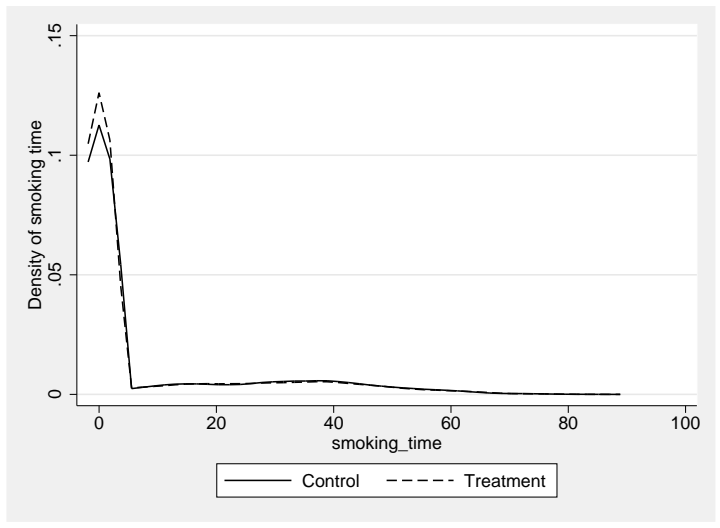

Source: Prepared by the authors.
Graph 30 - Density of daily smokers current age

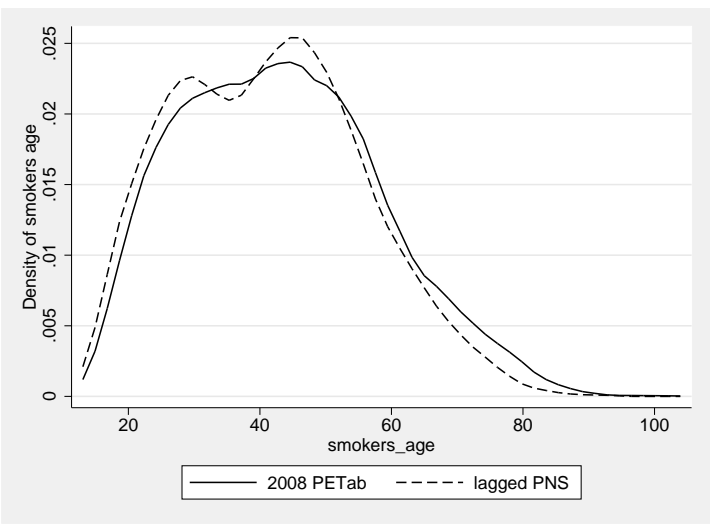

Source: Prepared by the authors. 



\section{APPENDIX C - Descriptive statistics}

Graph 31 - Evolution in the proportion of capital's residents for unities with and without smoking bans $(1960-2010)$

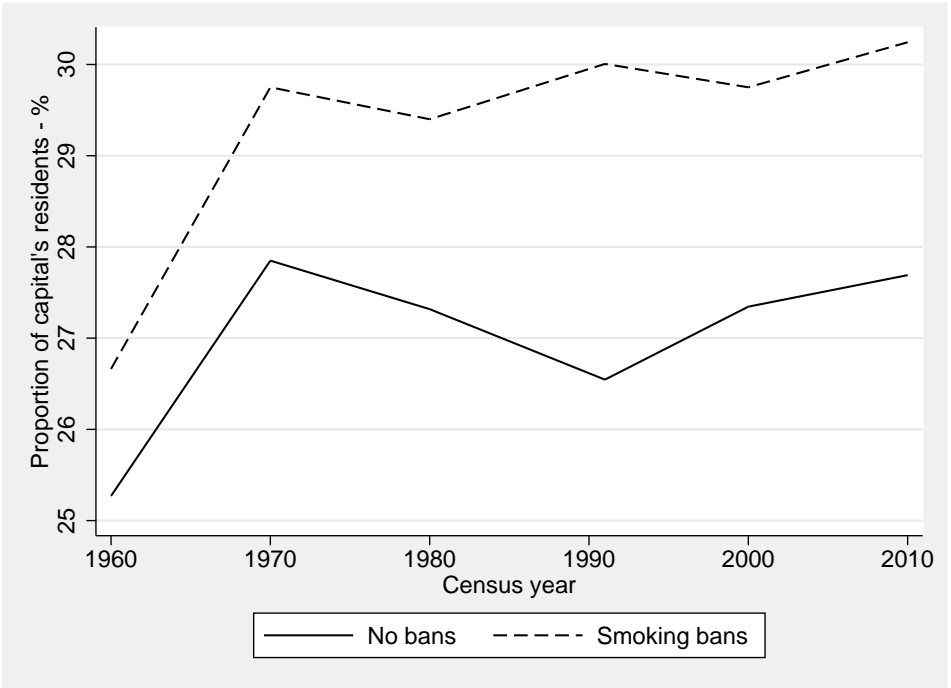

Source: Prepared by the authors using Brazilian Census data from IBGE.

Table 12 - Mean differences between capital states with and without smoking bans PETab 2008

\begin{tabular}{lccc} 
Variables & Smoking bans unities & No smoking bans & Difference \\
\hline Casual Smokers & $2.14 \%$ & $2.46 \%$ & -0.32 \\
Former Casual Smokers & $3.8 \%$ & $4.38 \%$ & -0.58 \\
Daily Smokers & $14.64 \%$ & $14.86 \%$ & -0.22 \\
Former Daily Smokers & $14.66 \%$ & $13.06 \%$ & 1.6 \\
Adults $^{a}$ & $82.7 \%$ & $82.3 \%$ & 0.40 \\
Youth $^{b}$ & $33.9 \%$ & $34.1 \%$ & -0.2 \\
Capital & $53.49 \%$ & $48.31 \%$ & 5.18 \\
\hline Observations & $\mathbf{1 1 , 3 4 1}$ & $\mathbf{8 , 5 0 7}$ & $\mathbf{1 9 , 8 4 8}$ \\
\hline
\end{tabular}

Source: Prepared by the authors using PETab 2008. Observations in the sample of capital residents from 15 to 64 years old, after dropping casual smokers. Samples weights were used to calculate the proportions. T-test estimated using cluster robust standard deviation. For inference: *** $1 \%$ significant; ** $5 \%$ significant; ${ }^{*} 10 \%$ significant. ${ }^{a}$ Sample of individuals aged from 18 to 64 years old. ${ }^{b}$ Sample of individuals aged from 15 to 29 years old. 



\section{APPENDIX D - Empirical Strategy}

Table 13 - State capitals in treatment and control groups

\begin{tabular}{c|c}
\hline Treatment Group & Control Group \\
\hline Teresina/PI & Espírito Santo/ES \\
Porto Velho/RO & Belo Horizonte/MG \\
São Paulo/SP & Macapá/AP \\
Maceió/AL & Fortaleza/CE \\
Boa Vista/RR & Florianópolis/SC \\
Curitiba/PR & Porto Alegre/RS \\
Belém/PA & São Luís/MA \\
Aracaju/SE & Recife/PE \\
Salvador/BA & Natal/RN \\
Goiânia/GO & Brasília/DF \\
Campo Grande/MS & Palmas/TO \\
Cuiabá/MT & \\
Manaus/AM & \\
João Pessoa/PB & \\
Rio Branco/AC & \\
Rio de Janeiro/RJ & \\
\hline
\end{tabular}

Source: Prepared by the authors. 



\section{APPENDIX E - Results}

Table 14 - Covariates' mean differences between treatment and control group by enforcement level, 2008

\begin{tabular}{lccc} 
Variables & Control & Diff. Low & Diff. Higher \\
\hline Youth proportion & $34.68 \%$ & $2.32 \%$ & $-1.78 \%$ \\
Population & $1,226,700$ & $-391,061$ & $1,934,282^{*}$ \\
GDP $^{a}$ & 7.68 & -4.18 & 14.8 \\
Health Exp. & $23 \%$ & $2.93 \%$ & $3.45 \%$ \\
\hline Observations & $\mathbf{1 1}$ & $\mathbf{7}$ & $\mathbf{8}$
\end{tabular}

Note: Statistics for 2008 measured using PNS, Munic(IBGE) and FINBRA. We have dropped Porto Velho/RO, but the results are robust when considering it. For inference: *** $1 \%$ significant; $* * 5 \%$ significant; * $10 \%$ significant. ${ }^{a}$ GDP measured in US\$ billion.

Graph 32 - Proportion of young individuals (15 - 29 years old) in treatment and control group

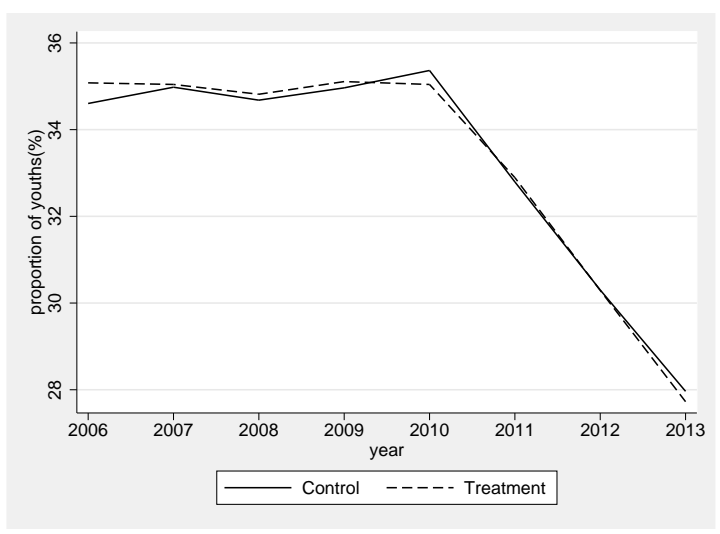

Source: Prepared by the authors.
Graph 33 - Proportion of young individuals (15 - 29 years old) in control and treatment group by enforcement level

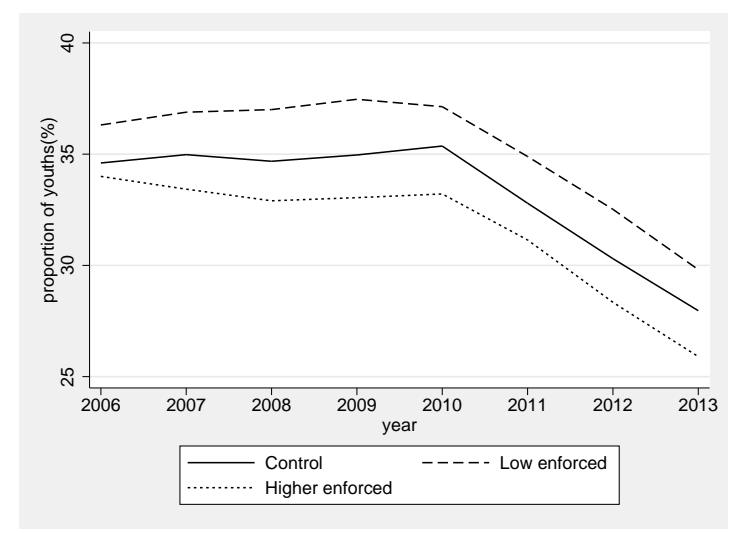

Source: Prepared by the authors. 
Graph 34 - Population in treatment and control group (million)

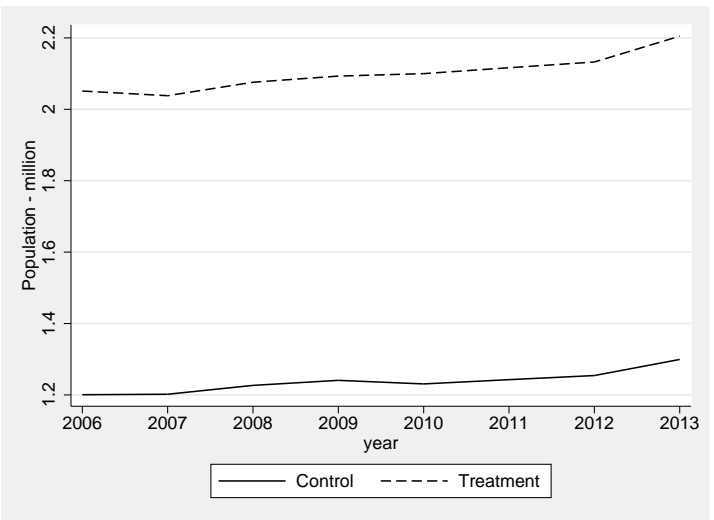

Source: Prepared by the authors.

Graph 36 - GDP in treatment and control group (billion US\$)

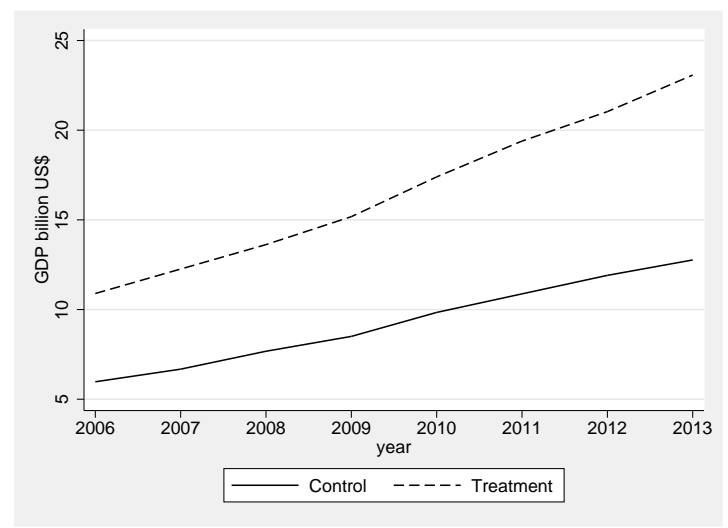

Source: Prepared by the authors.

Graph 38 - Proportion of Health expenditure in total municipal expenditure (\%)

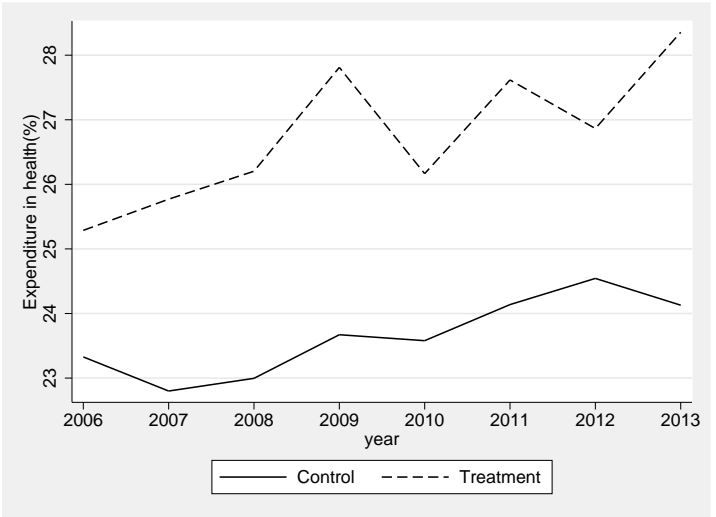

Source: Prepared by the authors.
Graph 35 - Population in control and treatment group by enforcement level (million)

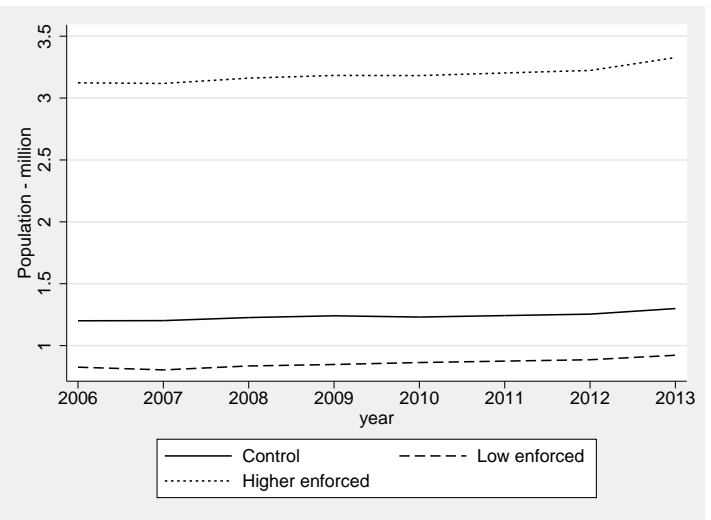

Source: Prepared by the authors.

Graph 37 - GDP in control and treatment group by enforcement level (billion US\$)

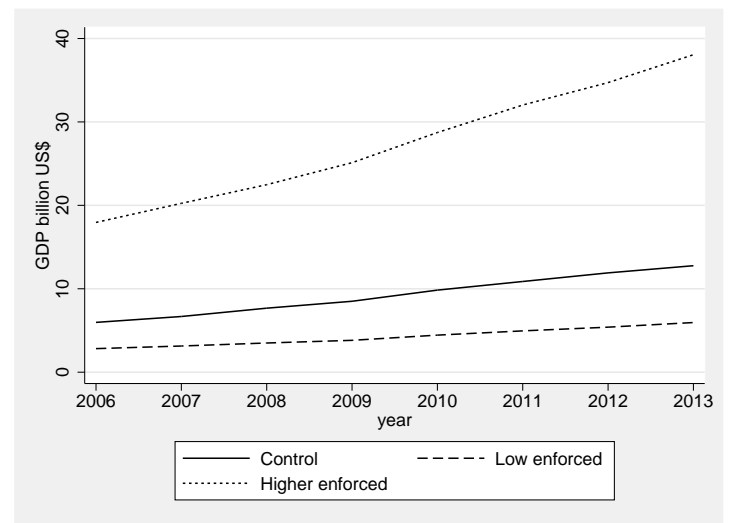

Source: Prepared by the authors.

Graph 39 - Proportion of Health expenditure in total municipal expenditure by enforcement level (\%)

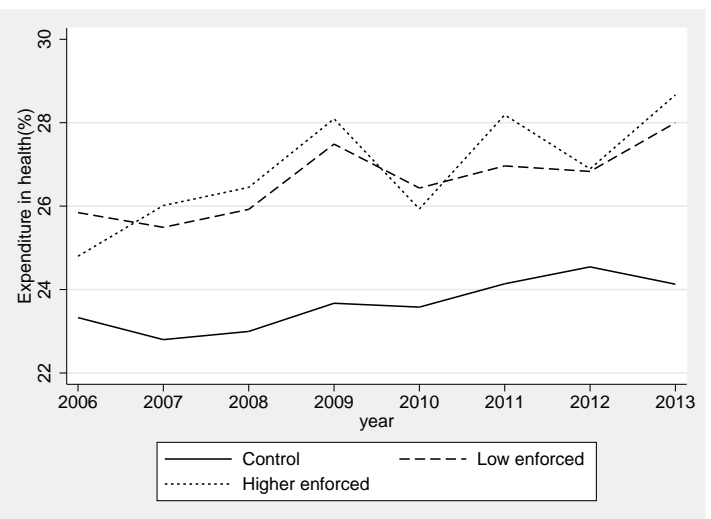

Source: Prepared by the authors. 
Graph 40 - Trajectory of smoking prevalence among adults (18-64 years old) in control, low enforced and high enforced treatment groups, 2007-2013

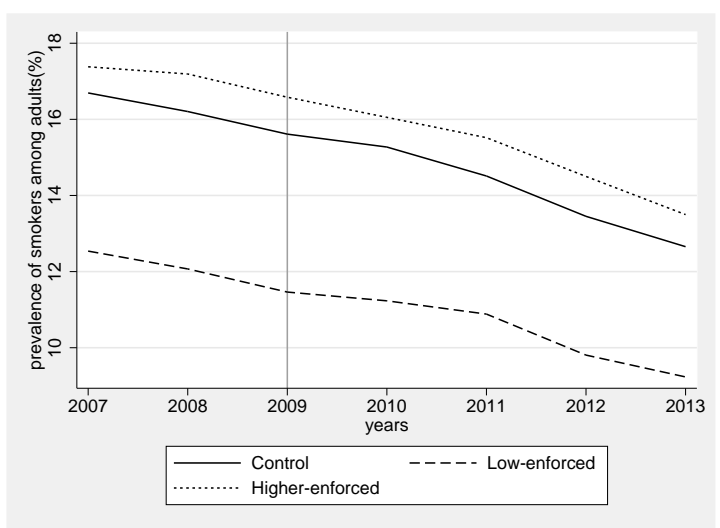

Source: Prepared by the authors using PNS 2013.
Graph 41 - Trajectory of smoking prevalence among youths (15-29 years old) in control, low enforced and high enforced treatment groups, 2007-2013

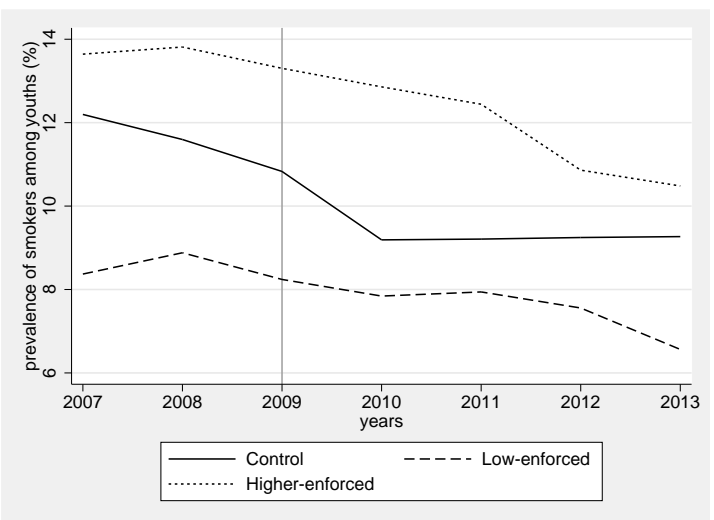

Source: Prepared by the authors using PNS 2013.

Table 15 - Smoking bans impacts on selected covariates (2007-2013)

\begin{tabular}{lccccc}
\hline \multirow{2}{*}{ VARIABLES } & $(1)$ & $(2)$ & $(3)$ & $(4)$ & $(5)$ \\
& Youths & Pop & GDP & Health Exp. & Price \\
$t_{-2}$ & 0.00104 & $-20,550$ & $-5.915 \mathrm{e}+09$ & -0.00806 & \\
& $(0.00442)$ & $(18,785)$ & $(6.684 \mathrm{e}+09)$ & $(0.00958)$ & \\
$t_{-1}$ & 0.000500 & $-5,828$ & $-3.660 \mathrm{e}+09$ & -0.00927 & \\
$t_{1}$ & $(0.00362)$ & $(6,337)$ & $(3.559 \mathrm{e}+09)$ & $(0.00637)$ & \\
& -0.00504 & 17,972 & $4.663 \mathrm{e}+09$ & -0.00700 & -0.0407 \\
$t_{2}$ & $(0.00359)$ & $(39,955)$ & $(5.279 \mathrm{e}+09)$ & $(0.00676)$ & $(0.127)$ \\
& -0.000243 & 24,694 & $9.438 \mathrm{e}+09$ & -0.00989 & -0.0532 \\
$t_{3}$ & $(0.00529)$ & $(42,354)$ & $(9.663 \mathrm{e}+09)$ & $(0.00988)$ & $(0.126)$ \\
& -0.00191 & 31,195 & $1.277 \mathrm{e}+10$ & -0.0150 & 0.000919 \\
$t_{4}$ & $(0.00691)$ & $(45,298)$ & $(1.301 \mathrm{e}+10)$ & $(0.0106)$ & $(0.120)$ \\
& -0.00563 & 71,775 & $1.853 \mathrm{e}+10$ & -0.00189 & 0.0426 \\
Constant & $(0.00619)$ & $(68,539)$ & $(1.710 \mathrm{e}+10)$ & $(0.00897)$ & $(0.127)$ \\
& $0.409^{* * *}$ & $1.820 \mathrm{e}+06^{* * *}$ & $4.231 \mathrm{e}+10^{* * *}$ & $0.241^{* * *}$ & $2.653^{* * *}$ \\
\hline Observations & $(0.00359)$ & $(17,983)$ & $(4.067 \mathrm{e}+09)$ & $(0.00691)$ & $(0.0477)$ \\
Number of UF & 161 & 161 & 161 & 161 & 115 \\
\hline
\end{tabular}

Note: Cluster Robust Standard Errors in parentheses. The models estimate the following equation: $y_{s t}=\alpha+\sum_{e} \beta_{e} S B_{s t}^{e}+\delta_{s}+d_{t}+\epsilon_{s t}$, where $y_{s t}$ is the proportion of young adults in Model (1); the population in Model (2); the GDP in (3); the proportion of the expenditure in public health in (4); and the price of cigarette box (20 unities) in Model (5). As we have obtained only price data from 2010 to 2013, in order to provide a pretreatment baseline, we have estimated the price for 2008 . We did so by aggregating state cigarette prices from information on individual purchases using PETab survey. All models include year $\left(d_{t}\right)$ and state fixed effects $\left(\delta_{s}\right)$. 


\section{E.1 Regression tables}

Table 16 - Smoking Bans impacts on smoking initiation and cessation over time

\begin{tabular}{lcccc}
\hline \multicolumn{4}{c}{ Initiation } & \multicolumn{2}{c}{ Cessation } \\
& Adults & Youth & Adults & Youth \\
\hline \multirow{4}{*}{$t_{-2}$} & 0.000413 & -0.00528 & -0.000656 & -0.0140 \\
$t_{-1}$ & $(0.00188)$ & $(0.00409)$ & $(0.0133)$ & $(0.0235)$ \\
& 0.000928 & -0.00247 & -0.00136 & -0.00950 \\
$t_{1}$ & $(0.00119)$ & $(0.00326)$ & $(0.00752)$ & $(0.0242)$ \\
& $0.00177^{*}$ & 0.00429 & -0.00863 & 0.00219 \\
$t_{2}$ & $(0.00102)$ & $(0.00371)$ & $(0.00511)$ & $(0.0130)$ \\
& 0.00124 & 0.00196 & -0.00881 & 0.0388 \\
$t_{3}$ & $(0.000752)$ & $(0.00412)$ & $(0.00624)$ & $(0.0230)$ \\
& -0.000142 & $-0.00742^{* *}$ & -0.00443 & 0.0188 \\
$t_{4}$ & $(0.000841)$ & $(0.00283)$ & $(0.0146)$ & $(0.0341)$ \\
& -0.000592 & $-0.00940^{* *}$ & -0.0147 & -0.0112 \\
Constant & $(0.000817)$ & $(0.00399)$ & $(0.0109)$ & $(0.0339)$ \\
& $-0.0703^{*}$ & $-0.235^{* *}$ & $1.754^{* * *}$ & 0.647 \\
& $(0.0361)$ & $(0.105)$ & $(0.239)$ & $(0.554)$ \\
\hline Cov. & Yes & Yes & Yes & Yes \\
Observations & 110,478 & 41,703 & 20,953 & 4,321 \\
Number of id & 17,425 & 7,725 & 3,093 & 871 \\
\hline
\end{tabular}

Note: Cluster Robust Standard Errors in parentheses. For inference: ${ }^{* *}$ significant at $1 \%,{ }^{* *}$ significant at 5\%, * significant at 10\%. Estimations only for 2009 treated. Porto Velho/RO, Maceió/AL, Cuiabá/MT and Teresina/PI were dropped. Models include individual and year fixed effects and cluster at capital level. Models (1) and (3) were estimated to individuals from 18 to 64 years old and models (2) and (4), from 15 to 29 years old. The covariates included in all models are age and age squared. 
Table 17 - Enforcement level smoking bans impacts on smoking initiation and cessation over time

\begin{tabular}{lcccc} 
& \multicolumn{2}{c}{ Initiation } & \multicolumn{2}{c}{ Cessation } \\
Low enforced & Adults & Youth & Adults & Youth \\
\hline \multirow{2}{*}{$t_{-2}$} & 0.00198 & -0.00378 & 0.0178 & -0.0374 \\
& $(0.00197)$ & $(0.00506)$ & $(0.0123)$ & $(0.0232)$ \\
$t_{-1}$ & $0.00405^{* * *}$ & 0.00296 & 0.00438 & -0.0205 \\
& $(0.00114)$ & $(0.00236)$ & $(0.0131)$ & $(0.0248)$ \\
$t_{1}$ & 0.00103 & 0.00432 & 0.00532 & 0.0150 \\
& $(0.00109)$ & $(0.00356)$ & $(0.00398)$ & $(0.0134)$ \\
$t_{2}$ & 0.00269 & 0.00598 & -0.00259 & 0.0155 \\
& $(0.00180)$ & $(0.00634)$ & $(0.0197)$ & $(0.0443)$ \\
$t_{3}$ & 0.00212 & 0.00269 & -0.00135 & 0.00466 \\
& $(0.00206)$ & $(0.00654)$ & $(0.0224)$ & $(0.0412)$ \\
$t_{4}$ & 0.00227 & 0.00244 & -0.00170 & -0.0544 \\
& $(0.00253)$ & $(0.00857)$ & $(0.0233)$ & $(0.0409)$ \\
\hline
\end{tabular}

\begin{tabular}{lcccc} 
& \multicolumn{2}{c}{ Initiation } & \multicolumn{2}{c}{ Cessation } \\
High enforced & Adults & Youth & Adults & Youth \\
\hline \multirow{2}{*}{$t_{-2}$} & $9.37 \mathrm{e}-05$ & -0.00564 & -0.00319 & -0.0108 \\
& $(0.00187)$ & $(0.00411)$ & $(0.0133)$ & $(0.0238)$ \\
$t_{-1}$ & 0.000293 & -0.00374 & -0.00213 & -0.00797 \\
& $(0.00114)$ & $(0.00368)$ & $(0.00758)$ & $(0.0243)$ \\
$t_{1}$ & 0.00193 & 0.00428 & $-0.0105^{* *}$ & 0.000796 \\
& $(0.00114)$ & $(0.00410)$ & $(0.00475)$ & $(0.0130)$ \\
$t_{2}$ & 0.000950 & 0.00101 & -0.00966 & $0.0419^{*}$ \\
& $(0.000765)$ & $(0.00468)$ & $(0.00586)$ & $(0.0227)$ \\
$t_{3}$ & -0.000608 & $-0.00985^{* * *}$ & -0.00488 & 0.0208 \\
& $(0.000874)$ & $(0.00293)$ & $(0.0156)$ & $(0.0373)$ \\
$t_{4}$ & -0.00118 & $-0.0123^{* * *}$ & -0.0164 & -0.00613 \\
& $(0.000717)$ & $(0.00422)$ & $(0.0109)$ & $(0.0356)$ \\
\hline \multirow{2}{*}{ Constant } & $-0.0702^{*}$ & $-0.235^{* *}$ & $1.754^{* * *}$ & 0.643 \\
\multirow{2}{*}{ Observations } & $(0.0361)$ & $(0.105)$ & $(0.239)$ & $(0.557)$ \\
Individuals & 110,478 & 41,703 & 20,953 & 4,321 \\
\hline
\end{tabular}

Note: Cluster Robust Standard Errors in parentheses. For inference: *** significant at $1 \%,{ }^{* *}$ significant at $5 \%,{ }^{*}$ significant at 10\%. Estimations only for 2009 treated. Porto Velho/RO, Maceió/AL, Cuiabá/MT and Teresina/PI were dropped. Models include individual and year FE and cluster at capital level. Models (1) and (3) were estimated to individuals from 18 to 64 years old and models (2) and (4), from 15 to 29 years old. The covariates included in all models are age and age squared. 



\section{APPENDIX F - Robustness}

\section{F.1 Including all unities: 2008, 2009, 2010 and 2011 treated}

Table 18 - Smoking Bans impacts on smoking prevalence over time: all treated

\begin{tabular}{lcccccc} 
& \multicolumn{2}{c}{ Average } & \multicolumn{2}{c}{ Low enforcement } & \multicolumn{2}{c}{ High enforcement } \\
& Adults & Youths & Adults & Youths & Adults & Youths \\
\hline \multirow{4}{*}{$t_{-2}$} & -0.000157 & $-0.00562^{*}$ & -0.000359 & $-0.00883^{* *}$ & -0.000233 & -0.00480 \\
& $(0.00188)$ & $(0.00321)$ & $(0.00234)$ & $(0.00345)$ & $(0.00217)$ & $(0.00353)$ \\
$t_{-1}$ & 0.000241 & -0.000446 & 0.000883 & 0.00465 & 0.000428 & -0.00166 \\
& $(0.00124)$ & $(0.00333)$ & $(0.00187)$ & $(0.00384)$ & $(0.00141)$ & $(0.00379)$ \\
$t_{1}$ & 0.000529 & 0.00218 & 0.00166 & 0.00397 & 0.000497 & 0.00195 \\
& $(0.00141)$ & $(0.00330)$ & $(0.00128)$ & $(0.00311)$ & $(0.00180)$ & $(0.00383)$ \\
$t_{2}$ & $-1.08 \mathrm{e}-06$ & 0.00206 & 0.00340 & 0.00472 & -0.000495 & 0.00147 \\
& $(0.00168)$ & $(0.00375)$ & $(0.00314)$ & $(0.00702)$ & $(0.00187)$ & $(0.00417)$ \\
$t_{3}$ & -0.00109 & $-0.00485^{*}$ & 0.00526 & 0.00679 & -0.00203 & $-0.00759^{* * *}$ \\
& $(0.00235)$ & $(0.00264)$ & $(0.00426)$ & $(0.00601)$ & $(0.00236)$ & $(0.00236)$ \\
$t_{4}$ & -0.00339 & $-0.00804^{* *}$ & 0.00696 & 0.00654 & $-0.00515^{*}$ & $-0.0119^{* * *}$ \\
& $(0.00313)$ & $(0.00341)$ & $(0.00421)$ & $(0.00761)$ & $(0.00292)$ & $(0.00282)$ \\
Const. & $0.153^{* * *}$ & $-0.228^{* *}$ & $0.164^{* * *}$ & $-0.230^{*}$ & $0.164^{* * *}$ & $-0.230^{*}$ \\
& $(0.0361)$ & $(0.110)$ & $(0.0342)$ & $(0.114)$ & $(0.0342)$ & $(0.114)$ \\
\hline Obs. & 149,331 & 52,267 & 144,461 & 50,187 & 144,461 & 50,187 \\
Ind. & 23,308 & 9,764 & 22,551 & 9,375 & 22,551 & 9,375 \\
\hline
\end{tabular}

Note: Cluster Robust Standard Errors in parentheses. For inference: ${ }^{* * *}$ significant at $1 \%,{ }^{* *}$ significant at $5 \%, *$ significant at $10 \%$. Estimations included all treated. Porto Velho/RO was dropped on enforcement models. Models include individual and year FE and cluster at capital level. Models (1), (3) and (5) were estimated to individuals from 18 to 64 years old and models (2), (4) and (6), from 15 to 29 years old. The covariates included in all models are age and age squared. 
Table 19 - Smoking Bans impacts on smoking initiation over time: all treated

\begin{tabular}{lcccccc} 
& \multicolumn{2}{c}{ Average } & \multicolumn{2}{c}{ Low enforcement } & \multicolumn{2}{c}{ High enforcement } \\
& Adults & Youths & Adults & Youths & Adults & Youths \\
\hline \multirow{4}{*}{$t_{-2}$} & -0.000730 & $-0.00472^{*}$ & -0.000409 & -0.00384 & -0.000791 & $-0.00513^{*}$ \\
& $(0.00114)$ & $(0.00251)$ & $(0.00167)$ & $(0.00319)$ & $(0.00119)$ & $(0.00266)$ \\
$t_{-1}$ & $-6.30 \mathrm{e}-05$ & -0.000167 & $0.00219^{* *}$ & $0.00759^{*}$ & -0.000614 & -0.00258 \\
& $(0.000707)$ & $(0.00323)$ & $(0.00102)$ & $(0.00403)$ & $(0.000743)$ & $(0.00311)$ \\
$t_{1}$ & 0.000433 & 0.00125 & -0.000908 & 0.00230 & 0.000935 & 0.00131 \\
& $(0.000927)$ & $(0.00307)$ & $(0.00124)$ & $(0.00281)$ & $(0.000987)$ & $(0.00374)$ \\
$t_{2}$ & $7.17 \mathrm{e}-05$ & $1.39 \mathrm{e}-05$ & 0.000419 & 0.00373 & $6.93 \mathrm{e}-05$ & -0.00127 \\
& $(0.000866)$ & $(0.00363)$ & $(0.00202)$ & $(0.00557)$ & $(0.000838)$ & $(0.00461)$ \\
$t_{3}$ & -0.000728 & $-0.00664^{* *}$ & 0.000720 & 0.00378 & -0.00103 & $-0.00942^{* * *}$ \\
& $(0.000864)$ & $(0.00275)$ & $(0.00217)$ & $(0.00652)$ & $(0.000899)$ & $(0.00302)$ \\
$t_{4}$ & -0.00117 & $-0.00866^{* *}$ & 0.000870 & 0.00319 & $-0.00162^{* *}$ & $-0.0123^{* *}$ \\
& $(0.000817)$ & $(0.00402)$ & $(0.00258)$ & $(0.00878)$ & $(0.000769)$ & $(0.00449)$ \\
Const. & $-0.0662^{* *}$ & $-0.217^{* *}$ & $-0.0675^{* *}$ & $-0.222^{* *}$ & $-0.0675^{* *}$ & $-0.222^{* *}$ \\
& $(0.0259)$ & $(0.0886)$ & $(0.0263)$ & $(0.0917)$ & $(0.0263)$ & $(0.0917)$ \\
\hline Obs. & 126,052 & 47,567 & 121,678 & 45,577 & 121,678 & 45,577 \\
Ind. & 19,872 & 8,815 & 19,187 & 8,444 & 19,187 & 8,444 \\
\hline
\end{tabular}

Note: Cluster Robust Standard Errors in parentheses. For inference: ${ }^{* * *}$ significant at $1 \%,{ }^{* *}$ significant at $5 \%$, * significant at 10\%. Estimations included all treated. Porto Velho/RO was dropped on enforcement models. Models include individual and year FE and cluster at capital level. Models (1), (3) and (5) were estimated to individuals from 18 to 64 years old and models (2), (4) and (6), from 15 to 29 years old. The covariates included in all models are age and age squared.

Table 20 - Smoking Bans impacts on smoking cessation over time: all treated

\begin{tabular}{lcccccc} 
& \multicolumn{2}{c}{ Average } & \multicolumn{2}{c}{ Low enforcement } & \multicolumn{2}{c}{ High enforcement } \\
& Adults & Youths & Adults & Youths & Adults & Youths \\
\hline \multirow{4}{*}{$t_{-2}$} & 0.000984 & -0.0183 & 0.0110 & $-0.0527^{* * *}$ & -0.00206 & -0.0111 \\
& $(0.00914)$ & $(0.0180)$ & $(0.00998)$ & $(0.0178)$ & $(0.0103)$ & $(0.0174)$ \\
$t_{-1}$ & -0.000168 & -0.00669 & -0.00440 & $-0.0324^{*}$ & 0.000499 & -0.00128 \\
& $(0.00535)$ & $(0.0165)$ & $(0.0132)$ & $(0.0188)$ & $(0.00608)$ & $(0.0167)$ \\
$t_{1}$ & -0.00216 & 0.00949 & 0.00469 & 0.00193 & -0.00450 & 0.00847 \\
& $(0.00507)$ & $(0.0159)$ & $(0.00492)$ & $(0.0223)$ & $(0.00584)$ & $(0.0156)$ \\
$t_{2}$ & -0.00392 & 0.0249 & -0.00122 & -0.0374 & -0.00449 & 0.0368 \\
& $(0.00571)$ & $(0.0262)$ & $(0.0159)$ & $(0.0621)$ & $(0.00611)$ & $(0.0216)$ \\
$t_{3}$ & -0.00336 & 0.0194 & -0.00641 & -0.0153 & -0.00382 & 0.0234 \\
& $(0.0129)$ & $(0.0323)$ & $(0.0220)$ & $(0.0448)$ & $(0.0141)$ & $(0.0349)$ \\
$t_{4}$ & -0.0142 & -0.00748 & -0.00664 & -0.0688 & -0.0153 & 0.000287 \\
\multirow{4}{*}{ Constant } & $(0.0111)$ & $(0.0333)$ & $(0.0243)$ & $(0.0435)$ & $(0.0114)$ & $(0.0364)$ \\
& $1.753^{* * *}$ & 0.845 & $1.791^{* * *}$ & 0.824 & $1.791^{* * *}$ & 0.824 \\
& $(0.206)$ & $(0.555)$ & $(0.204)$ & $(0.558)$ & $(0.204)$ & $(0.558)$ \\
\hline Obs. & 23,279 & 4,700 & 22,783 & 4,610 & 22,783 & 4,610 \\
Ind. & 3,436 & 949 & 3,364 & 931 & 3,364 & 931 \\
\hline
\end{tabular}

Note: Cluster Robust Standard Errors in parentheses. For inference: ${ }^{* * *}$ significant at $1 \%,{ }^{* *}$ significant at $5 \%, *$ significant at 10\%. Estimations included all treated. Porto Velho/RO was dropped on enforcement models. Models include individual and year FE and cluster at capital level. Models (1), (3) and (5) were estimated to individuals from 18 to 64 years old and models (2), (4) and (6), from 15 to 29 years old. The covariates included in all models are age and age squared. 


\section{F.2 Changing the month threshold of smoking quitting time}

\section{F.2.1 3 months threshold}

Table 21 - Smoking Bans impacts on smoking prevalence over time: 3 months threshold

\begin{tabular}{lcccccc} 
& \multicolumn{2}{c}{ Average } & \multicolumn{2}{c}{ Low enforcement } & \multicolumn{2}{c}{ High enforcement } \\
& Adults & Youths & Adults & Youths & Adults & Youths \\
\hline$S B_{-2}$ & 0.000211 & -0.00570 & 0.000761 & -0.00911 & $9.93 \mathrm{e}-05$ & -0.00497 \\
& $(0.00295)$ & $(0.00474)$ & $(0.00310)$ & $(0.00566)$ & $(0.00308)$ & $(0.00482)$ \\
$S B_{-1}$ & 0.000237 & -0.00303 & 0.00223 & -0.000513 & -0.000149 & -0.00361 \\
& $(0.00213)$ & $(0.00412)$ & $(0.00205)$ & $(0.00352)$ & $(0.00228)$ & $(0.00452)$ \\
$S B_{1}$ & -0.00107 & 0.000769 & $0.00235^{* *}$ & 0.00577 & -0.00172 & -0.000350 \\
& $(0.00169)$ & $(0.00346)$ & $(0.00107)$ & $(0.00367)$ & $(0.00173)$ & $(0.00350)$ \\
$S B_{2}$ & -0.000498 & 0.00119 & 0.00475 & 0.00905 & -0.00150 & -0.000592 \\
& $(0.00245)$ & $(0.00351)$ & $(0.00337)$ & $(0.00720)$ & $(0.00239)$ & $(0.00351)$ \\
$S B_{3}$ & -0.00159 & $-0.00540^{*}$ & $0.00813^{*}$ & 0.00729 & -0.00346 & $-0.00833^{* * *}$ \\
& $(0.00277)$ & $(0.00310)$ & $(0.00441)$ & $(0.00622)$ & $(0.00231)$ & $(0.00260)$ \\
$S B_{4}$ & -0.000587 & -0.00670 & $0.00977^{* *}$ & 0.00650 & -0.00259 & $-0.00979^{* *}$ \\
& $(0.00353)$ & $(0.00398)$ & $(0.00410)$ & $(0.00650)$ & $(0.00329)$ & $(0.00371)$ \\
Const. & $0.158^{* * *}$ & $-0.254^{*}$ & $0.160^{* * *}$ & $-0.253^{*}$ & $0.160^{* * *}$ & $-0.253^{*}$ \\
& $(0.0452)$ & $(0.128)$ & $(0.0453)$ & $(0.128)$ & $(0.0453)$ & $(0.128)$ \\
\hline Obs. & 131,417 & 46,012 & 131,417 & 46,012 & 131,417 & 46,012 \\
Ind. & 20,515 & 8,594 & 20,515 & 8,594 & 20,515 & 8,594 \\
\hline
\end{tabular}

Note: Cluster Robust Standard Errors in parentheses. For inference: ${ }^{* * *}$ significant at $1 \%,{ }^{* *}$ significant at $5 \%, *$ significant at 10\%. Estimations included only 2009 treated. Models include individual and year specific effects and cluster at capital level. Models (1), (3) and (5) were estimated to individuals from 18 to 64 years old; and models (2), (4) and (6), from 15 to 29 years old. The covariates included in all models are age and age squared. 
Table 22 - Smoking Bans impacts on smoking initiation over time: 3 months threshold

\begin{tabular}{lcccccc} 
& \multicolumn{2}{c}{ Average } & \multicolumn{2}{c}{ Low enforcement } & \multicolumn{2}{c}{ High enforcement } \\
& Adults & Youths & Adults & Youths & Adults & Youths \\
\hline$S B_{-2}$ & 0.000326 & -0.00532 & 0.00192 & -0.00409 & $-7.79 \mathrm{e}-08$ & -0.00561 \\
& $(0.00192)$ & $(0.00411)$ & $(0.00197)$ & $(0.00521)$ & $(0.00192)$ & $(0.00414)$ \\
$S B_{-1}$ & 0.000945 & -0.00243 & $0.00399^{* * *}$ & 0.00265 & 0.000325 & -0.00363 \\
& $(0.00125)$ & $(0.00323)$ & $(0.00115)$ & $(0.00247)$ & $(0.00122)$ & $(0.00362)$ \\
$S B_{1}$ & 0.000774 & 0.00202 & 0.000975 & 0.00431 & 0.000737 & 0.00147 \\
& $(0.00101)$ & $(0.00350)$ & $(0.00109)$ & $(0.00356)$ & $(0.00113)$ & $(0.00378)$ \\
$S B_{2}$ & 0.00107 & 0.000325 & 0.00262 & 0.00596 & 0.000756 & -0.00101 \\
& $(0.000647)$ & $(0.00396)$ & $(0.00180)$ & $(0.00633)$ & $(0.000593)$ & $(0.00437)$ \\
$S B_{3}$ & -0.000177 & $-0.00813^{* *}$ & 0.00245 & 0.00266 & -0.000719 & $-0.0107^{* * *}$ \\
& $(0.000825)$ & $(0.00298)$ & $(0.00238)$ & $(0.00654)$ & $(0.000739)$ & $(0.00291)$ \\
$S B_{4}$ & -0.000405 & $-0.00953^{* *}$ & 0.00136 & -0.000998 & -0.000766 & $-0.0116^{* *}$ \\
& $(0.000768)$ & $(0.00382)$ & $(0.00229)$ & $(0.00713)$ & $(0.000739)$ & $(0.00429)$ \\
Const. & $-0.0707^{*}$ & $-0.221^{* *}$ & $-0.0706^{*}$ & $-0.220^{* *}$ & $-0.0706^{*}$ & $-0.220^{* *}$ \\
& $(0.0361)$ & $(0.106)$ & $(0.0361)$ & $(0.106)$ & $(0.0361)$ & $(0.106)$ \\
\hline Obs. & 110,489 & 41,691 & 110,489 & 41,691 & 110,489 & 41,691 \\
Ind. & 17,426 & 7,723 & 17,426 & 7,723 & 17,426 & 7,723 \\
\hline
\end{tabular}

Note: Cluster Robust Standard Errors in parentheses. For inference: *** significant at 1\%, ** significant at $5 \%, *$ significant at $10 \%$. Estimations included only 2009 treated. Models include individual and year specific effects and cluster at capital level. Models (1), (3) and (5) were estimated to individuals from 18 to 64 years old; and models (2), (4) and (6), from 15 to 29 years old. The covariates included in all models are age and age squared.

Table 23 - Smoking Bans impacts on smoking cessation over time: 3 months threshold

\begin{tabular}{ccccccc} 
& \multicolumn{2}{c}{ Average } & \multicolumn{2}{c}{ Low enforcement } & \multicolumn{2}{c}{ High enforcement } \\
& Adults & Youths & Adults & Youths & Adults & Youths \\
\hline$S B_{-2}$ & 0.000244 & -0.00883 & 0.0122 & -0.0367 & -0.00140 & -0.00511 \\
& $(0.0129)$ & $(0.0227)$ & $(0.0125)$ & $(0.0235)$ & $(0.0131)$ & $(0.0229)$ \\
$S B_{-1}$ & -0.00372 & -0.00787 & 0.00253 & -0.0204 & -0.00456 & -0.00614 \\
& $(0.00749)$ & $(0.0239)$ & $(0.0129)$ & $(0.0248)$ & $(0.00768)$ & $(0.0239)$ \\
$S B_{1}$ & $-0.0105^{* *}$ & -0.00691 & 0.00599 & 0.0195 & $-0.0127^{* * *}$ & -0.00996 \\
& $(0.00471)$ & $(0.0146)$ & $(0.00384)$ & $(0.0136)$ & $(0.00425)$ & $(0.0153)$ \\
$S B_{2}$ & -0.00861 & 0.0188 & -0.00197 & 0.0135 & -0.00951 & 0.0197 \\
& $(0.00779)$ & $(0.0222)$ & $(0.0173)$ & $(0.0436)$ & $(0.00765)$ & $(0.0225)$ \\
$S B_{3}$ & -0.00912 & 0.0333 & 0.00662 & 0.0146 & -0.0112 & 0.0360 \\
& $(0.0110)$ & $(0.0327)$ & $(0.0218)$ & $(0.0410)$ & $(0.0116)$ & $(0.0355)$ \\
$S B_{4}$ & -0.00160 & 0.0229 & 0.00786 & -0.00516 & -0.00288 & 0.0262 \\
& $(0.0124)$ & $(0.0406)$ & $(0.0252)$ & $(0.0499)$ & $(0.0123)$ & $(0.0415)$ \\
Const. & $1.792^{* * *}$ & 0.746 & $1.792^{* * *}$ & 0.741 & $1.792^{* * *}$ & 0.741 \\
& $(0.248)$ & $(0.672)$ & $(0.248)$ & $(0.677)$ & $(0.248)$ & $(0.677)$ \\
& $(0.0361)$ & $(0.106)$ & $(0.0361)$ & $(0.106)$ & $(0.0361)$ & $(0.106)$ \\
\hline Obs. & 20,928 & 4,321 & 20,928 & 4,321 & 20,928 & 4,321 \\
Ind. & 3,089 & 871 & 3,089 & 871 & 3,089 & 871 \\
\hline
\end{tabular}

Note: Cluster Robust Standard Errors in parentheses. For inference: ${ }^{* * *}$ significant at $1 \%$, ** significant at 5\%,* significant at 10\%. Estimations included only 2009 treated. Models include individual and year specific effects and cluster at capital level. Models (1), (3) and (5) were estimated to individuals from 18 to 64 years old; and models (2), (4) and (6), from 15 to 29 years old. The covariates included in all models are age and age squared. 


\section{F.2.2 9 months threshold}

Table 24 - Smoking Bans impacts on smoking prevalence over time: 9 months threshold

\begin{tabular}{lcccccc} 
& \multicolumn{2}{c}{ Average } & \multicolumn{2}{c}{ Low enforcement } & \multicolumn{2}{c}{ High enforcement } \\
& Adults & Youths & Adults & Youths & Adults & Youths \\
\hline \multirow{3}{*}{$S B_{-2}$} & 0.000110 & -0.00599 & 0.000697 & -0.00801 & $-7.39 \mathrm{e}-06$ & -0.00556 \\
& $(0.00286)$ & $(0.00494)$ & $(0.00302)$ & $(0.00555)$ & $(0.00299)$ & $(0.00511)$ \\
$S B_{-1}$ & 0.00118 & -0.00317 & $0.00421^{* *}$ & -0.000100 & 0.000590 & -0.00388 \\
& $(0.00200)$ & $(0.00430)$ & $(0.00203)$ & $(0.00345)$ & $(0.00207)$ & $(0.00477)$ \\
$S B_{1}$ & 0.000273 & 0.00310 & $0.00233^{* *}$ & 0.00487 & -0.000113 & 0.00271 \\
& $(0.00154)$ & $(0.00391)$ & $(0.00103)$ & $(0.00375)$ & $(0.00168)$ & $(0.00424)$ \\
$S B_{2}$ & -0.000173 & 0.00416 & 0.00445 & 0.00882 & -0.00106 & 0.00311 \\
& $(0.00184)$ & $(0.00359)$ & $(0.00356)$ & $(0.00722)$ & $(0.00170)$ & $(0.00393)$ \\
$S B_{3}$ & -0.00266 & $-0.00629^{* *}$ & 0.00502 & 0.00592 & -0.00414 & $-0.00912^{* * *}$ \\
& $(0.00274)$ & $(0.00297)$ & $(0.00407)$ & $(0.00617)$ & $(0.00260)$ & $(0.00272)$ \\
$S B_{4}$ & -0.00142 & $-0.00768^{* *}$ & $0.00807^{*}$ & 0.00634 & -0.00326 & $-0.0110^{* * *}$ \\
& $(0.00288)$ & $(0.00302)$ & $(0.00405)$ & $(0.00704)$ & $(0.00251)$ & $(0.00225)$ \\
Const. & $0.154^{* * *}$ & $-0.253^{*}$ & $0.155^{* * *}$ & $-0.252^{*}$ & $0.155^{* * *}$ & $-0.252^{*}$ \\
& $(0.0401)$ & $(0.125)$ & $(0.0402)$ & $(0.125)$ & $(0.0402)$ & $(0.125)$ \\
\hline Obs. & 131,440 & 46,029 & 131,440 & 46,029 & 131,440 & 46,029 \\
Ind. & 20,520 & 8,597 & 20,520 & 8,597 & 20,520 & 8,597 \\
\hline
\end{tabular}

Note: Cluster Robust Standard Errors in parentheses. For inference: ${ }^{* * *}$ significant at $1 \%,{ }^{* *}$ significant at $5 \%, *$ significant at $10 \%$. Estimations included only 2009 treated. Models include individual and year specific effects and cluster at capital level. Models (1), (3) and (5) were estimated to individuals from 18 to 64 years old; and models (2), (4) and (6), from 15 to 29 years old. The covariates included in all models are age and age squared. 
Table 25 - Smoking Bans impacts on smoking initiation over time: 9 months threshold

\begin{tabular}{lcccccc} 
& \multicolumn{2}{c}{ Average } & \multicolumn{2}{c}{ Low enforcement } & \multicolumn{2}{c}{ High enforcement } \\
& Adults & Youths & Adults & Youths & Adults & Youths \\
\hline \multirow{3}{*}{$S B_{-2}$} & 0.000431 & -0.00532 & 0.00198 & -0.00384 & 0.000115 & -0.00567 \\
& $(0.00188)$ & $(0.00409)$ & $(0.00197)$ & $(0.00505)$ & $(0.00188)$ & $(0.00411)$ \\
$S B_{-1}$ & 0.000945 & -0.00245 & $0.00405^{* * *}$ & 0.00295 & 0.000313 & -0.00372 \\
& $(0.00119)$ & $(0.00326)$ & $(0.00115)$ & $(0.00235)$ & $(0.00115)$ & $(0.00367)$ \\
$S B_{1}$ & $0.00175^{*}$ & 0.00414 & 0.00101 & 0.00425 & 0.00190 & 0.00411 \\
& $(0.00102)$ & $(0.00373)$ & $(0.00109)$ & $(0.00357)$ & $(0.00114)$ & $(0.00413)$ \\
$S B_{2}$ & $0.00128^{*}$ & 0.00187 & 0.00273 & 0.00598 & 0.000990 & 0.000896 \\
& $(0.000745)$ & $(0.00416)$ & $(0.00180)$ & $(0.00634)$ & $(0.000758)$ & $(0.00473)$ \\
$S B_{3}$ & -0.000237 & $-0.00783^{* *}$ & 0.00204 & 0.00237 & -0.000706 & $-0.0103^{* * *}$ \\
& $(0.000836)$ & $(0.00294)$ & $(0.00206)$ & $(0.00657)$ & $(0.000872)$ & $(0.00306)$ \\
$S B_{4}$ & -0.000451 & $-0.00871^{* *}$ & 0.00253 & 0.00303 & -0.00107 & $-0.0116^{* * *}$ \\
& $(0.000799)$ & $(0.00380)$ & $(0.00240)$ & $(0.00819)$ & $(0.000682)$ & $(0.00389)$ \\
Const. & $-0.0710^{*}$ & $-0.237^{* *}$ & $-0.0709^{*}$ & $-0.237^{* *}$ & $-0.0709^{*}$ & $-0.237^{* *}$ \\
& $(0.0361)$ & $(0.104)$ & $(0.0361)$ & $(0.104)$ & $(0.0361)$ & $(0.104)$ \\
\hline Obs. & 110,460 & 41,708 & 110,460 & 41,708 & 110,460 & 41,708 \\
Ind. & 17,423 & 7,726 & 17,423 & 7,726 & 17,423 & 7,726 \\
\hline
\end{tabular}

Note: Cluster Robust Standard Errors in parentheses. For inference: ${ }^{* * *}$ significant at $1 \%,{ }^{* *}$ significant at 5\%,* significant at 10\%. Estimations included only 2009 treated. Models include individual and year specific effects and cluster at capital level. Models (1), (3) and (5) were estimated to individuals from 18 to 64 years old; and models (2), (4) and (6), from 15 to 29 years old. The covariates included in all models are age and age squared.

Table 26 - Smoking Bans impacts on smoking cessation over time: 9 months threshold

\begin{tabular}{lcccccc} 
& \multicolumn{2}{c}{ Average } & \multicolumn{2}{c}{ Low enforcement } & \multicolumn{2}{c}{ High enforcement } \\
& Adults & Youths & Adults & Youths & Adults & Youths \\
\hline \multirow{2}{*}{$S B_{-2}$} & -0.000801 & -0.0118 & 0.0109 & -0.0271 & -0.00240 & -0.00973 \\
& $(0.0123)$ & $(0.0235)$ & $(0.0117)$ & $(0.0272)$ & $(0.0125)$ & $(0.0238)$ \\
$S B_{-1}$ & 0.00194 & -0.00936 & $0.0175^{*}$ & -0.0198 & -0.000181 & -0.00791 \\
& $(0.00735)$ & $(0.0241)$ & $(0.00853)$ & $(0.0249)$ & $(0.00721)$ & $(0.0242)$ \\
$S B_{1}$ & -0.00726 & -0.00285 & 0.00612 & 0.00931 & $-0.00908^{*}$ & -0.00422 \\
& $(0.00480)$ & $(0.0145)$ & $(0.00412)$ & $(0.0148)$ & $(0.00447)$ & $(0.0144)$ \\
$S B_{2}$ & -0.00762 & 0.0383 & -0.00179 & 0.0140 & -0.00841 & $0.0415^{*}$ \\
& $(0.00595)$ & $(0.0229)$ & $(0.0196)$ & $(0.0442)$ & $(0.00559)$ & $(0.0226)$ \\
$S B_{3}$ & -0.0156 & 0.0175 & -0.00968 & 0.00141 & -0.0164 & 0.0197 \\
& $(0.0146)$ & $(0.0341)$ & $(0.0206)$ & $(0.0409)$ & $(0.0157)$ & $(0.0373)$ \\
$S B_{4}$ & -0.00667 & -0.00151 & -0.00572 & -0.0640 & -0.00686 & 0.00554 \\
& $(0.0122)$ & $(0.0389)$ & $(0.0244)$ & $(0.0396)$ & $(0.0125)$ & $(0.0407)$ \\
Const. & $1.715^{* * *}$ & 0.717 & $1.714^{* * *}$ & 0.714 & $1.714^{* * *}$ & 0.714 \\
& $(0.222)$ & $(0.563)$ & $(0.223)$ & $(0.565)$ & $(0.223)$ & $(0.565)$ \\
\hline Obs. & 20,980 & 4,321 & 20,980 & 4,321 & 20,980 & 4,321 \\
Ind. & 3,097 & 871 & 3,097 & 871 & 3,097 & 871 \\
\hline
\end{tabular}

Note: Cluster Robust Standard Errors in parentheses. For inference: ${ }^{* * *}$ significant at $1 \%,{ }^{* *}$ significant at $5 \%, *$ significant at $10 \%$. Estimations included only 2009 treated. Models include individual and year specific effects and cluster at capital level. Models (1), (3) and (5) were estimated to individuals from 18 to 64 years old; and models (2), (4) and (6), from 15 to 29 years old. The covariates included in all models are age and age squared. 


\section{F.3 Wild Cluster Bootstrap}

We have used Cluster Robust Variance Estimator (CRVE) in the analysis of significance of the coefficients. However, as the number of clusters is small (overall, 23 in total and 15 in the treatment group) and the number of individuals in each cluster is not balanced, we verify the significance of ours estimations by Wild Cluster Bootstrap (BERTRAND; DUFLO; MULLAINATHAN, 2004; CAMERON; MILLER, 2015; MACKINNON; WEBB, 2016).

One limitation in using Wild Cluster Bootstrap is that it does not estimate the same coefficients as diff-in-diff with fixed effects and CRVE when the panel is not balanced at the individual level ${ }^{1}$. In order to check if our inference is robust to Wild Cluster Bootstrap, we have estimated Equation (I) considering both balanced and unbalanced panel. The coefficients are shown in Table 27.

The coefficients for balanced panel are the same in both situations, but slightly different from our main estimations due to sample restrictions. Columns CRVE and Wild show the p-value considering both robustness for the variance and we can see that the p-values are very similar. For the unbalanced panel, the coefficients for CRVE and Wild Cluster Bootstrap are a bit different, but the p-values are also similar. These results do not show evidence of underestimation of the standard errors in our evaluations.

It is worth mentioning, however, that we could not check the sensibility of the standard errors estimation to young individuals. The reason is that, when limiting the age range to 15 to 29 years old, we have lost half of the observations.

Table 27 - Coefficient and respective p-values for Cluster Robust Standard Deviation (CRVE) and Wild Cluster Bootstrap

\begin{tabular}{l|ccc|cccc} 
& \multicolumn{3}{|c|}{ Balanced Panel } & \multicolumn{4}{c}{ Unbalanced Panel } \\
Variables & Coefficient & CRVE p-value & Wild p-value & Coefficient CRVE & p-value & Coefficient Wild & p-value \\
\hline$t_{-2}$ & 0.0008525 & 0.736 & 0.722 & 0.0001950 & 0.948 & 0.00027225 & 0.952 \\
$t_{-1}$ & 0.0000906 & 0.967 & 0.907 & 0.0006646 & 0.738 & 0.00072183 & 0.782 \\
$t_{1}$ & -0.0002619 & 0.869 & 0.967 & 0.0000297 & 0.986 & -0.00009101 & 0.957 \\
$t_{2}$ & -0.0005434 & 0.762 & 0.817 & -0.0004701 & 0.810 & -0.0003323 & 0.902 \\
$t_{3}$ & -0.0000939 & 0.976 & 1 & -0.0009633 & 0.742 & -0.00096761 & 0.682 \\
$t_{4}$ & -0.0016065 & 0.620 & 0.677 & -0.0029305 & 0.406 & -0.00385296 & 0.351 \\
Const. & 0.0118268 & $0.000^{* * *}$ & $0.000^{* * *}$ & 0.0142023 & $0.000^{* * *}$ & 0.01279153 & $0.000^{* * *}$ \\
\hline Obs. & \multicolumn{3}{|c}{131,431} \\
Ind. & & 118,363 & & & 20,518 & \\
\hline
\end{tabular}

Note: Estimations include only 2009 treated and individuals from 18 to 64 years old. Models include individual and year fixed effects and cluster at capital level. No covariates were included.

\footnotetext{
${ }^{1}$ The panel used is our regressions is not balance, since we have restricted the adults' models to individuals from 18 to 64 years old and, to youths, from 15 to 29 years old in each period.
} 



\section{APPENDIX G - Price and Other Policies Analysis}
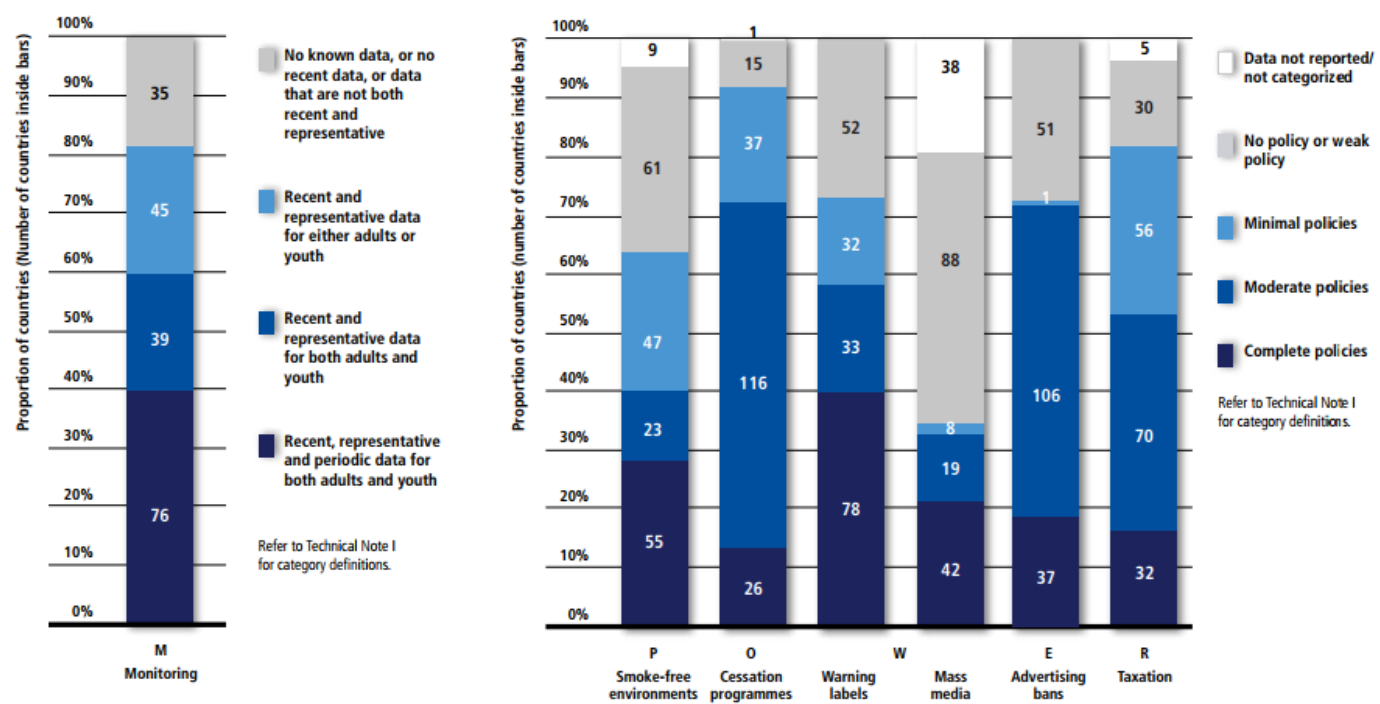

Figure 42 - The state of selected tobacco control policies in the world in 2016 Source: WHO (2017b).

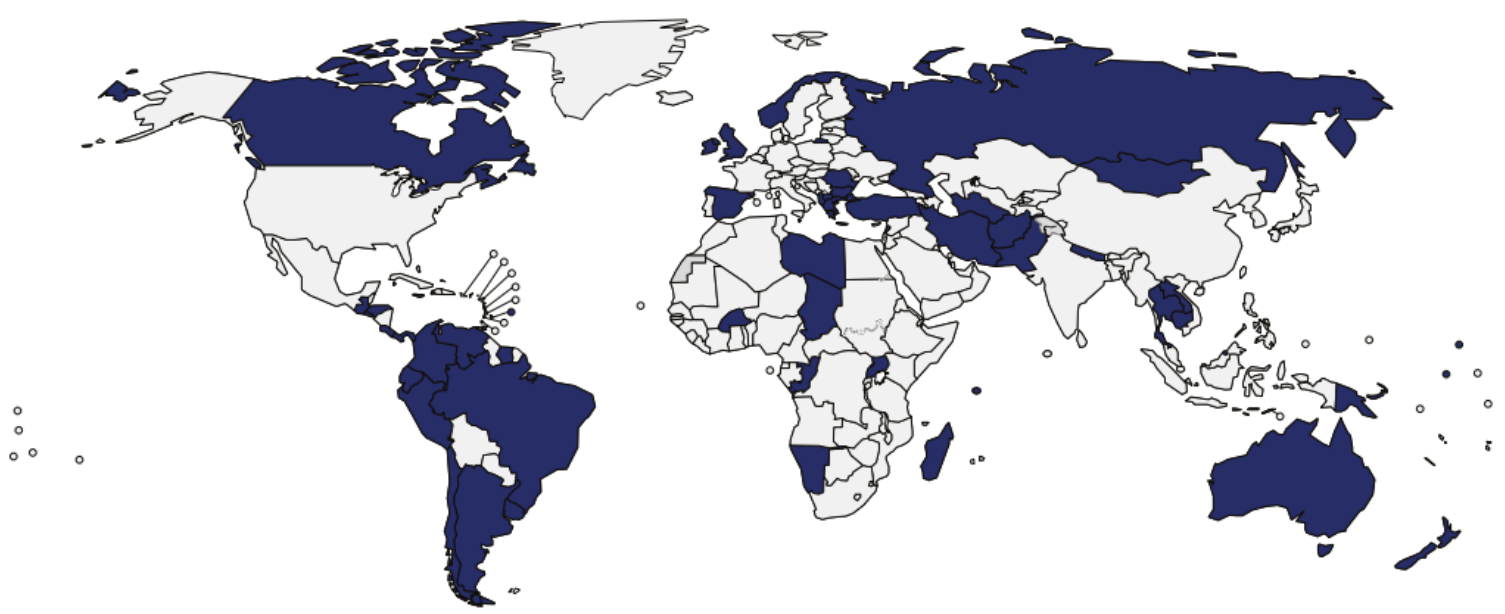

Figure 43 - Smoke-free environments - highest achieving countries and territories in 2016

Source: WHO (2017b). The highest level of achievement refers to "all public places completely smoke-free or at least $90 \%$ of the population covered by complete subnational smoke-free legislation" (WHO, 2017b, p.65). 
Table 28 - Statistics on Cigarette Prices (box with 20 cigarettes)

\begin{tabular}{c|cccc|cccc|ccc|ccccc} 
& \multicolumn{4}{|c|}{ Control } & \multicolumn{4}{c|}{ All treated } & \multicolumn{4}{c}{ 2009 Treated High enforced } \\
Year & Mean & SD & Max. & Min. & Mean & SD & Max. & Min. & Mean & SD & Max. & Min. & Mean & SD & Max. & Min. \\
\hline 2010 & 3.75 & 0 & 3.75 & 3.75 & 3.78 & 0.085 & 4 & 3.75 & 3.77 & 0.07 & 4 & 3.75 & 3.79 & 0.10 & 4 & 3.75 \\
2011 & 4 & 0 & 4 & 4 & 4.02 & 0.066 & 4.25 & 4 & 4 & 0.029 & 4.1 & 4 & 4.02 & 0.041 & 4.1 & 4 \\
2012 & 5.5 & 0 & 5.5 & 5.5 & 5.58 & 0.176 & 6 & 5.5 & 5.56 & 0.16 & 6 & 5.5 & 5.54 & 0.10 & 5.75 & 5.5 \\
2013 & 6.25 & 0 & 6.25 & 6.25 & 6.39 & 0.22 & 6.75 & 6.25 & 6.35 & 0.2 & 6.75 & 6.25 & 6.29 & 0.10 & 6.5 & 6.25 \\
\hline
\end{tabular}

Note: Prices for the box with 20 cigarettes of the brand Free. Mean, Standard Deviation (SD), Maximum Price and Minimum Price for 2010 to 2013, for Control and Treatment groups. Prepared by the authors based on data from the Federal Revenue Service.

Graph 44 - Evolution of cigarette box's prices from 2010 to 2013 in Control and All Treatment Groups

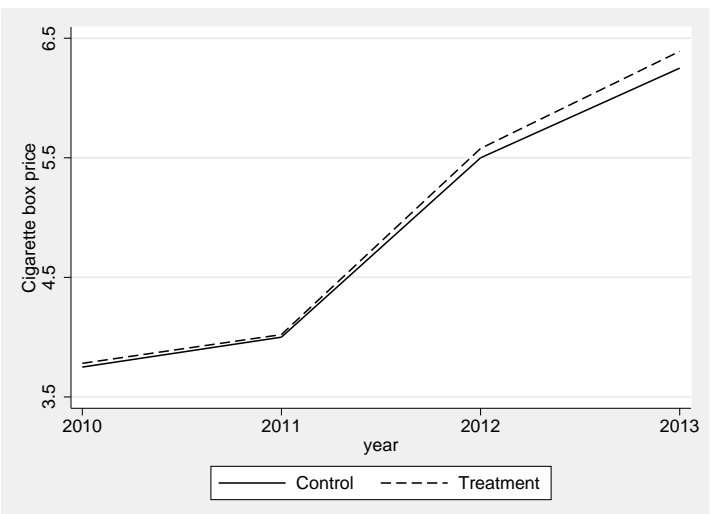

Note: Prices for the box with 20 cigarettes of the brand Free. Prepared by the authors based on data from the Federal Revenue Service.
Graph 45 - Evolution of cigarette box's prices from 2010 to 2013 in Control and High Enforcement Treatment Groups

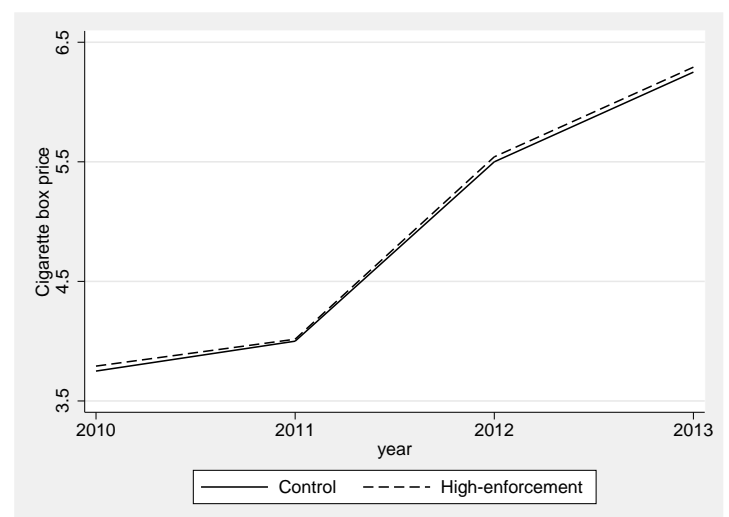

Note: Prices for the box with 20 cigarettes of the brand Free. Prepared by the authors based on data from the Federal Revenue Service.

Graph 46 - Series of Price Index related to cigarette box from 2006 to 2017 in Control and Treatment Groups

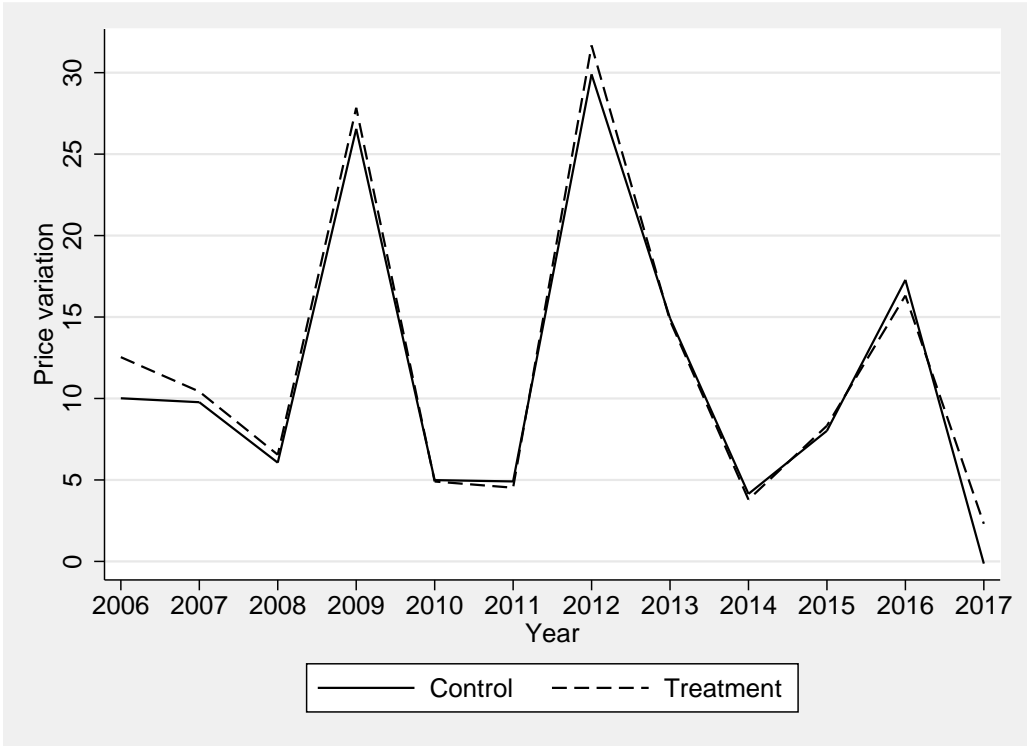

Source: Prepared by the authors based on data from IBGE. 
Graph 47 - Distribution of price paid per cigarette pack by adults in 2013 in Control and All Treatment Groups

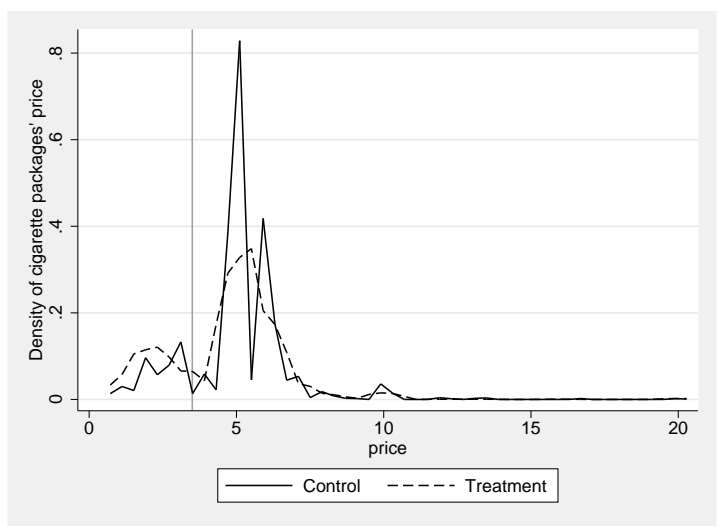

Note: Price per pack with 20 cigarettes. The vertical line indicates the current minimum price in 2013 (3.5 Brazilian reais - around 1 dollar). Prepared by the authors based on data from PNS 2013.

Graph 49 - Distribution of price paid per cigarette pack by adults in 2013 in Control and High Enforcement Treatment Groups

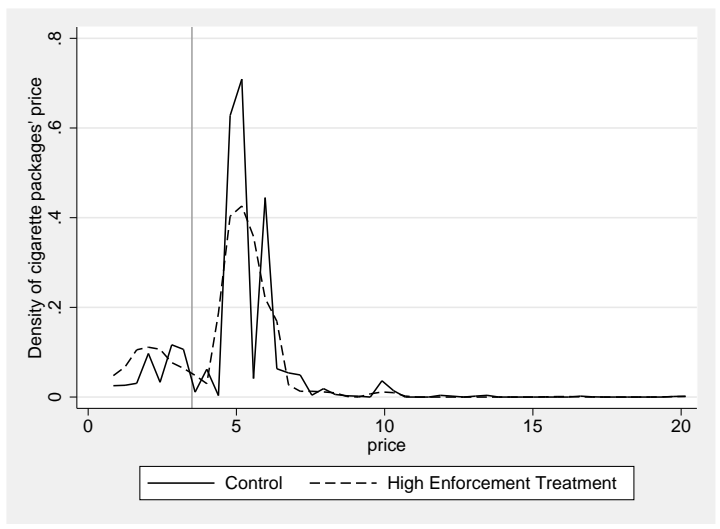

Note: Price per pack with 20 cigarettes. The vertical line indicates the current minimum price in 2013 (3.5 Brazilian reais - around 1 dollar). Prepared by the authors based on data from PNS 2013.
Graph 48 - Distribution of price paid per cigarette pack by youths in 2013 in Control and All Treatment Groups

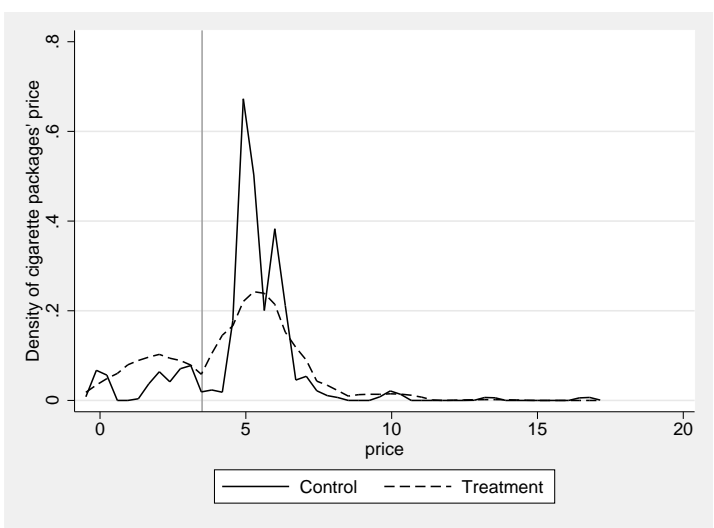

Note: Price per pack with 20 cigarettes. The vertical line indicates the current minimum price in 2013 (3.5 Brazilian reais - around 1 dollar). Prepared by the authors based on data from PNS 2013.

Graph 50 - Distribution of price paid per cigarette pack by youths in 2013 in Control and High Enforcement Treatment Groups

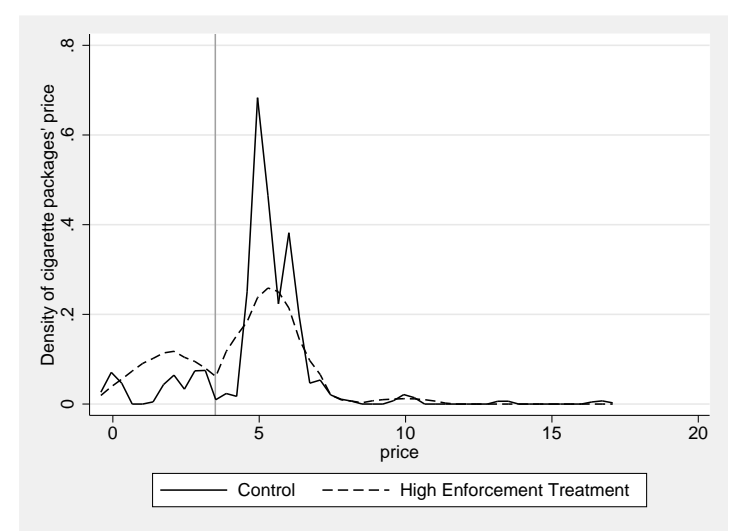

Note: Price per pack with 20 cigarettes. The vertical line indicates the current minimum price in 2013 (3.5 Brazilian reais - around 1 dollar). Prepared by the authors based on data from PNS 2013. 